
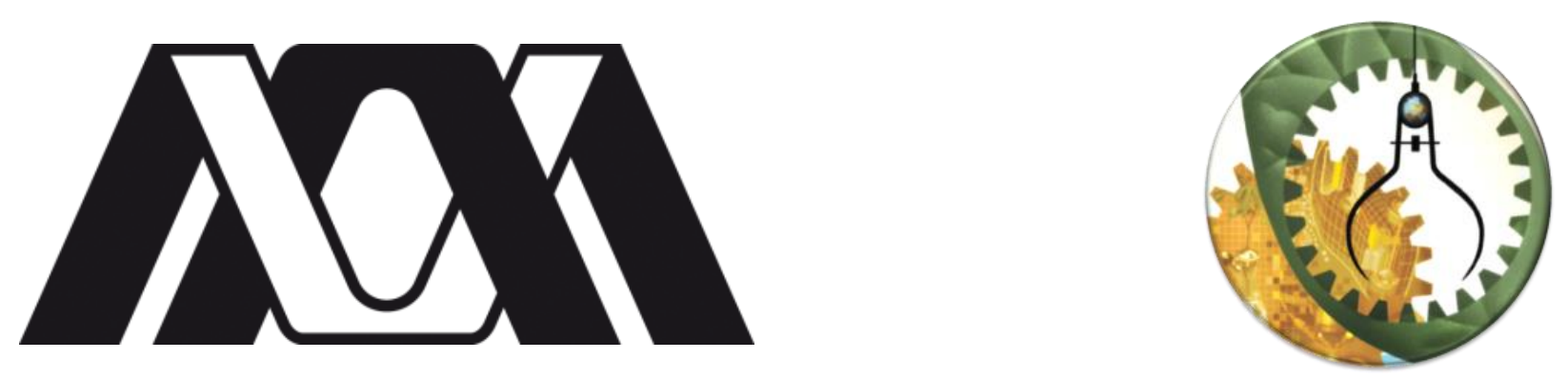

DIVISIÓN DE CIENCIAS BÁSICAS E INGENIERÍA

DIVISIÓN DE CIENCIAS BIOLÓGICAS Y DE LA SALUD

POSGRADO EN ENERGÍA Y MEDIO AMBIENTE

ANÁLISIS ENERGÉTICO Y AMBIENTAL DE LA PRODUCCIÓN DE BIO-ETANOL EN MÉXICO A PARTIR DE LA FRACCIÓN ORGÁNICA DE LOS RESIDUOS SÓLIDOS URBANOS

TESIS QUE PRESENTA:

Tania Paola Mendoza Tinoco

Para obtener el grado de:

Maestra en Ciencias (Energía y Medio Ambiente) 


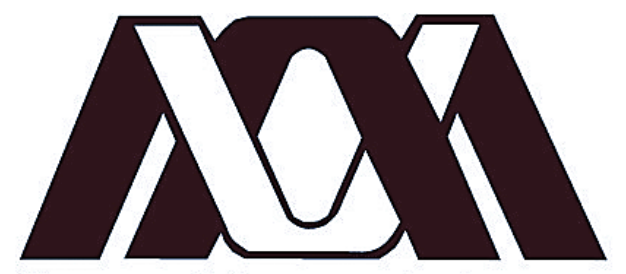

Casa abierta al tiempo

UNIVERSIDAD AUTÓNOMA METROPOLITANA
UNIVERSIDAD AUTÓNOMA

METROPOLITANA UNIDAD

IZTAPALAPA

POSGRADO EN ENERGÍA Y MEDIO AMBIENTE

\title{
ANÁLISIS ENERGÉTICO Y AMBIENTAL DE LA PRODUCCIÓN DE BIO-ETANOL EN MÉXICO A PARTIR DE LA FRACCIÓN ORGÁNICA DE LOS RESIDUOS SÓLIDOS URBANOS
}

\author{
TESIS \\ Para obtener el grado de: \\ MAESTRA EN CIENCIAS \\ (ENERGÍA Y MEDIO AMBIENTE) \\ PRESENTA: \\ Tania Paola Mendoza Tinoco \\ Director: \\ Dr. J. Gerardo Saucedo Castañeda \\ Asesores \\ Dra. Lysete Sandra Hernández Gámez \\ M. en C. Raziel Jesús Estrada Martínez
}

Ciudad de México, 19 de noviembre de 2018 


\section{Agradecimientos}

La Maestría en Ciencias (Energía y Medio Ambiente) de la Universidad Autónoma Metropolitana Unidad Iztapalapa, pertenece al Padrón Nacional de Posgrados de Calidad del CONACyT y cuenta con apoyo del mismo consejo con el convenio 003893; por lo que agradece la beca recibida, a través del convenio No. CVU/BECARIO: 738328/597861 para el desarrollo de esta tesis.

Esta tesis fue desarrollada gracias al apoyo recibido del proyecto "Captura del $\mathrm{CO}_{2}$ generado durante la mineralización del carbono de los residuos sólidos orgánicos en condiciones aerobias y de la producción de biocombustibles", clave 215467 de la convocatoria de Proyectos de Desarrollo Científico para atender Problemas Nacionales 2013. En atención al área de Investigación: Energía y desarrollo sustentable y la Modalidad: Grupos de Investigación Consolidados 


\section{Agradecimientos personales}

A mi compañero de vida Luis, quien estuvo a mi lado en esta aventura.

A mis profesores y particularmente a mis asesores, al Dr. J. Gerardo Saucedo Castañeda, al M. en C. Raziel Jesús Estrada Martínez y a la Dra. Lysete Sandra Hernández Gámez que me brindaron su conocimiento y apoyo en cada momento en la elaboración de esta tesis.

Finalmente, agradezco a mis amigos, familiares y compañeros de posgrado que creyeron en mí y me brindaron apoyo cuando lo necesite.

Gracias.

No te rindas, por favor no cedas, Aunque el frío queme, Aunque el miedo muerda, Aunque el sol se ponga y se calle el viento, Aún hay fuego en tu alma, Aún hay vida en tus sueños Porque cada día es un comienzo nuevo, Porque esta es la hora y el mejor momento... 


\section{Comité tutorial}

Director:

Dr. J. Gerardo Saucedo Castañeda. Departamento de Biotecnología, División de Ciencias Biológicas y de la Salud, Universidad Autónoma Metropolitana, Unidad Iztapalapa.

Asesora:

Dra. Lysete Sandra Hernández Gámez. Departamento de Ingeniería de Procesos e Hidráulica, Área de Ingeniería en Recursos Energéticos, División de Ciencias Básicas e Ingeniería, Universidad Autónoma Metropolitana, Unidad Iztapalapa.

Asesor:

M. en C. Raziel Jesús Estrada Martínez. Departamento de Biotecnología, División de Ciencias Biológicas y de la Salud, Universidad Autónoma Metropolitana, Unidad Iztapalapa. 


\title{
El jurado designado por la \\ Comisión Académica del Posgrado en Energía y Medio Ambiente \\ De la Unidad Iztapalapa, aprobó la tesis que presentó
}

TANIA PAOLA MENDOZA TINOCO

El lunes 19 de noviembre del 2018

\section{Miembros del Jurado}

\author{
Dr. Ricardo Beristain Cardoso
}

Presidente

Dra. Lysete Sandra Hernández Gámez

Secretaria

Dra. Fabiola Sosa Rodríguez

M. en C. Raziel Jesús Estrada Martínez

Vocales 


\section{Resumen}

En el presente trabajo se evalúa el desempeño energético y ambiental del proceso de producción de bio-etanol a partir de la fracción orgánica de los residuos sólidos urbanos (FORSU). Para el análisis energético se realizó un inventario del proceso y se determinó el consumo de energía de los equipos involucrados en las etapas de: disminución de partícula, explosión a vapor, fermentación y destilación. Para el análisis ambiental, inicialmente se realizó la simulación de los procesos en el software Aspen Plus. Una vez obtenidos los balances de materia y energía de los procesos, se evaluó el impacto ambiental utilizando el algoritmo de reducción de residuos (algoritmo WAR), con el cual, se puede determinar la amigabilidad ambiental de un proceso. Para el caso energético se utilizó la metodología de la Tasa de Retorno Energético, para evaluar la viabilidad energética del proceso de acuerdo a la relación del consumo de energía utilizada en la producción contra la energía obtenida por el bio-etanol. Como resultado de dichos análisis, se obtuvo una tasa de retorno energético (TRE) de 1.21 unidades de energía obtenida por unidad de energía invertida. A las condiciones planteadas, la TRE del proceso se encuentra entre el rango de los biocombustibles líquidos. Por otro lado, los impactos ambientales que se generan por el proceso de producción de bio-etanol son mínimos; el mayor impacto corresponde a la categoría de formación de smog tanto a nivel piloto como a nivel industrial. Se obtuvo un valor de $3.47 \times 10^{3} \mathrm{PIA} / \mathrm{hr}$ para la categoría de formación de smog a nivel industrial. Con los análisis realizados, el proceso resulta ambientalmente viable, sin embargo, el análisis energético no fue favorable, ya que requiere una TRE de $\geq 5$ para ser considerado viable, no obstante si se llegara a producir bio-etanol a partir de la FORSU que se genera al año en México, se podría llegar a producir $1.4 \times 10^{6} \mathrm{~m}^{3}$ de bio-etanol al año. Además de ello, la relación del costo de la FORSU por litro de etanol obtenido (\$5.4/L) es menor en comparación a otras materias primas como el maíz y la caña de azúcar. El bioproceso objeto de esta tesis puede ser mejorado, como por ejemplo: implementando fuentes de energía renovables (trituradores manuales, calentadores y destiladores solares). La producción de bio-etanol en México es un proceso que está en vías de desarrollo, por lo que todavía se pueden optimizar los rendimientos de producción y condiciones de operación de los equipos, principalmente, en la etapa de fermentación, por ejemplo, realizar una agitación intermitente en lugar de continua para disminuir el consumo energético.

Palabras clave: Bio-etanol, impactos ambientales, consumo energético 


\begin{abstract}
This work evaluates the energy and environmental performance of the bioethanol production process from the organic fraction of municipal solid wastes (OFMSW). For the energy analysis, an inventory of the process was made and the energy consumption of the equipment involved in the stages of: particle reduction, steam explosion, fermentation and distillation was determined. For the environmental analysis, the processes were initially simulated in the Aspen Plus software. Once the material and energy balances of the processes were obtained, the environmental impact analysis was carried out using the waste reduction algorithm (WAR algorithm), which evaluates the environmental friendliness of a process. From the results obtained, the process obtained an Energy Return On Investment (EROI) of 1.21 units of energy obtained per unit of energy invested. The EROI of the process is between the range of liquid biofuels under the above conditions. On the other hand, the environmental impacts generated by the process are minimal and have greatest impact on category of smog formation and the pilot level as an industrial level. The value obtained in this category is $3.47 \times 10^{3} \mathrm{PIE} / \mathrm{hr}$ for industrial level, according to the analysis made the process is environmentally viable, however, the energy analysis was not favorable since it requires a EROI of $\geq 5$ to be viable, however, if it comes to produce bio-ethanol from the OFMSW, which is generated every year in Mexico, can produce $1.4 \times 10^{6} \mathrm{~m}^{3}$ of bio-ethanol per year. In addition, the ratio of the cost of the OFMSW per liter of ethanol obtained $(\$ 5.4 / \mathrm{L})$ is lower compared to other raw materials such as corn and sugarcane. The bioprocess object of this test can be improved, such as: implementing renewable energy sources (manual crushers, heaters and solar distillers). The production of bioethanol in Mexico is a process that is in the process of development, so that it is still possible to optimize the production yields and operating conditions of the equipment, mainly in the fermentation stage, for example, carrying out an intermittent agitation instead of continuing to decrease energy consumption.
\end{abstract}

Keywords: Bioethanol, environmental impacts, energy consumption 


\section{Contenido}

1 Introducción _ 1

2 Antecedentes _ 4

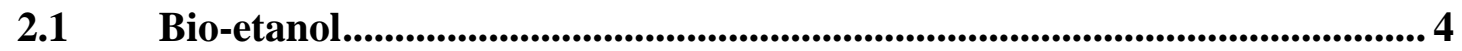

2.1.1 Materias primas y procesos de producción de bio-etanol .................... 6

2.2 Retos y oportunidades en la producción de bio-etanol ................................. 10

2.2.1 Impactos ambientales sobre suelo.......................................................... 11

2.2.2 Pérdida de biodiversidad ................................................................... 11

2.2.3 Demanda energética................................................................................. 12

2.2.4 Requerimientos hídricos................................................................... 11

$2.3 \quad$ Análisis de ciclo de vida (ACV) .......................................................... 13

2.3.1 Metodología y escenarios de aplicación................................................. 14

2.3.2 Herramientas de análisis ......................................................................... 17

2.4 Tasa de retorno energético (TRE)............................................................. 21

2.4.1 Metodología para determinar la tasa de retorno energético.............. 22

2.4.2 Biocombustibles y su tasa de retorno energético................................... 24

3 Hipótesis 26

4 Objetivos 27

4.1 Objetivo general........................................................................................ 27

4.2 Objetivos particulares ............................................................................. 27

5 Metodología__ 28

5.1 Determinación de la tasa de retorno energético para la producción de bioetanol a partir de FORSU a nivel piloto. ........................................................................ 29

5.1.1 Etapa I. Disminución de partícula ........................................................... 31

5.1.2 Etapa II. Explosión a vapor..................................................................... 33

5.1.3 Etapa III. Fermentación ...........................................................................34

5.1.4 Etapa V. Destilación........................................................................36

5.2 Análisis de ciclo de vida para la producción de bio-etanol a partir de FORSU a nivel piloto.......................................................................................................... 36

5.2.1 Evaluación de impacto ambiental...........................................................39

5.3 Análisis de ciclo de vida para la producción de bio-etanol a partir de a nivel industrial (Planta de compostaje de bordo poniente)............................................. 40

5.3.1 Descripción del caso de estudio ................................................................ 40

5.3.2 Simulación y análisis de datos................................................................. 41

6 Resultados y discusión___ 42

6.1 Determinación de la tasa de retorno energético para la producción de bioetanol a partir de FORSU a nivel piloto. 42 
6.2 Análisis de ciclo de vida para la producción de bio-etanol a partir de FORSU a nivel piloto.

6.3 Análisis de ciclo de vida para la producción de bio-etanol a partir de a nivel industrial (Planta de compostaje de bordo poniente)........................................ 57 7 Conclusiones _ 61

8 Referencias 63

9 Anexos 67

9A Anexo A. Inventario del proceso. ...................................................................6 67

9.B Anexo B. Reporte de simulación Aspen plus 7.3........................................ 77

9.C Anexo C. Resumen de resultados de impactos ambientales de la planta piloto (WAR GUI)......................................................................................................... 110

9.D Anexo D. Resumen de resultados de impactos ambientales de la planta de compostaje de Bordo Poniente (WAR GUI) ............................................................. 112

9.E Anexo E. Tasa de retorno energético de la producción de bio-etanol a partir de la fracción orgánica de los residuos sólidos urbanos............................... 115 


\section{Índice de Figuras}

Figura 2.1. Ruta metabólica de la Glucólisis (Fuente: Van Maris y col., 2006) ............................... 9

Figura 2.2. Etapas generales del ACV para la obtención de bio-etanol ......................................... 16

Figura 2.3. Potencial de impacto de salida por categoría para los dos casos de estudio.................. 20

Figura 2.4. TRE de diferentes combustible (Ballenilla y Ballenilla, 2007 ..................................... 25

Figura 5.1. Estrategia de investigación en el análisis de uso de la FORSU para la producción de

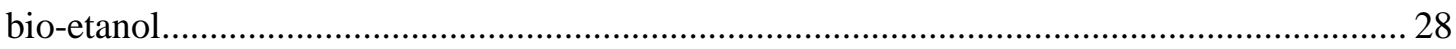

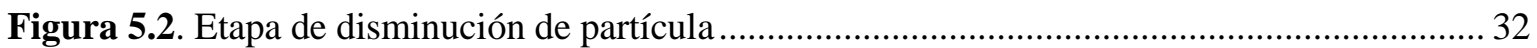

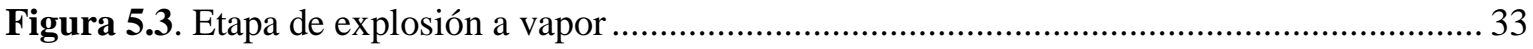

Figura 5.4. Reactor utilizado en la etapa de fermentación ............................................................... 35

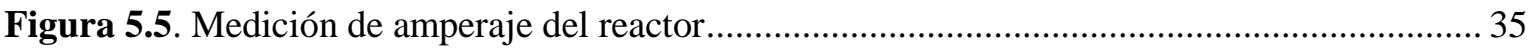

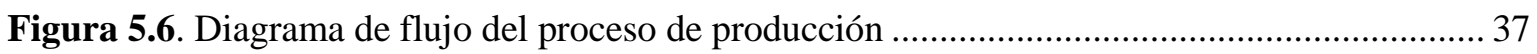

Figura 6.1. PIA después del proceso por unidad de producto ...................................................... 52

Figura 6.2. PIA durante el proceso por unidad de producto ……................................................... 53

Figura 6.3. PIA después del porceso por unidad de producto incluyendo el uso de energía ........... 54

Figura 6.4. PIA durante el proceso por unidad de producto incluyendo el uso de energía.............. 55

Figura 6.5. Comparación de impactos ambientales del proceso vs el uso de energía...................... 55

Figura 6.6. Índice después del proceso por unidad de producto para la PCBP.............................. 57

Figura 6.7. Índice durante el proceso por unidad de producto para la PCBP .................................. 58

Figura 6.8. Comparación de impactos ambientales del proceso vs el uso de energía a nivel industrial.

Figura 6.9. Índice después del proceso por unidad de tiempo FORSU vs maíz y caña de azúcar.. 59 


\section{Índice de Tablas}

Tabla 2.1. Características y especificaciones que debe cumplir el bio-etanol para su uso como combustible

Tabla 2.2. Métodos de pretratamiento para material lignocelulósico 8

Tabla 5.1. Estructura del inventario. 29

Tabla 5.2. Compuestos considerados en la simulación (\% p/p) 38

Tabla 5.3. Condiciones de operación por etapa y equipos ..... 39

Tabla 6.1. Amperaje de línea a neutro. 43

Tabla 6.2. Consumo energético de la etapa de disminución de partícula 43

Tabla 6.3. Voltaje y amperaje de la bomba 44

Tabla 6.4. Consumo energético de la caldera... 45

Tabla 6.5. Consumo energético del reactor 46

Tabla 6.6. Consumo energético del calentador . 47

Tabla 6.7. Consumo energético de la bomba 47

Tabla 6.8. Energía invertida por etapa 49

Tabla. 6.9. Índice de salida por unidad de tiempo para la FORSU, maíz y caña de azúcar. 60 


\section{Lista de acrónimos y abreviaturas}

$\%$ p/p: porcentaje peso a peso.

$\% \mathrm{v} / \mathrm{v}$ : porcentaje volumen a volumen.

${ }^{\circ} \mathrm{C}$ : grados celcius.

A: intensidad amperes.

ACV: Análisis de Ciclo de Vida.

AP: Potencial de Acidificación.

ATP: Potencial de Toxicidad Acuática.

$\mathrm{C}_{2} \mathrm{H}_{6} \mathrm{O}$ : etanol

$\mathrm{CH}_{4}$ : metano.

CO: monóxido de carbono.

$\mathrm{CO}_{2}$ : dióxido de carbono.

COV: componentes orgánicos volátiles

Cp: poder calorífico de la sustancia a calentar $\left(\mathrm{k} \mathrm{cal} / \mathrm{kg}{ }^{\circ} \mathrm{C}\right)$.

EPA: Agencia de Protección Ambiental de los Estados Unidos.

FORSU: fracción orgánica de los residuos sólidos.

FP: factor de potencia.

$\mathrm{G} / \mathrm{cm} 3$ : unidades de densidad.

GWP: Potencial de Calentamiento Global.

$\mathrm{H}_{2} \mathrm{SO}_{4}$ : acido sulfúrico.

HMF: Hidroximetilfurfural.

HP: caballo de fuerza.

HPLC: cromatografía líquida de alta resolución.

HTPE: Potencial de Toxicidad Humana por Exposición.

HTPI: Potencial de Toxicidad Humana por Ingestión.

I: corriente en línea en amperios (A).

ISO: Organización Internacional para la Estandarización.

$\mathrm{Kcal} / \mathrm{kg}{ }^{\circ} \mathrm{C}$ : unidades de calor específico.

$\mathrm{Kg} / \mathrm{cm}^{2:}$ presión en libra por pulgada cuadrada.

$\mathrm{kW}$ h: kilo watt por hora.

$\mathrm{KW}$ : kilo watt.

L: litro.

$m$ : flujo de la sustancia a calentar $(\mathrm{kg} / \mathrm{h})$.

MJ: mega joule.

$\mathrm{mL} \min ^{-1}$ : mililitros por minuto. 
mM: nanometro.

OCDE: Organización para la Cooperación y el Desarrollo Económico.

ODP: Potencial del Deterioro de la Capa de Ozono.

$\mathrm{P}(\mathrm{W})$ : potencia en Watts.

$\mathrm{P} / \mathrm{v}$ : peso volumen.

PCOP: Potencial de Formación de Smog.

Q: calor térmico $(\mathrm{kW} \mathrm{h})$.

RPM: revoluciones por minuto.

RSU: residuos sólidos urbanos.

Ton: tonelada.

TRE: tasa de retorno energético.

TTP: Potencial de Toxicidad Terrestre.

$\mathrm{V}$ : corriente volts.

V: L - L: voltaje de líneas en voltios (V).

VL-N: voltaje de línea a neutro en voltios (V).

W: watt.

WAR: Algoritmo de reducción de residuos.

$\Delta \mathrm{T}$ : diferencia en la temperatura inicial y final $\left({ }^{\circ} \mathrm{C}\right)$. 


\section{Introducción}

El manejo inadecuado de los residuos sólidos urbanos (RSU), ha tenido y tiene repercusiones en la calidad del aire, agua y suelo. Esto se debe a la proliferación de fauna nociva, generación de lixiviados y emisión de gases de efecto invernadero tales como metano $\left(\mathrm{CH}_{4}\right)$, dióxido de carbono $\left(\mathrm{CO}_{2}\right)$ y monóxido de carbono $(\mathrm{CO})$ (Lobo Garcia de Cortazar, Hernández-Berriel, y Mañón-Salas, 2016).

Actualmente en México, se recolectan diariamente 42 mil toneladas de basura (SEMARNAT, 2013), el 52 \% de los residuos sólidos urbanos (RSU) representan la fracción orgánica (FORSU), (SEDESOL, 2012), que terminan en sitios de disposición final o rellenos sanitarios.

Además de la gran generación de residuos y a pesar que México cuenta con un plan de manejo de residuos, el $87 \%$ de los tiraderos de basura son a cielo abierto, la mayoría de estos sitios de disposición final no cuentan con las condiciones establecidas en la NOM-083SEMARNAT-2003 (captación de gases, drenado de lixiviados, plantas de combustión y neutralización de gases, etc.) y tan solo el 13\% son rellenos sanitarios (Robles Martínez, 2005).

Por esta razón es necesario darle un valor agregado a los residuos orgánicos, con lo cual se impediría que llegaran a sitios de disposición final, donde tendrían un mal manejo y se presentarían un conjunto de problemas ambientales, como toxicidad terrestre, toxicidad acuática y calentamiento global, entre otros. Debido a esto, se propone el aprovechamiento de estos residuos para la producción de bio-etanol.

La biomasa lignocelulósica está compuesta principalmente por: celulosa, hemicelulosa, lignina y partes minoritarias como ácidos, sales o minerales. La celulosa y hemicelulosa son los componentes mayoritarios (polisacáridos) que pueden someterse a hidrólisis dando lugar a carbohidratos cuya fermentación resulta en la formación de bio-etanol. La fracción orgánica de los residuos sólidos urbanos (FORSU), es un ejemplo de este tipo de biomasa. La FORSU, es una materia prima abundante en México de fácil acceso y no compite con el consumo de alimentos, además, se evita el uso de cultivos de materias primas de consumo humano, como la caña de azúcar o maiz. Esto representaría una ventaja en la producción de los bio-combustibles, al no utilizar materias primas que impliquen una huella hídrica mayor, 
pérdida de biodiversidad y competencia con la industria alimentaria (Bravo, 2006). Al ser un desecho, su aprovechamiento podría desarrollar la industria del bio-etanol en México.

En los países en vías de desarrollo, los cultivos destinados a la producción de biocombustibles compiten con los destinados a la alimentación, lo cual, puede contribuir al aumento en los precios de los alimentos y de la hambruna. Por otra parte, la producción de dichos energéticos implica un mayor uso de fertilizantes y pesticidas (lo cual afecta la calidad del agua y suelo), así como, de un cambio en el uso de suelo de forestal a agrícola (Pol y Gómez, 2007).

El presente trabajo tiene como objetivo, realizar un análisis energético y ambiental del uso de la fracción orgánica de los residuos sólidos urbanos (FORSU) para producir bioetanol en México. Con el fin de determinar si el proceso es sustentable, energéticamente viable y para ser aplicado como una estrategia para la mitigación del cambio climático y dar un paso más hacia la transición energética. Esta tesis se estructura de la siguiente manera:

El capítulo I, plantea la problemática que pretende atacar esta investigación.

El capítulo II, señala las bases teóricas que servirán para el desarrollo de los capítulos posteriores; los temas tratados más importantes son: producción de bio-etanol, tasa de retorno energético y análisis de ciclo de vida, entre otros.

El capítulos III, contienen la hipótesis que se pretende probar mediante los objetivos establecidos.

En el capítulo IV, se describe la metodología a seguir para desarrollar el análisis ambiental y energético de la producción de bio-etanol, utilizando el análisis de ciclo de vida y la tasa de retorno energético.

En el capítulo V, se presentan y discuten los resultados obtenidos a partir del análisis energético y ambiental dividido en tres apartados: análisis de ciclo de vida, tasa de retorno energético y aplicación del proceso.

En el capítulo VI, se presentan las conclusiones y recomendaciones para mejorar el rendimiento de la producción de bio-etanol.

En el capitulo VII, se muestran todas las referencias consultadas para comprender el tema de estudio asi como determinar la metodología a seguir. 
En el capitulo VIII, se muestran los anexos donde se encuentra la información mas detallada de las simulaciones realizadas

Introducción: Análisis energético y ambiental de la producción de bio-etanol a partir de la FORSU. T. P. Mendoza Tinoco 


\section{Antecedentes}

\subsection{Bio-etanol}

El bio-etanol $\left(\mathrm{C}_{2} \mathrm{H}_{6} \mathrm{O}\right)$, es un producto químico obtenido generalmente a partir de procesos fermentativos empleando levaduras, que aprovechan los carbohidratos presentes en los vegetales, tales como cereales, remolacha, caña de azúcar o biomasa para convertirlos en bio-etanol. Estos carbohidratos están presentes en forma de sacarosa, almidón, hemicelulosa y celulosa, que se concentran en la parte fibrosa de la planta (García y García, 2006).

Su principal aplicación en el transporte es como aditivo en gasolinas, en mezclas del 5 , 10, 20 y $85 \%$ de bio-etanol conocidas como mezclas E5, E10, E20 y E85. El bio-etanol como oxigenante le da a la mezcla estabilidad y resta volatilidad, lo que facilita su uso, almacenamiento y transporte. En la medida que aumenta la proporción de bio-etanol mezclado con la gasolina, se reduce el impacto ambiental, específicamente, disminuye la producción de monóxido de carbono. Sin embargo, para el uso de las mezclas con un alto contenido de bio-etanol es necesario modificar el diseño de los motores automotrices (Callejas y Quezada, 2009).

En Brasil y otros países tropicales, se produce bio-etanol a partir de caña de azúcar. En los países de la Organización para la Cooperación y el Desarrollo Económico (OCDE), la mayor parte del bio-etanol se produce a partir del componente feculento de los cereales (aunque también se usa la remolacha azucarera), por su fácil conversión en azúcar fermentable.

Un litro de bio-etanol contiene aproximadamente el $66 \%$ de la energía suministrada por un litro de gasolina, pero posee un nivel más elevado de octano, que evita el golpeteo en el motor (Castillo y col, 2012). Sin embargo, la combustión de bio-etanol también provoca una reacción más fuerte con el nitrógeno de la atmósfera, lo que puede resultar en un aumento de los gases de óxido de nitrógeno (Castello, 2008). 
Actualmente, los diferentes métodos de producción, utilizan en su mayoría energía proveniente de combustibles fósiles, con la excepción del bio-etanol elaborado a partir de la caña de azúcar, donde la mayor parte de la energía necesaria para la conversión proviene del bagazo de caña (Castello, 2008).

En la Tabla 2.1, se muestran las características que debe de cumplir el bio-etanol para ser utilizado como carburante.

Tabla 2.1. Características y especificaciones que debe cumplir el bio-etanol para su uso como combustible

\begin{tabular}{ccccc}
\hline \multirow{2}{*}{ Características } & \multirow{2}{*}{ Unidades } & \multicolumn{2}{c}{ Método } & Especificaciones \\
\cline { 3 - 4 } & & ASTM* & ABNT/NBR** & \\
\hline Aspecto & - & Visual & - & $\begin{array}{c}\text { Limpio y sin } \\
\text { impurezas }\end{array}$ \\
Color & - & Visual & - & Incoloro \\
$\begin{array}{c}\text { Acidez total } \\
\text { (ácido acético })\end{array}$ & $\mathrm{mg} / \mathrm{L}$ & $\mathrm{D} 1613$ & 9866 & 30 Máx \\
$\begin{array}{c}\text { Conductividad } \\
\text { eléctrica }\end{array}$ & $\mu \mathrm{s} / \mathrm{m}$ & $\mathrm{D} 1125$ & 10547 & 500 Máx \\
$\begin{array}{c}\text { Masa específica } \\
\text { a } 20{ }^{\circ} \mathrm{C}\end{array}$ & $\mathrm{Kg} / \mathrm{m}^{3}$ & $\mathrm{D} 4052$ & 5992 & 791.15 Máx \\
$\begin{array}{c}\text { Ion cloruro } \\
\text { Grado de bio- } \\
\text { etanol }\end{array}$ & $\mathrm{mg} / \mathrm{kg}$ & $\mathrm{D} 5001$ & $10894 / 12120$ & 1.1 \\
Hierro & $\% \mathrm{vol}$ & - & & 99.3 min \\
Sodio & $\mathrm{mg} / \mathrm{kg}$ & - & 113331 & 5.5 Máx \\
Cobre & $\mathrm{mg} / \mathrm{kg}$ & - & 10422 & 2.2 Máx \\
\hline
\end{tabular}

Fuente: Gracia y Pérez, 2014

*American Society for Testing and Materials

**Asociación Brasileña de normas y técnicas

Para que el bio-etanol sea empleado como carburante solo o en mezcla, debe de cubrir ciertas propiedades físicas y químicas con el fin de asegurar su calidad, las cuales, se muestran en la Tabla 2.1. Estas determinan cómo funcionará el biocombustible y el motor. Por ejemplo, la acidez total, indica la corrosividad del bio-etanol, tomando en cuenta el material del cual está hecho el motor del automóvil que lo utilizará. La conductividad eléctrica indica la cantidad de iones presentes en el bio-etanol, mientras más iones contengan, su conductividad es mayor y su poder corrosivo en el sistema de distribución del

Antecedentes: Análisis energético y ambiental de la producción de bio-etanol a partir de la FORSU. T. P. Mendoza Tinoco 
combustible aumenta. El aspecto y color permite la identificación de impurezas en el líquido, las cuales, pueden causar problemas en filtros, depósitos e inyectores de los automóviles y el color también indica el empobrecimiento del combustible, causado por la oxidación de aldehídos y alcoholes (Gracida y Pérez, 2014). Todas estas características pueden variar dependiendo de la materia prima utilizada y la eficiencia en las técnicas de producción.

\subsubsection{Materias primas y procesos de producción de bio-etanol}

El bio-etanol se ha producido desde hace más de 30 años y la materia prima utilizada ha sido muy variada, por lo cual, se ha clasificado la producción de bio-etanol de acuerdo a la materia prima empleada: bio-etanol de primera, segunda, tercera y cuarta generación, las cuales se explican a continuación:

En la producción de bio-etanol de primera generación, se utilizan cultivos y materiales con alto contenido de sacarosa (caña de azúcar, sorgo dulce y melazas) y cultivos amiláceos con alto contenido de almidón (maíz, trigo, cebada, yuca, camote, papa y malanga). Estos cultivos, presentan una competencia directa con el consumo de alimentos para humanos, sin embargo, son los que han tenido un mayor desarrollo para la producción de bio-etanol. Actualmente, se están produciendo aproximádamente el equivalente a 20 millones de toneladas de bio-etanol, lo que significa el 1\% del consumo mundial total (Callejas Salinas y Gasca Quezada, 2009).

El de segunda generación, es producido a partir de biomasa vegetal, es decir, material lignocelulósico, que son desechos y no tienen una función alimentaria, pero su producción aún está en desarrollo. Las principales materias primas utilizadas son: residuos de cultivos forestales (álamo, sauce y eucalipto), hierbas perennes (miscanthus, alpiste, hierba y caña) y residuos de la industria maderera, como el aserrín (Naik, y Dalai, 2010).

Los de tercera generación, utilizan micro algas como materia prima. Los cultivos de micro algas pueden realizarse en áreas sumergidas, tierras infértiles e incluso con agua de mar. Además, los cultivos de biomasa algal tienen como ventaja que pueden ser utilizados como materia prima de biocombustibles y tiene un impacto ambiental favorable al reducir la concentración de gases de efecto invernadero, debido a que utiliza grandes cantidades de $\mathrm{CO}_{2}$ durante su cultivo (Fernández y col, 2012). 
La cuarta generación, todavía está en estudio y aún no se ha conseguido obtener un resultado real. Se menciona la producción de biocombustibles a partir de bacterias genéticamente modificadas empleando dióxido de carbono. (Dutta y col., 2014).

El bio-etanol obtenido a partir de la materia prima analizada en esta investigación es considerado de segunda generación, debido a que no compite con el abastecimiento de alimentos y son carbohidratos fácilmente fermentables.

La conversión de las diferentes materias primas a bio-etanol, como se mencionó anteriormente, se llevan a cabo por la fermentación alcohólica, sin embargo, cada una de las materias primas necesitan diferentes métodos de pretratamiento para aumentar la disponibilidad de los carbohidratos y facilitar su fermentación. El proceso de producción del bio-etanol está constituido por tres etapas principales: pretratamiento, fermentación y destilación (Abril y Navarro, 2012).

\section{Pretratamiento}

En la Tabla 2.2, se muestras los diferentes tipos de pretratamiento que se pueden llevar a cabo en la producción de bio-etanol. El pretratamiento tiene como objetivo hidrolizar a la materia prima para facilitar su fermentación y aumentar la concentración del producto final. Los tipos de pretratamiento pueden ser físicos, físico-químicos, químicos y biológicos. Se pueden observar (Tabla 2.2) los diferentes tipos de pretratamiento para la biomasa lignocelulósica, como por ejemplo: la explosión a vapor, que es el pretratamiento principal utilizado en la presente investigación. Con esta técnica, se puede hidrolizar del 80-100\% de la hemicelulosa. La explosión a vapor, consiste en introducir los sólidos en el reactor, el cual, es saturado con vapor directo para alcanzar altas presiones, durante un tiempo relativamente corto (2-10 $\mathrm{min}$ ) hasta alcanzar el tiempo de residencia deseado y se despresuriza instantáneamente. Durante el pretratamiento de los materiales lignocelulósicos, los principales inhibidores son compuestos como el furfural, el hidroximetilfurfural (HMF) y el ácido acético (Taherzadeh y Karimi, 2007), que podrían ser liberados durante el pretratamiento del material lignocelulósico a condiciones ácidas. Esto ha llevado a la búsqueda y empleo de microorganismos, los cuales, además de producir bio-etanol con altos rendimientos, son resistentes a los inhibidores presentes en los hidrolizados. 
Tabla 2.2. Métodos de pretratamiento para material lignocelulósico

\section{Métodos de pretratamiento}

\begin{tabular}{|c|c|c|c|}
\hline Pretratamientos físicos & Procedimiento /Agentes & Especificaciones & Tipos de materiales pre tratados \\
\hline Pulverizado Mecánico & Reducción a astillas, trituración o molienda. & $\begin{array}{l}\text { Uso de molinos vibratorio de bolas (tamaño final: } 0.2- \\
2 \mathrm{~mm} \text { ), de cuchillas o martillo (tamaño final: } 3-6 \mathrm{~mm} \text { ). }\end{array}$ & $\begin{array}{l}\text { Maíz, caña de azúcar, residuos de } \\
\text { madera y forestales }\end{array}$ \\
\hline Pretratamientos físico-químicos & Procedimiento/agentes & Especificaciones & Tipos de materiales pretratados \\
\hline Explosión a vapor & Vapor saturado a $160-260^{\circ} \mathrm{C}, \mathrm{P}: 0.69-4.85 \mathrm{MPa}$. & $\begin{array}{l}\text { Se satura con vapor por varios segundos o minutos, luego se } \\
\text { descomprime abruptamente hasta presión atmosférica, } \\
\text { utilizado usualmente en concentraciones altas de sólidos }\end{array}$ & $\begin{array}{l}\text { Bagazo, madera blanda, paja de } \\
\text { arroz, madera de aspen y madera de } \\
\text { eucalipto }\end{array}$ \\
\hline Explosión con $\mathrm{CO}_{2}$ & Dosis de $4 \mathrm{~kg} \mathrm{CO}_{2} / \mathrm{kg}$ de fibra, P: $5.62 \mathrm{MPa}$ & $\begin{array}{c}\text { Conversión a glucosa durante la hidrólisis de celulosa }>75 \% \\
\text { (alfalfa). No forma compuestos inhibitorios. }\end{array}$ & $\begin{array}{c}\text { Alfalfa, mezcla de papel reciclado y } \\
\text { bagazo de caña. }\end{array}$ \\
\hline Pretratamientos químicos & Procedimiento/Agentes & Especificaciones & Tipos de materiales pretratados \\
\hline Ozonólisis & $\begin{array}{l}\text { Ozono, reacción a temperatura y presión } \\
\text { ambientales. }\end{array}$ & $\begin{array}{c}\text { Degradación principalmente de lignina. Conversión durante } \\
\text { la hidrólisis de celulosa: } 57 \% \text { (aserrín). No se forman } \\
\text { inhibidores. }\end{array}$ & $\begin{array}{l}\text { Paja de trigo, bagazo, heno verde, } \\
\text { cacahuete, pino, paja de algodón y } \\
\text { aserrín de álamo. }\end{array}$ \\
\hline Hidrólisis con ácido diluido & $\begin{array}{c}\mathrm{H}_{2} \mathrm{SO}_{4}, \mathrm{HCl}, \mathrm{HNO}_{3} \text { al } 1-5 \% \text {. } \\
\text { T: } 160-200{ }^{\circ} \mathrm{C} \text {; procesos por lotes a alta carga de } \\
\text { sólidos }(10-40 \%) \text { a T: } 120-160^{\circ} \mathrm{C} \text {. Presiones } \\
\text { cercanas a } 1 \mathrm{MPa} .\end{array}$ & $\begin{array}{l}\text { Hidrólisis del } 80-100 \% \text { de la hemicelulosa, altas } \\
\text { conversiones de xilano a xilosa. La alta temperatura es } \\
\text { favorable para la hidrólisis de celulosa. Se requiere } \\
\text { neutralizar el pH para la posterior hidrólisis enzimática }\end{array}$ & $\begin{array}{l}\text { Desechos de maíz, bagazo de caña, } \\
\text { madera de álamo, hierba de césped, } \\
\text { paja de trigo y astillas de álamo. }\end{array}$ \\
\hline Pretratamiento biológico & Procedimiento/Agentes & Especificaciones & Tipos de materiales pretratados \\
\hline Pretratamiento con hongos & $\begin{array}{l}\text { Hongos de la pudrición blanca, blanda y parda. } \\
\text { Producción de celulasas por fermentación en } \\
\text { sustrato sólido. }\end{array}$ & $\begin{array}{c}\text { Los hongos producen celulasas, hemicelulasas y enzimas } \\
\text { degradadoras de lignina: ligninasas, lignin-peroxidasas, } \\
\text { polifenoloxidasas, lacasas y enzimas reductoras de } \\
\text { quinonas. }\end{array}$ & Paja de trigo y desechos de maíz. \\
\hline
\end{tabular}




\section{Fermentación}

Una vez que se ha realizado el pretratamiento, la materia prima es fermentada. En esta etapa, se lleva a cabo una reacción que permite transformar los carbohidratos en bio-etanol y dióxido de carbono. La conversión se representa mediante la siguiente estequiometria:

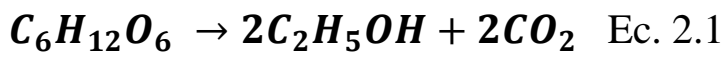

Para acelerar e incrementar la producción de bio-etanol se utilizan métodos biológicos (Tabla 2.2) amigables con el medio ambiente que ayudan a incrementar los rendimientos de hidrólisis. Sin embargo, es un proceso lento que limita su aplicación a nivel industrial. Los biocatalizadores como la levadura Saccharomyces cerevisiae, tiene la habilidad de inducir de manera sinérgica y secuencial la degradación de celulosa para producir bio-etanol. Tienen como ventaja que son de fácil manejo y tienen una alta velocidad de crecimiento a comparación de otras bacterias o levaduras en condiciones anaeróbias y puede fermentar las hexosas que se generan por la degradación de la biomasa vegetal (Vázquez y Dacosta, 2007).

En la Figura 2.1, se muestra las rutas metabólicas que se llevan a cabo para formar bioetanol.

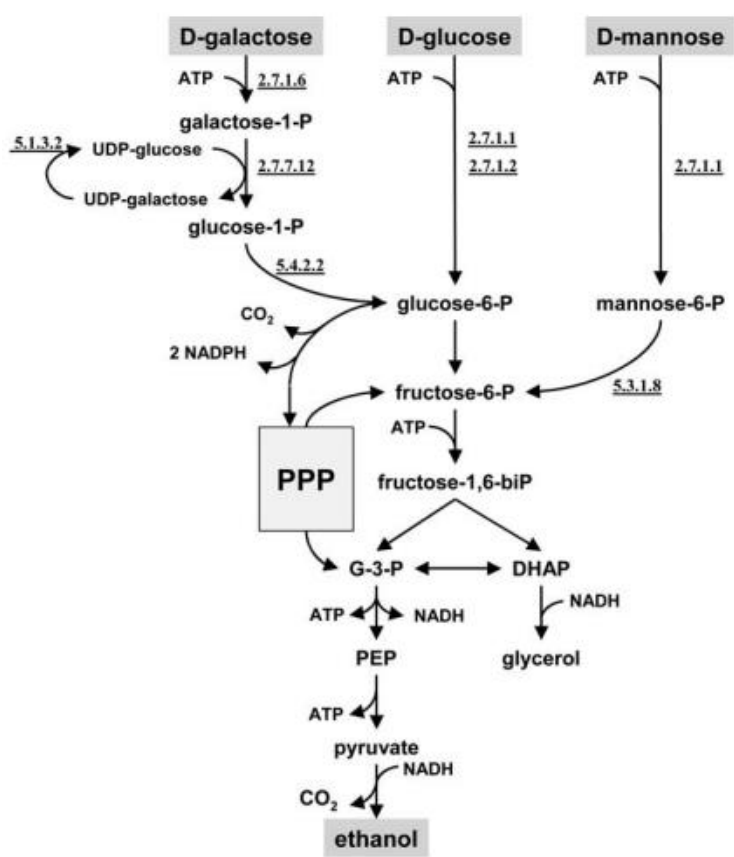

Figura 2.1. Ruta metabólica de la Glucólisis (Fuente: Van Maris y col., 2006)

Las levaduras asimilan los carbohidratos presentes en el medio de fermentación para su crecimiento por la ruta Embden-Meyerhof-Parnas (Figura 2.1). Esta ruta consiste en 10 
reacciones enzimáticas consecutivas que convierten a la glucosa en dos moléculas de piruvato, lo que resulta en la formación neta de dos moléculas de ATP y NADH en condiciones anaeróbicas (Van Maris y col., 2006).

\section{Destilación}

Una de las etapas que representan un costo energético considerable es la destilación. Con la destilación convencional, es posible obtener condiciones cercanas a la composición azeotrópica (96\% p/p); sin embargo, para que el bio-etanol pueda ser utilizado como oxigenante necesita una concentración cercana al 99\%. Los problemas de azeotropía de la mezcla bio-etanol-agua han exigido la consideración de diferentes alternativas para eliminar o superar el azeótropo, las cuales se mencionan a continuación.

La destilación al vacío, consiste en disminuir la presión del sistema por debajo de los 6 kPa para que el azeótropo desaparezca y la separación de los componentes se lleve a cabo. La destilación azeotrópica, consiste en la adición de un agente de separación que modifica las condiciones de azeotropía. El agente de separación se selecciona bajo criterios económicos, de baja toxicidad y eficiencia energética. Los mejores agentes son el pentano y el ciclohexano, desde un punto de vista energético. La destilación con la adición de sal iónica, soluble y no volátil, como el cloruro de sodio, pretende modificar el comportamiento de la fase líquida. Consiste en eliminar la humedad ligada, lo cual, se consigue fundiendo o calentando la sal hasta una temperatura que permita asegurar que la sal está libre de líquido (Uyazán y Caicedo, 2004).

\subsection{Retos y oportunidades en la producción de bio-etanol}

La producción de bio-etanol, siempre ha sido tema de discusión debido a los altos impactos ambientales que este conlleva, principalmente, por las grandes cantidades de emisiones de gases de efecto invernadero. Al no contar con una infraestructura basada en energías renovables, este proceso ha sido considerado como no viable. Aunque el proceso analizado en la presente investigación no presenta una etapa de cultivo agrícola para obtener la materia prima (FORSU), es importante contextualizar los impactos ambientales provocados directa o indirectamente para la producción de bio-etanol.

La naturaleza y la magnitud de los impactos ambientales provocados por la producción de bio-etanol dependerán de factores tales como: la escala de la producción, el tipo de materia prima, las prácticas de cultivo y de gestión de la tierra como la ubicación y los 
métodos de producción. Los principales impactos ambientales reportados por la producción de bio-etanol son: escasez y contaminación del agua, degradación del suelo, agotamiento de los nutrientes y pérdida de la biodiversidad silvestre y agrícola (Castello, 2008).

\subsubsection{Impactos ambientales sobre suelo}

En los suelos agrícolas, el grado de impacto dependerá de los métodos y prácticas de cultivo que se empleen. Las prácticas de cultivo inadecuadas pueden reducir la materia orgánica del suelo e incrementar la erosión del mismo mediante la eliminación de la cubierta permanente del suelo. La eliminación de residuos vegetales puede reducir el contenido de nutrientes del suelo y aumentar las emisiones de gases de efecto invernadero debido a la pérdida de carbono del suelo. Sin embargo, si se tienen buenas prácticas de cultivo agrícola, se puede mejorar el rendimiento de la producción de materia prima y mejorar las propiedades del suelo. Aunque esto también depende del tipo de materia prima a cultivar. Al emplear la FORSU como materia prima, el impacto ambiental sobre el suelo no aplica para el proceso propuesto, ya que como se menciona anteriormente, se consideró a la FORSU como un desecho. Aunque la FORSU proviene de una etapa de cultivo agrícola previa, esta no se contempla en el presente análisis.

\subsubsection{Pérdida de biodiversidad}

La biodiversidad silvestre se ve amenazada por la pérdida del hábitat y paisaje debido a la conversión de tierras, como bosques o praderas, para la producción de cultivos. Esto es debido, al aumento de incentivos económicos en países con posibilidades de producir biocombustibles para convertir ecosistemas naturales en plantaciones de materia prima, como la palma de aceite, en Brasil. Al emplear la FORSU como materia prima la pérdida de biodiversidad no aplica en el proceso propuesto.

\subsubsection{Requerimientos hídricos}

El consumo de agua para la producción de bio-etanol es uno de los factores limitantes para su desarrollo. Los recursos hídricos para la agricultura son cada vez más escasos en muchos países como resultado de una mayor competencia con los usos domésticos o industriales. Otros efectos que pueden aumentar el cambio climático son la escasez de precipitación y escorrentía. Los cultivos agrícolas más utilizados en la actualidad para la producción de bio-etanol son el maíz y la caña de azúcar. Estos cultivos requieren cantidades

Antecedentes: Análisis energético y ambiental de la producción de bio-etanol a partir de la 
relativamente elevadas de agua 857 y 1333 litros de agua por litro de bio-etanol, respectivamente (FAO, 2008). Al emplear la FORSU como materia prima para la producción de bio-etanol, el impacto ambiental por los requerimientos hídricos destinados a la agricultura, no se aplica para el caso del proceso propuesto.

\subsubsection{Demanda energética}

Además del aspecto ambiental, otro reto importante es el ámbito energético, que tiene diferentes aspectos a analizar, como son: demanda energética, rendimiento en términos de producción y uso, así como la introducción en el mercado. A nivel mundial, la producción de bio-combustibles dentro de las energías renovables representa aporoximádamente entre el 0.8-1.0 \% y solo son pocos los países que los producen y comercializan. En México, el bio-etanol no está incluido dentro de las fuentes de energía, aunque cuenta con diferentes ingenios en los cuales se podría producir bio-etanol a partir de caña de azúcar (o sus desechos). La baja producción de bio-etanol en el país, es debido a la competencia directa que se daría con la industria alimentaria y con la reducida superficie cultivable en México.

El uso de bio-etanol como sustituto de las gasolinas en México no sería viable ya que tan solo en la Zona Metropolitana del Valle de México, la cual comprende las 16 alcaldias de la Ciudad de México, 59 municipios del Estado de México y un municipio del Estado de Hidalgo, el 29\% de los vehículos en circulación son modelos 1990 y/o anteriores; por lo que resulta poco factible la posibilidad de modificar o cambiar todo el parque vehicular por modelos capaces de utilizar mezclas con un contenido de bio-etanol mayor por los costos que esto implicaría. Por ello, la reformulación de gasolina con bio-etanol en un porcentaje (E15) bajo es la alternativa más viable para el Valle de México (Abril y Navarro, 2012).

Otro aspecto importante, es la eficiencia del uso de bio-etanol como oxigenante en las gasolinas. Algunos estudios, han revelado que su uso reduce las emisiones de $\mathrm{CO}_{2}$ en un $80 \%$, con respecto a las gasolinas que no han sido diluidas (FAO, 2008). Sin embargo, una de las mayores preocupaciones es que nunca logrará competir con la energía que se obtiene de la gasolina sin diluir. Además, el uso del bio-etanol puede afectar los motores y debido a esto, reducir la eficiencia y el rendimiento del combustible.

Estudios realizados en gasolinas mexicanas han demostrado que el uso de bio-etanol, aumenta el número de octanaje en mezclas E15 (Castillo y col., 2012). La demanda 
energética en el sector transporte, en países líderes productores de bio-etanol, no se han llegado a satisfacer debido a que el territorio para cultivo no es suficiente. Actualmente, el estudio de la producción de bio-etanol de segunda generación intenta contribuir en la disminución del impacto ambiental generado por los combustibles derivados del petróleo y mejorar la calidad del aire.

Para identificar los impactos ambientales generados por el proceso de producción de bioetanol pueden emplearse técnicas como el Análisis de Ciclo de Vida, con el cual, se puede conocer los impactos producidos antes, durante y después del proceso de producción. El Análisis del Ciclo de Vida, es una herramienta que puede determinar la viabilidad de un proceso y combinar con el análisis de Tasa de Retorno Energético para reflejar la relación de la energía invertida contra la energía producida. Estas dos metodologías son descritas a continuación.

\subsection{Análisis de ciclo de vida (ACV)}

El análisis de ciclo de vida es una técnica que se emplea para determinar los posibles impactos que produce algún producto. El ACV, analiza cada etapa involucrada con la obtención de un producto, en este caso el bio-etanol, con el fin de determinar las oportunidades de prevención y reducción en el origen de la contaminación y las alternativas viables para realizar dicha reducción, esto genera una producción limpia y contribuye al desarrollo sustentable. El análisis dependerá de los límites del sistema de estudio, donde algunos puntos a considerar son:

- Adquisición de materias primas

- Procesos y fábricas

- Distribución y transporte

- Mantenimiento, uso y reutilización

- Reciclaje

- Gestión de residuos

Usualmente, el ACV inicia con la obtención de la materia prima y finaliza hasta que el producto ha terminado su vida útil, convirtiéndose en un residuo. Cada ACV deberá establecer estos límites de acuerdo a su objetivo de estudio. Esta técnica se aplica con mayor frecuencia en empresas, que deben evaluar el impacto ambiental del proceso e informar 
sobre el impacto que ocasionan las partes involucradas hasta que el producto llega al consumidor (proveedores, distribuidores y consumidores). El ACV, plantea manejar los residuos en una forma sustentable desde el punto de vista ambiental minimizando todos los impactos asociados con el sistema de manejo.

La Organización Internacional para la Estandarización (ISO) es el organismo que ha desarrollado una serie de estándares enfocados a la administración o gestión ambiental. Estos estándares incluyen las series ISO-14040 sobre el ACV, que son de carácter voluntario (Naranjo y SAS, 2013).

La norma ISO 14040:1997 establece que "el ACV es una técnica para determinar los aspectos ambientales e impactos potenciales asociados con un producto, lo cual, se efectúa recopilando un inventario de las entradas y salidas relevantes del sistema. También, se evalúan los impactos ambientales potenciales asociados a esas entradas y salidas, finalmente se interpretan los resultados de las fase del inventario".

\subsubsection{Metodología del ACV y escenarios de aplicación}

De acuerdo con la ISO 14040, la metodología del ACV consta de cuatro fases: definición del alcance y los objetivos, análisis del inventario, evaluación del impacto e interpretación de resultados.

\subsubsection{Alcance y objetivos}

El alcance del sistema de estudio permitirá definir los límites del sistema, estos tendrán que estar enfocados al objetivo planteado. Es decir, se determinarán las etapas, materiales, insumos, energía, etc., que ayuden a cumplir con el objetivo del estudio siempre y cuando la entrada o salida de información sea justificada, para que el resultado del análisis sea lo más fiable posible. Por otro lado, el objetivo de estudio puede estar enfocado a una sola parte del proceso o a todo el conjunto de etapas, entre más grandes sean los límites del sistema, más fiable será la información de los resultados y más complejo de analizar.

\subsubsection{Inventario}

El inventario, requiere de una recopilación de información de cada una de las etapas involucradas en el proceso. Las etapas consideradas dentro del inventario pueden ser muy variadas, a continuación se mencionan las más generales: 
Adquisición de materia prima: etapa de actividades de acción directa sobre el medio natural. En este punto, se incluye el material no renovable, el agua y la biomasa de recolección.

Procesamiento de material a granel: tratamiento de la materia prima (por ejemplo, separación y purificación), que consiste en adecuar los materiales o materias primas para ser transformadas posteriormente.

Producción de materiales técnicos y de especialidad: algunos autores combinan esta etapa con la anterior designándola, tratamiento de materiales.

Fabricación y ensamble: en esta etapa, se acaban de producir los materiales de base y los materiales técnicos.

Transporte y distribución: con el actual sistema globalizado, esta etapa adquiere especial importancia dadas las grandes distancias que deben recorrer los productos para su comercialización.

Uso y servicio: en esta etapa, se considera el mantenimiento y las reparaciones que necesita el producto durante su uso por el consumidor.

Retiro y tratamiento: en este paso se considera la reutilización o el reciclaje de los materiales y reutilización de residuos.

Disposición, destino final: cuando el material no es valorizado termina su ciclo de vida. En este punto se valora la forma en que éste es depositado en el medio natural.

\subsubsection{Análisis de inventario e impactos ambientales}

En la fase de análisis de inventario, se ejecutan los balances de materia y energía, y se cuantifican las descargas. Estas se definen mediante el consumo de energía, las emisiones al aire/agua y los residuos sólidos generados.

Posteriormente, en la etapa de evaluación de impactos y después de haber recolectado la información del inventario, se clasifican las descargas o residuos en un número de categorías reconocidas como impacto ambiental y se caracterizan a través de la evaluación de sus impactos potenciales, es decir, se cuantifican mediante una unidad estándar de medida, usualmente $\mathrm{Kg}$ de contaminante por unidad de tiempo o por unidad de producto.

Los impactos se evalúan mediante la asignación de ponderaciones a los mismos con el fin de indicar su importancia relativa. Este procedimiento se conoce como valoración. La

Antecedentes: Análisis energético y ambiental de la producción de bio-etanol a partir de la 
fase final es identificar las posibles soluciones para mejorar el desempeño del sistema (Sánchez y col., 2012).

La estructura del ACV se representa por cuatro normas: ISO-14040, ISO-14041, ISO14042 e ISO-14043.

En la norma ISO 14040, se establecen los fundamentos de la evaluación del ciclo de vida, es decir, el marco metodológico, y se explica brevemente cada una de las fases, la preparación del informe y el proceso de revisión crítica. Mientras que en las tres normas restantes se explican de forma detallada cada una de las fases del ACV (Rodríguez, 2003).

ISO 14040: Principios generales y requerimientos.

ISO 14041: Guía para determinar objetivos y alcance.

ISO 14042: Guía para impacto ambiental.

ISO 14043: Interpretación de resultados.

En la Figura 2.2, se muestra el proceso que se llevaría a cabo en el ACV de la producción de bio-etanol, a partir de FORSU.

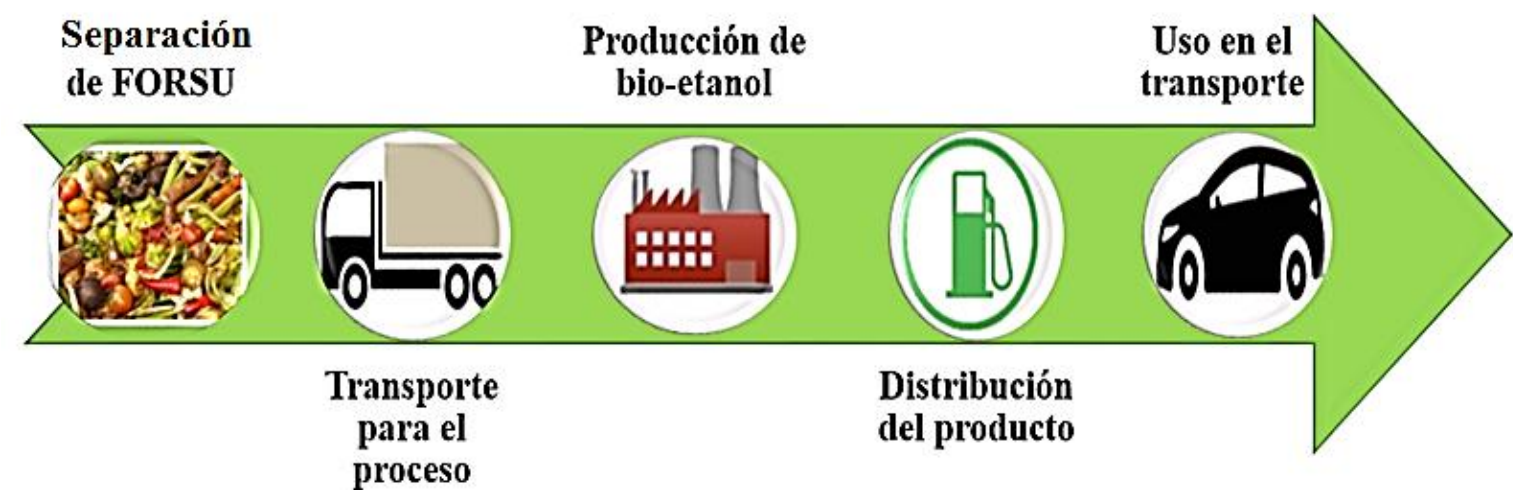

Figura 2.2. Etapas generales del ACV para la obtención de bio-etanol

Esta técnica puede ser empleada para diferentes escenarios, uno de ellos es la producción de energías renovables. Algunos aspectos del proceso no son convencionales ya que la mayoría son prácticamente nuevas y la forma de evaluar los impactos dependerá de la información disponible y los indicadores establecidos por el investigador. Las etapas a considerar dentro del análisis de la producción de bio-etanol (Figura 2.2) pueden ser diferentes dependiendo de la materia prima utilizada. En esta investigación las etapas que 
pueden ser consideradas son: generación de FORSU, transporte para el proceso, producción de productos y subproductos, distribución del producto y finalmente su uso en gasolinas.

\subsubsection{Herramientas de análisis}

Existen diferentes métodos para llevar a cabo el análisis del inventario, el uso de programas (softwares) es usual para análisis de este tipo, los softwares más utilizados son Sima Pro y GaBi que siguen los estándares de la norma ISO 14040. Los softwares incluyen datos generalizados para el inventario, sin embargo, la veracidad de los resultados puede variar dependiendo del sistema a evaluar y los límites establecidos. Otra metodología establecida recientemente es el uso de dos softwares en conjunto el programa WAR GUI y Aspen plus.

\subsubsection{Algoritmo de reducción de residuos (WAR)}

El algoritmo de reducción de residuos, WAR por sus siglas en inglés (WAste Reduction), fue desarrollado para que los impactos ambientales de los procesos pudieran ser evaluados fácilmente por la Agencia de Protección Ambiental de los Estados Unidos (Environmental Protection Agency, EPA, por sus siglas en inglés). El objetivo de WAR, es reducir al mínimo la generación de residuos que pudiera provocar un impacto adverso al ambiente o salud humana, es usualmente utilizado en la etapa de diseño de un proceso y se puede obtener una simulación de los impactos generados por el mismo. El proceso de evaluación de los impactos que evalúa WAR se basa en una unidad de medida PEI (Potential Environmental Impact, en español, potencial de impacto ambiental) basada en los flujos de entrada y salida ,ya sea, de energía o materia que puedan generar un impacto si estos son liberados al medio ambiente. Los impactos que evalúa el programa se dividen en dos grupos: contaminación atmosférica y toxicidad. Estos impactos son definidos mediante una base de datos que contiene información sobre un número muy grande de elementos y cuáles son sus efectos en el medio ambiente, esta información fue obtenida mediante estudios realizados por la EPA (US EPA, 2010).

El algoritmo de estimación de impacto es avanzado técnicamente y lo suficientemente flexible para permitir a los usuarios enfatizar o restarle importancia a los diferentes riesgos, según sea necesario para los usos particulares. Por ejemplo, un proceso en una zona que sufren de contaminación por smog, se destacan los efectos de la contaminación atmosférica, 
mientras que un proceso en el que los trabajadores están expuestos rutinariamente a los productos químicos, se destacará los efectos sobre la salud humana. El programa puede evaluar los impactos ambientales del proceso, así como, los generados por la fuente de energía utilizada para su desarrollo (US EPA, 2010). Los impactos atmosféricos son: Potencial de acidificación, Potencial del Deterioro de la Capa de Ozono, Potencial de Calentamiento Global, Potencial de Formación de Smog y los impactos relacionados con la toxicidad humana, acuática y terrestre. La descripción de cada uno de estos impactos se detalla a continuación.

\section{Potencial de acidificación (AP por sus siglas en ingles)}

La acidificación es el resultado de la emisión de contaminantes de carácter ácido, tales como $\mathrm{SO}_{2}$ o $\mathrm{NO}_{x}$, a la atmósfera. Mezclado con la lluvia, se llega a transformar en ácido sulfúrico y provoca la denominada "lluvia ácida". El viento puede facilitar que este corrosivo elemento recorra miles de kilómetros antes de precipitarse en bosques, lagos, canales y ríos. Algunos ejemplos de estas sustancias son: nitratos, sulfatos, etc. La unidad de caracterización de este impacto es $\mathrm{Kg}$ de dióxido de azufre $\left(\mathrm{SO}_{2}\right)$ equivalente por $\mathrm{Kg}$ de emisión.

\section{Potencial del Deterioro de la Capa de Ozono (ODP por sus siglas en ingles)}

La destrucción de la capa de ozono se refiere a la reducción del espesor de la capa de ozono estratosférico debido a la emisión de sustancias químicas que atacan y descomponen las moléculas de ozono. Éstas producen daños en los seres humanos debido al incremento de la exposición a los rayos UV. Un ejemplo de este tipo de sustancias son: los clorofluorocarbonos (CFCs). La unidad de cálculo que define está categoría son los $\mathrm{Kg}$ de CFC equivalentes por $\mathrm{Kg}$ de emisión.

\section{Potencial de toxicidad}

Actualmente, muchos procesos industriales emplean sustancias peligrosas o tóxicas para las personas y/o los ecosistemas. La toxicidad de una sustancia dependerá de la propia sustancia, pero también de la vía de administración o exposición, la dosis, tiempo de exposición, etc. Dependiendo del caso se dividen en: toxicidad humana por ingestión o inhalación y toxicidad para los ecosistemas tanto acuáticos como terrestres. 


\section{Potencial de Calentamiento Global (GWP por sus siglas en ingles)}

Es una medida relativa de cuánto calor puede ser atrapado por un determinado gas de efecto invernadero, en comparación con un gas de referencia, por lo general, $\mathrm{CO}_{2}$.

\section{Potencial de Formación de Smog (PCOP por sus siglas en ingles)}

El smog fotoquímico se forma cuando los fotones de la luz solar chocan con moléculas de diferentes tipos de agentes contaminantes en la atmósfera. Los fotones hacen que se produzcan reacciones químicas. Las moléculas de contaminación se convierten en otros productos químicos nocivos, los químicos presentes en el smog incluyen óxidos de nitrógeno, componentes orgánicos volátiles (COV), ozono troposférico y nitrato peroxiacetílico (Papong, 2017).

Como se menciona este programa en conjunto con un simulador de procesos permite emular un proceso químico a diferentes escalas y seleccionando diferentes tipos de escenarios. El programa utilizado para simular procesos es conocido como Aspen plus.

\subsubsection{Sistema avanzado para la ingeniería de procesos (Aspen Plus)}

Aspen Plus, es un programa de simulación de procesos químicos que puede ser empleado en el área de la biotecnología, con el cual, se puede optimizar el proceso de estudio. Se alimenta principalmente de los flujos de masa y energía, y de los equipos involucrados en el proceso. También, permite realizar: (1) la estimación de propiedades de compuestos, (2) el análisis de sensibilidad de variables de proceso, (3) obtener especificaciones de diseño de proceso y (4) la síntesis y análisis de procesos químicos.

Una vez determinados los balances de materia y energía para cada proceso, se puede realizar la evaluación del impacto ambiental utilizando el algoritmo WAR. Este programa puede ser acoplado con el simulador de procesos (Aspen Plus) de tal forma que los datos sobre las sustancias involucradas en el proceso y los flujos másicos del mismo son tomados directamente del simulador (Montoya y col 2006).

Cardona y col. (2006), evaluaron los impactos ambientales para la producción de bioetanol de caña de azúcar y maíz utilizando el software WAR y Aspen Plus. Realizaron primero una simulación para una planta de producción de 537.72 L/día de bio-etanol. Se contemplaron las etapas de lavado y extracción del jugo de caña, esterilización, 
fermentación, concentración del bio-etanol por destilación, deshidratación por adsorción con tamices moleculares y concentración de vinazas. Para el caso del maíz, se consideró el lavado, molienda del grano, licuefacción del almidón, sacarificación y fermentación simultáneas, concentración del bio-etanol por destilación, deshidratación por adsorción con tamices moleculares y producción de granos secos de destilería con solubles (Distillers Dried Grains with Solubles, DDGS, por sus siglas en Inglés). Una vez determinados los balances de materia y energía para cada proceso, procedieron a realizar la evaluación de los impactos ambientales utilizando el algoritmo WAR.

En la Figura 2.3, se muestran los resultados obtenidos para el índice de salida para las 8 categorías de impacto por unidad de tiempo.

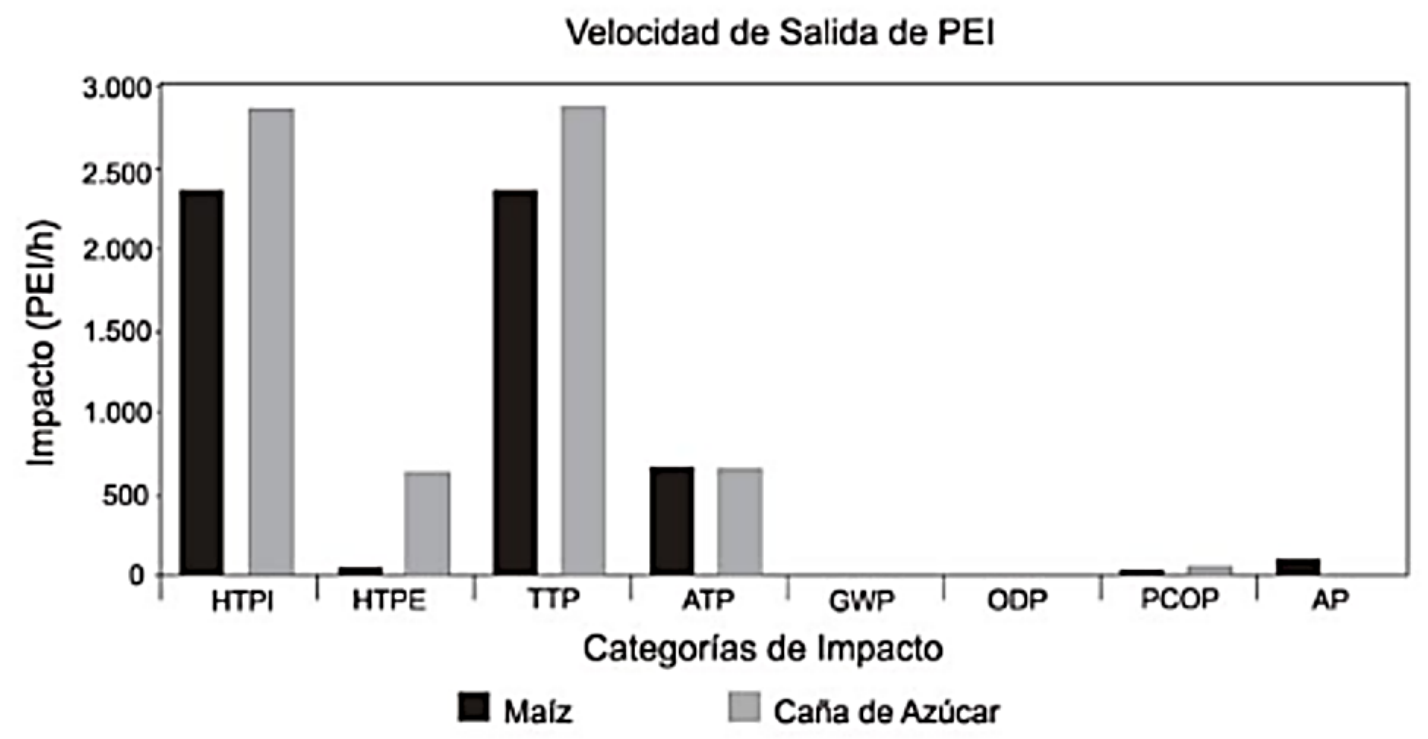

Figura 2.3. Potencial de impacto de salida por categoría para los dos casos de estudio.

Los resultados se mostraron como el potencial de impacto ambiental por unidad de tiempo (PEI/h por sus siglas en ingles) y se evaluaron las ocho categorías de impacto antes mencionadas. Los resultados indican, que la producción de bio-etanol a partir de caña de azúcar tiene un grado mayor de impacto. Se observa que las categorías que contribuyen en mayor proporción con el PEI de salida para ambos casos son el potencial de toxicidad humana por ingestión (HTPI) y el potencial de toxicidad terrestre (TTP).

Estas dos categorías están estrechamente relacionadas, ya que ambas se calculan en función de la dosis letal a través de ingestión que mataría el 50 \% de una muestra de ratas 
$\left(\mathrm{LD}_{50}\right)$. Casi todos los componentes (materias primas e insumos como: lípidos, proteínas, cenizas, fibra, almidón, azúcares, enzimas y amoniaco (como fuente de nitrógeno), y los formados en la etapa de fermentación: etanol, dióxido de carbono, biomasa, acetaldehído, oxígeno, alcoholes de fusel y glicerol) involucrados en ambos procesos contribuyen a estas categorías, aunque unos en mayor proporción que otros. Como ejemplo, se encuentra el amoníaco, el cual, posee un $\mathrm{LD}_{50}$ de $350.00 \mathrm{mg} / \mathrm{kg}$, mientras que el glicerol presenta un valor de $12.60 \mathrm{mg} / \mathrm{kg}$, lo que hace del amoníaco el mayor contribuyente a estas categorías de impacto.

En cuanto al resto de las categorías, el potencial de impacto ambiental es menor. En orden de mayor impacto a menor impacto son: ATP, HTPE, APP, COP, ODP y GWP. Estas categorías son influenciadas principalmente por la alta carga orgánica de las vinazas.

Esta metodología de análisis tiene la ventaja de que el programa WAR se puede obtener de la plataforma de la EPA y que la simulación permite establecer diferentes escenarios modificando los equipos y etapas con el fin de tener una mayor eficiencia en el proceso.

\subsection{Tasa de retorno energético (TRE)}

La TRE (Energy Return On Investment, por sus siglas en ingles, EROI), es una estimación de la relación entre la energía invertida y la energía recuperada de un sistema de estudio. Se desarrolló debido a la preocupación por la disminución y posible agotamiento de los recursos fósiles, por lo que es importante conocer la cantidad de energía útil que se obtiene de una fuente de generación determinada y la energía invertida para lograrlo.

La TRE, es un criterio importante ya que determinará qué tan viable es un proceso. La TRE del petróleo es cada vez menor. En los últimos años, se obtuvo una relación 10:1 (Murphy y Hall, 2010), esto quiere decir, que por cada unidad de energía invertida se obtienen diez de energía útil. Esta relación es debido a que cada vez es más difícil obtener el petróleo, lo que se ve reflejado en un mayor costo energético y una disminución de la tasa de retorno. Para que un proceso sea considerado viable este debe tener una TRE mayor a 5. Al realizar el análisis del proceso, se pueden tomar medidas para hacerlo más eficiente y elevar el valor de la TRE (Ballenilla y Ballenilla, 2007). 
La TRE, es una medida útil de la calidad de los recursos. La calidad, se define como la capacidad de una unidad de calor para generar una producción económica. Los recursos de alta TRE se consideran, más útiles que los recursos con TRE bajos.

\subsubsection{Metodología para determinar la tasa de retorno energético}

Aunque no existe una metodología en específico para llevar a cabo el cálculo se tiene una base que consta de: limitación del sistema de estudio, inventario y cálculo de la TRE. En principio, la estimación de la TRE será más fiable, en la medida que se haya especificado cómo se han realizado los cálculos técnicos y cuantos más elementos se consideren en el balance. Por otra parte, en el balance también se debe considerar la energía aportada por los subproductos. La TRE real será menor ya que en muchos casos no está incluida la energía invertida en mantener la infraestructura del proceso y la invertida en crearla. Además, hay que considerar que se trata de una tasa contextualizada, es decir, la TRE para un mismo proceso varía con el año y el contexto.

La elección de los límites del sistema es una parte muy importante ya que con ellos se reflejará la complejidad del análisis, entre más profundo sea el análisis los límites del sistema serán más grandes, por eso es importante definir y especificar que consideración se tendrán. Una de las metodologías que se plantean es el análisis de procesos, también conocido como análisis de abajo hacia arriba y similar al análisis del ciclo de vida, explica las entradas y salidas de energía en un proceso agregándolas a través de las etapas secuenciales de producción.

Dentro del inventario, los insumos de energía pueden considerar la energía utilizada directamente en el propio proceso, como por ejemplo, el combustible consumido en una plataforma de perforación. Pero también se puede considerar la energía que se ha utilizado para extraer y entregar los insumos materiales a un proceso, como por ejemplo, la energía usada para construir la plataforma de perforación. Estas máquinas involucradas en el proceso también han requerido energía para su fabricación, al igual que las máquinas que construyeron esas máquinas, y así sucesivamente. Podemos diferenciar entre insumos energéticos e insumos materiales como insumos directos e indirectos, con numerosas subdivisiones dentro de estas amplias clasificaciones. Algunas de las metodologías usadas para la estimación de la TRE son las siguientes: 
Estimación por cálculos analíticos: Se realiza una estimación por medio de cálculos analíticos directos, realizando la relación de la energía invertida y la energía útil obtenida, considerando la energía invertida como el conjunto de la maquinaria y equipo utilizado para la explotación del recurso. El cálculo no solo contempla el gasto en construcción y funcionamiento de los distintos equipos utilizados en la extracción y/o explotación de la fuente energética, sino también, de toda la cadena de producción hasta llegar a la materia prima. También se refiere al gasto realizado en transporte y equipos necesarios y pérdidas energéticas de índole eléctricas, térmicas, hidráulicas, etc.

Estimación por análisis monetario basado en un ACV: Permite realizar un diseño, investigación y evaluación de un proceso productivo y del impacto ambiental asociado durante la explotación del recurso energético en cuestión. La finalidad, es evaluar el impacto potencial sobre el ambiente a lo largo de todo su ciclo de vida mediante la cuantificación del uso de recursos, como en este caso la energía consumida.

En el primer paso se establecerán los límites del sistema a analizar, es decir, que tan grande o minucioso será el análisis, por el cual, se determinaran las etapas que serán incluidas en el análisis (obtención de la materia primas, producción, transporte, etc.). En el segundo paso se analizarán las pérdidas de energía de los subsistemas, lo cual puede ser ocasionado por el mal funcionamiento de los equipos, en tercer lugar se realizarán correcciones en la calidad de energía, es decir, evitando dichas perdidas y que esta sea aprovechada al máximo. Posteriormente, se efectuará la conversión económica-monetaria de energía, realizando la conversión del consumo energético ( $\mathrm{kW}, \mathrm{MJ}, \mathrm{W}$, etc.) en el costo económico equivalente de acuerdo al sitio donde se esté realizando el estudio y por último se analizan las estadísticas obtenidas.

Estimación por análisis de sistemas dinámicos (ADS): La herramienta VENSIM ${ }^{\circledR}$ permite establecer relaciones entre las distintas variables, con el fin de obtener el diagrama causal del modelo dinámico a analizar. La mayor ventaja de trabajar con flujos de energía/potencia, es que se puede conocer el ahorro energético obtenido y la consecuente disminución de las emisiones (Camargo y Schweickardt, 2016). 
Una vez determinados los diferentes flujos de energía, se calcula la TRE que se presenta como una relación entre la energía invertida y la energía útil, como se muestra en la Ecuación 2.2 .

TRE $=\frac{\text { Eret }}{\text { Einv }}$ Ec. 2.2

Donde:

TRE $=$ Tasa de Retorno Energético

Eret= Energía útil obtenida por el producto

Einv $=$ Energía invertida para producir el producto

\subsubsection{Biocombustibles y su TRE}

La TRE es un tema que ha sido estudiado para la mayoría de las energías renovables y especialmente para la producción de bio-etanol. La mayoría de las estimaciones de TRE se realizan desde la etapa de obtención materia prima hasta la distribución del producto. Sin embargo, el valor obtenido varía demasiado, debido a las diferentes consideraciones y metodologías empleadas.

Para realizar el cálculo de la energía útil obtenida por el uso de bio-etanol, se utiliza su poder calorífico que es de 23.6 MJ por litro. Hammeschlan y col. (2006), realizaron un análisis sobre la TRE en el proceso de producción de bio-etanol. Obtuvieron una TRE promedio de 0.84 - 1.65 para el bio-etanol obtenido a partir de maíz y de 4.40-6.61 para el bio-etanol a partir de material celulósico. Aunque en el caso del maíz este tiene una tasa de retorno viable $(\geq 5)$ este valor aún es bajo para competir otros combustibles como el carbón, petróleo o gas natural. Por lo que a partir de este estudio se puede concluir que el uso del maíz como sustrato para la producción de bio-etanol no es viable.

En la Figura 2.4, se puede observar los valores de TRE para diferentes combustibles.

La tasa de retorno puede cambiar con el tiempo como es el caso del petróleo, en los años 30's se tenía una TRE de casi de 80:1. Sin embargo, para el año del 2005 bajo a 10, esto es debido a que los procesos de extracción son cada vez más difíciles e implican mayores consumos de energía. Es debido a esto que existe una necesidad de producir combustibles alternos que puedan competir con el petróleo y sean obtenidos a partir de sustratos con una TRE viable.

Antecedentes: Análisis energético y ambiental de la producción de bio-etanol a partir de la FORSU. T. P. Mendoza Tinoco 


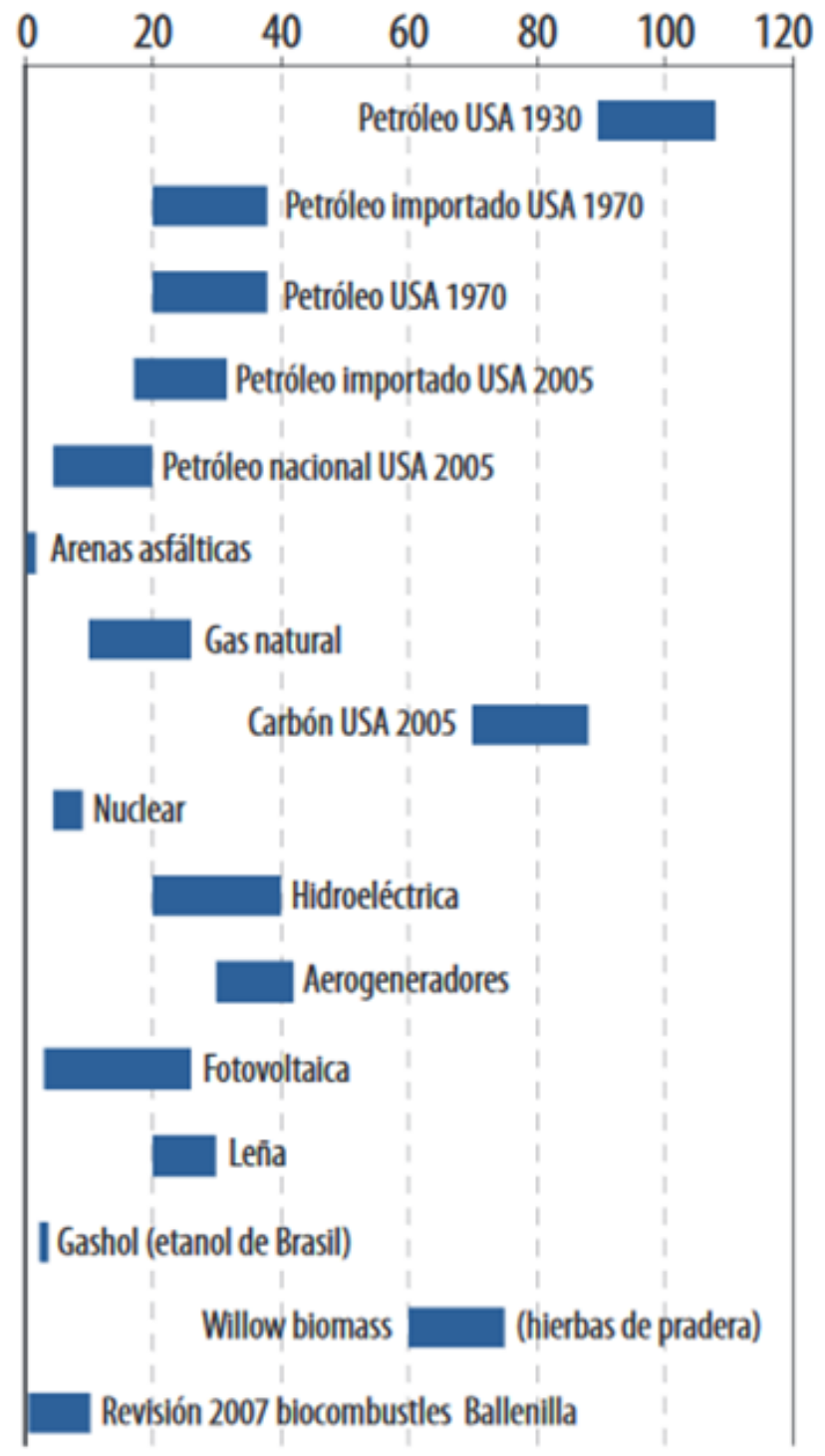

Figura 2.4. TRE de diferentes combustible (Ballenilla y Ballenilla, 2007

Antecedentes: Análisis energético y ambiental de la producción de bio-etanol a partir de la FORSU. T. P. Mendoza Tinoco 


\section{Hipótesis}

El uso de la fracción orgánica de los residuos sólidos urbanos (FORSU) como materia prima para la producción de bio-etanol, podrá disminuir la energía invertida y los impactos ambientales en la producción de una fuente de energía renovable.

Hipótesis: Análisis energético y ambiental de la producción de bio-etanol a partir de la FORSU. T. P. Mendoza Tinoco 


\section{Objetivos}

\subsection{Objetivo general}

Realizar un análisis energético y ambiental del proceso de producción de bio-etanol a partir de la fracción orgánica de los residuos sólidos urbanos (FORSU).

\subsection{Objetivos particulares}

-Analizar el proceso teórico de la producción de bio-etanol a partir de la FORSU.

- Determinar la tasa de retorno energético de la producción con base en los datos de los equipos.

- Realizar una simulación del proceso con ayuda del programa Aspen Plus 7.3.

- Determinar el grado de impacto ambiental ocasionado por el proceso con el algoritmo WAste Reduction (WAR GUI).

Objetivos: Análisis energético y ambiental de la producción de bio-etanol a partir de la 


\section{Metodología}

La presente investigación se llevó a cabo resaltando tres puntos: Tasa de Retorno Energético, Análisis de Ciclo de Vida, discusión y recomendaciones, como se muestra en la Figura 5.1, con el fin de poder realizar un análisis ambiental y energético del uso de la FORSU para producir bio-etanol.

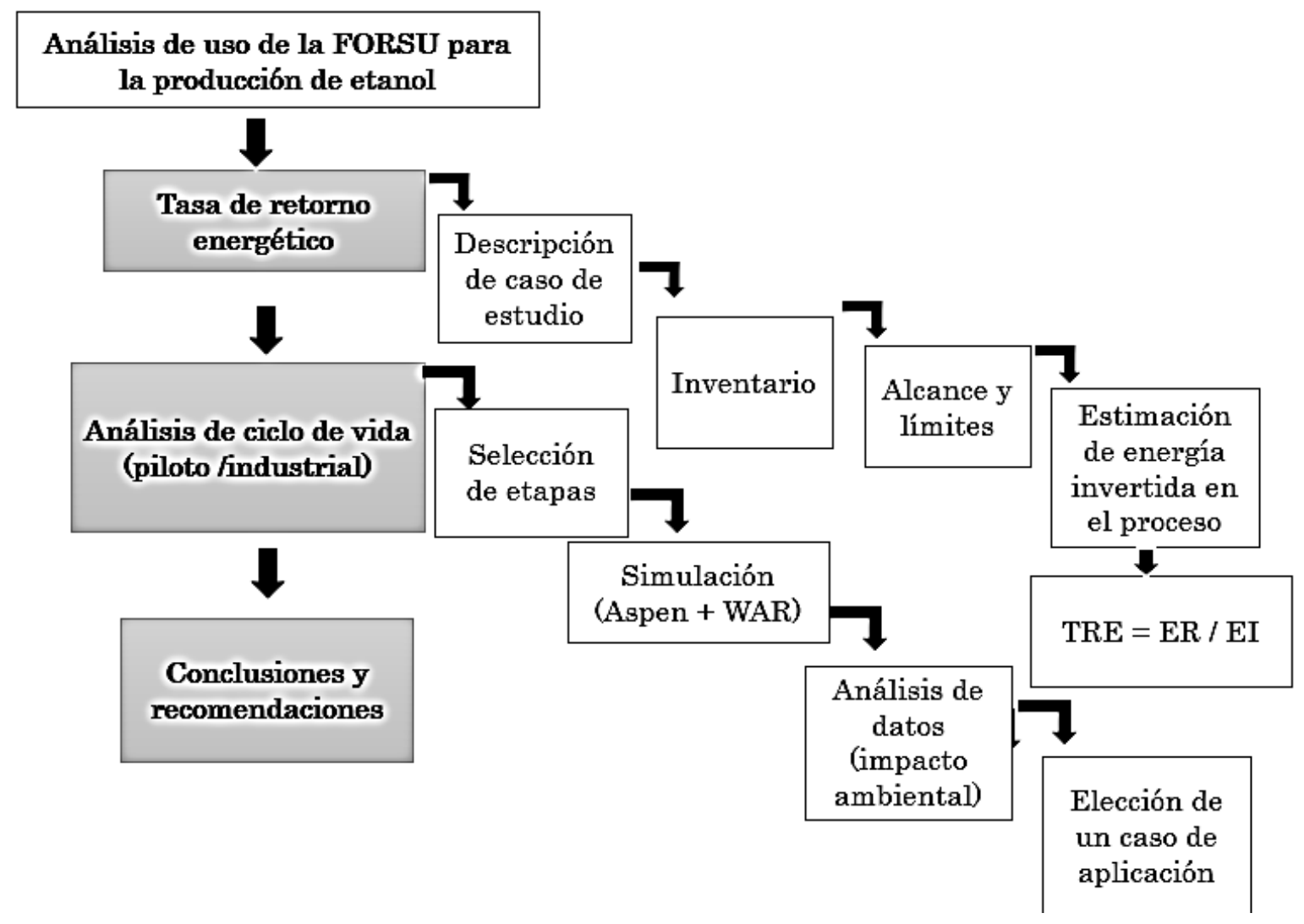

Figura 5.1. Estrategia de investigación en el análisis de uso de la FORSU para la producción de bio-etanol.

Tasa de retorno energético: se seleccionó el proceso de producción de bio-etanol a escala piloto como caso de estudio, posteriormente se realizó un inventario de las etapas para delimitar los límites del sistema, cuantificar el consumo energético de cada etapa contemplada y determinar la tasa de retorno energético.

Análisis de ciclo de vida: con base al inventario generado en la etapa anterior se realizó una simulación del proceso en el programa Aspen plus, para posteriormente evaluar los impactos ambientales con el programa WAR provocados por el proceso a nivel piloto e industrial.

Metodología: Análisis energético y ambiental de la producción de bio-etanol a partir de la FORSU. T. P. Mendoza Tinoco 
Discusión y recomendaciones: en esta parte se realiza un análisis de los resultados obtenidos para cada uno de los análisis, destacando la información más relevante de acuerdo a los objetivos planteados, finalmente se generan recomendaciones para favorecer y enriquecer el tema de investigación.

\subsection{Determinación de la TRE para la producción de bio-etanol a partir de FORSU a nivel piloto.}

Caso de estudio: El análisis se realizó tomando como base los resultados obtenidos en la fermentación de los carbohidratos de la FORSU y producción de bio-etanol de la tesis doctoral que realiza el M. en C. Raziel Estrada Mtz, en las instalaciones de la planta piloto 4 de la Universidad Autónoma Metropolitana, Unidad Iztapalapa.

Inventario: Se realizó un inventario de los insumos, materiales, equipos y etapas involucradas en el proceso de producción. Esta etapa tiene como objetivo, conocer el proceso de producción de bio-etanol y determinar los límites del sistema de estudio.

En la Tabla 5.1, se muestra la estructura del inventario que se utilizó para la determinación de la tasa de retorno energético y el análisis del ciclo de vida

Tabla 5.1. Estructura del inventario.

\begin{tabular}{|c|c|c|c|}
\hline $\begin{array}{l}\text { Objetivo de } \\
\text { estudio }\end{array}$ & Categoría & Indicadores & Especificaciones \\
\hline \multirow{4}{*}{$\begin{array}{l}\text { Etapa del } \\
\text { proceso }\end{array}$} & Equipo & $\begin{array}{c}\text { Energía consumida por equipo } \\
\text { y tiempo de trabajo por } \\
\text { muestra }\end{array}$ & $\begin{array}{l}\text { Equipo, consumo de energía por } \\
\text { equipo, tiempo de trabajo, número de } \\
\text { muestras y fuente: lugar y fecha }\end{array}$ \\
\hline & Insumos & $\begin{array}{l}\text { Cantidad y tipo de insumos } \\
\text { utilizados en la etapa }\end{array}$ & $\begin{array}{l}\text { Tipo de insumo, cantidad, número de } \\
\text { muestras y fuente: lugar y fecha }\end{array}$ \\
\hline & $\begin{array}{l}\text { Sustancia o } \\
\text { químico }\end{array}$ & $\begin{array}{l}\text { Cantidad y tipo de sustancia o } \\
\text { químico utilizados en la etapa }\end{array}$ & $\begin{array}{c}\text { Tipo de sustancia o químico, cantidad, } \\
\text { número de muestras y fuente: lugar y } \\
\text { fecha }\end{array}$ \\
\hline & $\begin{array}{l}\text { Residuos, } \\
\text { emisiones y } \\
\text { descargas }\end{array}$ & $\begin{array}{l}\text { Tipo y cantidad de residuos, } \\
\text { emisiones o descargas } \\
\text { realizadas en esta etapa }\end{array}$ & $\begin{array}{l}\text { Tipo de residuo, cantidad y fuente: } \\
\text { lugar y fecha }\end{array}$ \\
\hline
\end{tabular}

El inventario se realizó de manera presencial, los indicadores corresponden de forma cuantitativa a las categorías analizadas. Las especificaciones de cada etapa se describen en el anexo A.

Metodología: Análisis energético y ambiental de la producción de bio-etanol a partir de la 
Descripción del proceso: De manera experimental, el proceso inicia con la recolección de la materia orgánica, obtenida de locales de comida cercanos a las instalaciones de la UAM Iztapalapa y que se dedican a la venta de ensaladas, jugos y cócteles de fruta. Los locales ubican aproximádamente a $190 \mathrm{~m}$ del sitio de estudio, donde se llevó a cabo la producción de bio-etanol. Una vez recolectados los residuos se estandarizaron, es decir, se ajustaron los porcentajes de cada residuo, para obtener la siguiente composición: 93\% de residuos orgánicos (naranja 30\%, sandia 15\%, piña 15\%, limón $10 \%$, zanahoria $10 \%$, papaya $10 \%$, plátano 5\%, pepino 5\%), $4 \%$ aserrín y $3 \%$ papel triturado.La mezcla de residuos formulada se trituró para facilitar su pretratamiento y su posterior fermentación.

La etapa de crecimiento y conservación del microorganismo no fue considerada dentro del análisis energético y ambiental, ya que los equipos utilizados para esta etapa (cuarto de temperatura controlada $\left(30^{\circ} \mathrm{C}\right)$ y cuarto frio $\left.\left(4^{\circ} \mathrm{C}\right)\right)$ tienen capacidades 10 veces más grandes en comparación con el resto de los equipos y los métodos de medición podrían resultar no confiables.

Se realizó un pretratamiento de los residuos por explosión a vapor en una autoclave modificada de $180 \mathrm{~L}$. Los residuos $(50 \mathrm{Kg})$ fueron introducidos en la autoclave. La autoclave se presurizó con vapor hasta alcanzar una presión de $2.7 \mathrm{Kg} / \mathrm{cm}^{2}$ durante $15 \mathrm{~min}$. Una vez pasado el tiempo del pretratamiento se realizó una liberación rápida de la presión, en menos de 2 min. El bioreactor fue esterilizado usando vapor a presión atmosférica durante $2 \mathrm{~h}$ a $92^{\circ} \mathrm{C}$. Sin embargo, esta estapa no fue considerada dentro del análisis ya que solo se consideraron las operaciones unitarias principales. Los residuos pretratados se introdujeron asépticamente de manera manual en un biorreactor tipo batch de 170 L y se inoculó con una levadura de panadería (Saccharomyces cerevisiae) en una proporción $10 \%(\mathrm{p} / \mathrm{v})$. Los residuos fueron fermentados durante $24 \mathrm{~h}$ a $30^{\circ} \mathrm{C}$, con agitación intermitente (c/30 min). Una vez transcurrido el tiempo de fermentación se llevó a cabo la extracción de bio-etanol y de carbohidratos no fermentados para su posterior análisis. Para ello, se tomaron muestras (10 g) y se mezclaron con $40 \mathrm{~mL}$ de agua destilada (dilución 1:5), se mezclaron y se centrifugaron a $3500 \mathrm{rpm} \mathrm{a} 4^{\circ} \mathrm{C}$, durante $20 \mathrm{~min}$. El sobrenadante fue filtrado con una membrana de $0.22 \mu \mathrm{m}$ (tamaño de poro) y fue analizado para determinar las concentraciones de sacarosa, glucosa, fructosa, bio-etanol y ácido acético. Los diferentes compuestos fueron analizados en un equipo de cromatografía líquida de alta resolución (HPLC) Shimadzu Promenence (Shimadzu Corp, Kyoto, Japón) con detector de arreglo de diodos SPD-M20A 
y detector de índice de refracción RID-20A. La separación se llevó a cabo usando una columna Aminex HPX-87H (Bio-Rad, Hércules, CA, USA). Como fase móvil se utilizó solución acuosa $5 \mathrm{mM}$ de $\mathrm{H}_{2} \mathrm{SO}_{4}$. La velocidad de flujo y la temperatura de operación usada fueron de $0.6 \mathrm{~mL} \min ^{-1}$ y $60^{\circ} \mathrm{C}$, respectivamente. Los compuestos se cuantificaron basándose en los tiempos de retención y las áreas obtenidas de soluciones estándar.

La estimación de la tasa de retorno energético inicialmente se pretendía realizar en base a los flujos de energía obtenidos por una simulación del proceso que se llevó a cabo en el programa Aspen plus en la cual se intentó imitar los equipos y condiciones de operación de la planta piloto, las etapas simuladas fueron: disminución de partícula, explosión a vapor, fermentación y destilación. Sin embargo, la simulación no ayudó a determinar una TRE fiable, debido a que el programa no contiene algunos de los equipos utilizados, especialmente en la etapa de fermentación, pero los resultados de los flujos de materia obtenidos sirvieron para determinar los impactos ambientales que se verán en el siguiente apartado.

Se determinó la TRE con ayuda de los datos del inventario como son: potencia, tiempo de operación y capacidad de los equipos. La TRE presentada contempla dos consumos: el obtenido por medio de las especificaciones del fabricante para cada equipo utilizado contra el consumo real. Para el consumo real, se realizaron mediciones con los equipos en funcionamiento, utilizando un amperímetro de gancho para determinar su corriente (V) e intensidad (A). A continuación, se muestra la metodología empleada para cada etapa.

\subsubsection{Etapa I. Disminución de partícula}

Descripción de la etapa: Se utilizó una trituradora de cuchillas, con una potencia de 2238 $\mathrm{kW}$, la cual, tritura la FORSU ( $50 \mathrm{Kg}$ ) en $30 \mathrm{~min}$, el equipo funciona por medio de un motor trifásico de inducción cerrada.

En la Figura 5.2, se muestra el equipo utilizado para esta etapa. En la figura 5.2A, se presenta el equipo de trituración, en la Figura 5.2B la placa con las características del equipo de trituración y en la Figura 5.2C y D, las mediciones realizadas al equipo. 
A

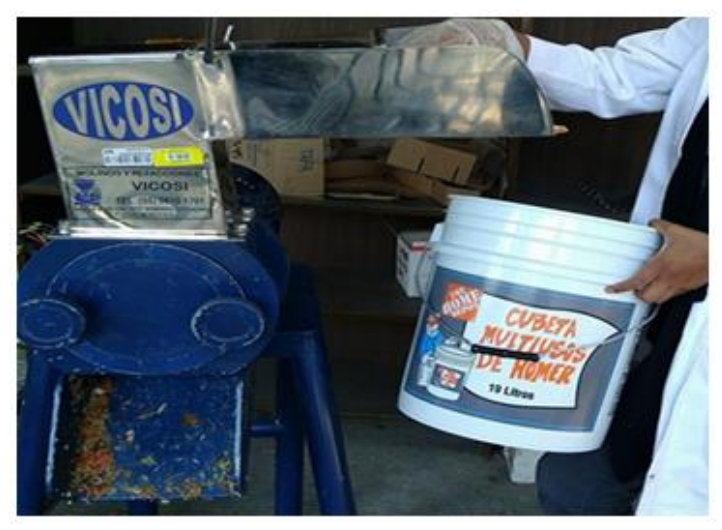

C

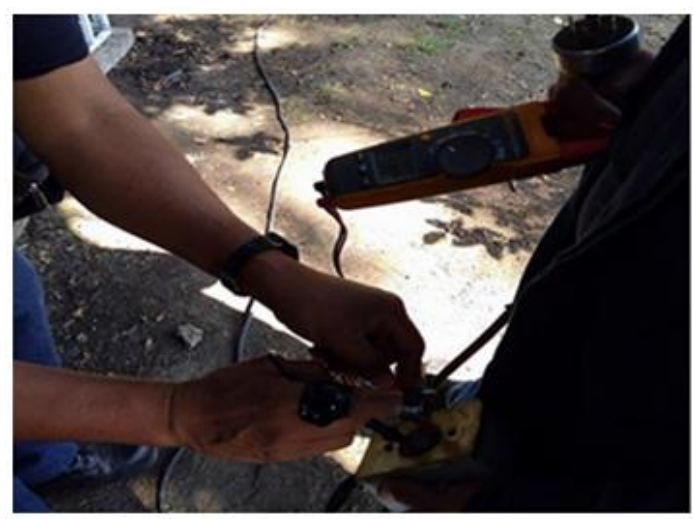

B

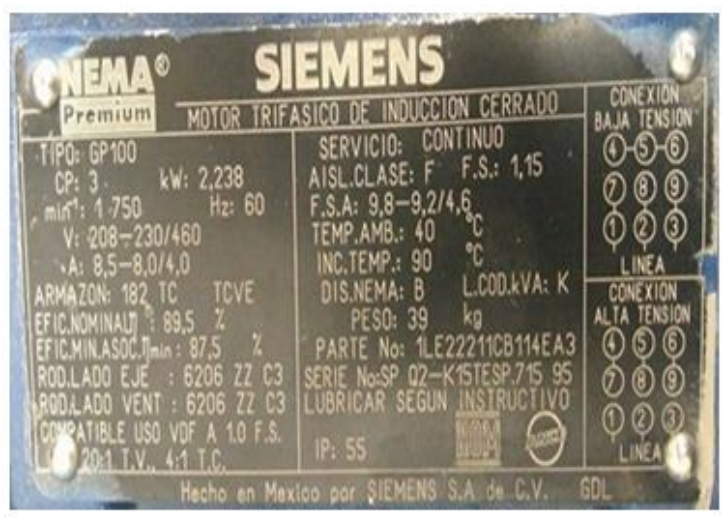

D

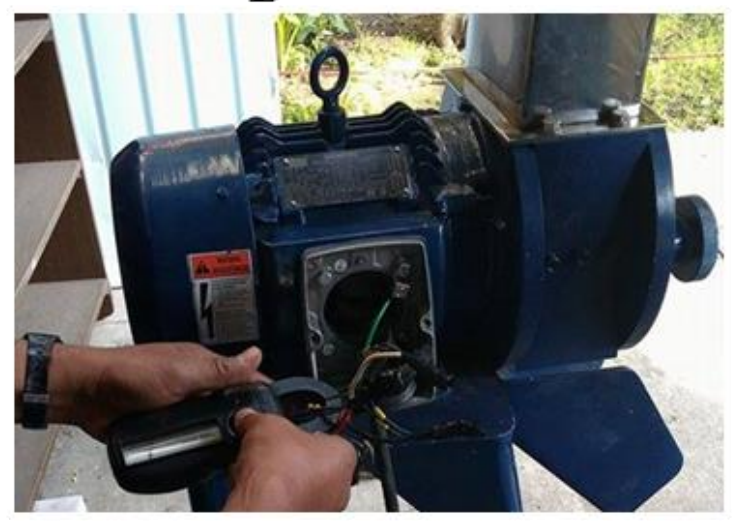

Figura 5.2. Etapa de disminución de partícula

Se realizó el cálculo del consumo energético del equipo de acuerdo a la Ecuación 5.1 de potencia para un motor trifásico, considerando los datos reportados en la placa de información del fabricante (Figura 5.2B) y las mediciones realizadas con el amperímetro de gancho. Con el amperímetro, se midió el voltaje y el ampreraje con el equipo puesto en marcha, es decir, triturando un $\mathrm{Kg}$ de la FORSU. Esto se realizó para las tres fases como se muestra en la Figura 5.2C y 5.2D. Una vez obtenido el resultado en $\mathrm{kW}$ fue convertido en $\mathrm{kW}$ h tomando en cuenta el tiempo de operación del equipo.

$$
P(W)=\sqrt{3 * F P} * I(A) * V(V: L-L) \text { Ec. } 5.1
$$

Metodología: Análisis energético y ambiental de la producción de bio-etanol a partir de la FORSU. T. P. Mendoza Tinoco 
Donde:

$\mathrm{P}(\mathrm{W})$ : potencia en Watts

V: L - L: voltaje de líneas en voltios (V)

I: corriente en línea en amperios (A)

FP: factor de potencia

\subsubsection{Etapa II. Explosión a vapor}

Para el pretratamiento por explosión a vapor, se suministró vapor a una autoclave modificada de $180 \mathrm{~L}$ hasta alcanzar una presión de $2.7 \mathrm{Kg} / \mathrm{cm}^{2}$. El vapor suministrado se obtuvo de una caldera de vapor (Clayton, México, 1995) que presenta las siguientes características: presión de $7 \mathrm{Kg} / \mathrm{cm}^{2}$, un voltaje de $220 \mathrm{~V}$, utiliza gas como combustible y se suministra el agua por medio de una bomba de 3 HP. En la Figura 5.3, se muestran los equipos utilizados para la etapa de explosión a vapor. En la Figura 5.3A, se presenta la autoclave modidificada para la liberación de vapor, en la Figura 5.3B, se muestra la caldera de vapor, en la Figura 5.3C, la placa con las carácteristicas de la caldera y en la figura 5.3D, la técnica de medición del consumo energético.

A

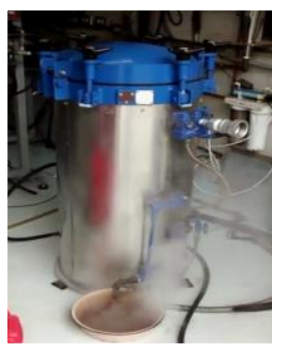

C

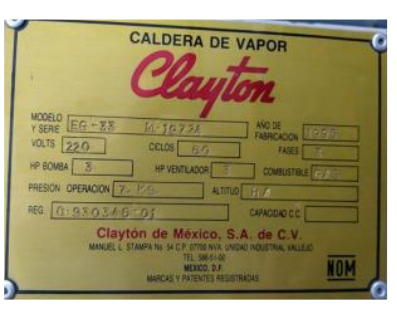

B

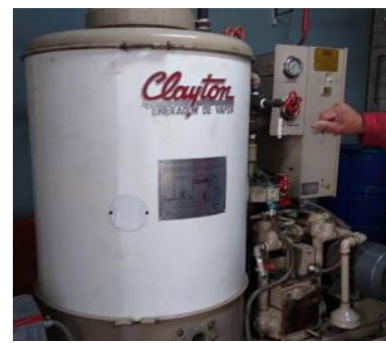

D

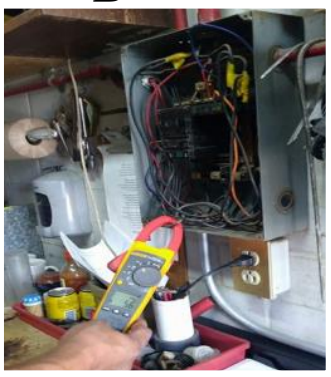

Figura 5.3. Etapa de explosión a vapor

Se realizó el cálculo del consumo energético por medio de la información de placa del fabricante del equipo (Figura 5.3 C) y del consumo de combustible. Se realizó la medición 
del amperaje y voltaje de la caldera con un amperímetro de gancho en las tres líneas con el equipo en funcionamiento y sin funcionamiento.

Para el cálculo del consumo de gas, se determinó el flujo de agua necesaria para saturar la autoclave de $180 \mathrm{~L}$, tomando como base la densidad de la FORSU. La densidad de la FORSU se determinó a partir de la sumatoria de las densidades de cada compuesto que fue considerado y su fracción másica (Agua $0.70 \mathrm{~g} / \mathrm{cm}^{3}$, Carbohidrato $0.22 \mathrm{~g} / \mathrm{cm}^{3}$, Cenizas 0.03 $\mathrm{g} / \mathrm{cm}^{3}$, Almidón $0.16 \mathrm{~g} / \mathrm{cm}^{3}$, Proteínas $0.07 \mathrm{~g} / \mathrm{cm}^{3}$ ) obteniendo una densidad de $0.7 \mathrm{~g} / \mathrm{cm}^{3}$ por kilogramo de FORSU húmeda. Esta densidad fue convertida a $\mathrm{kg} / \mathrm{cm}^{3}$, para obtener el volumen que esta ocupaba en la autoclave, dando un resultado de $71.43 \mathrm{~L}$.

Para el cálculo del consumo de gas se utilizó la ecuación que se muestra a continuación:

Donde:

$$
Q=m * C p * \Delta T \text { Ec. } 5.2
$$

Q: calor térmico $(\mathrm{kW} \mathrm{h})$

$m$ : flujo de la sustancia a calentar $(\mathrm{kg} / \mathrm{h})$

$\mathrm{Cp}$ : poder calorífico de la sustancia a calentar $\left(\mathrm{k} \mathrm{cal} / \mathrm{kg}{ }^{\circ} \mathrm{C}\right)$

$\Delta \mathrm{T}$ : diferencia en la temperatura inicial y final $\left({ }^{\circ} \mathrm{C}\right)$

\subsubsection{Etapa III. Fermentación}

Se utilizó un biorreactor horizontal tipo batch con una capacidad nominal de $170 \mathrm{~L}$, el cual, se mantuvo a $30^{\circ} \mathrm{C}$ entre 24 y $30 \mathrm{~h}$, la temperatura fue controlada con agua calentada por medio de un serpentín y se recirculó por la chaqueta del reactor. El reactor tiene una agitación constante por medio de un motor trifásico a $0.75 \mathrm{rpm}$.

En la Figura 5.4, se muestran los equipos involucrados en la etapa de fermentación. En la Figura 5.4A, se presenta en el biorreactor batch 170L, en la Figura 5.4B, la placa con las características delo motor trifásico, en la Figura 5.4C, el sistema de calentamiento del agua recirculada y en la Figura 5.4D, la placa con las características de funcionamiento del serpetin que calienta el agua de recirculación.

Metodología: Análisis energético y ambiental de la producción de bio-etanol a partir de la 
A

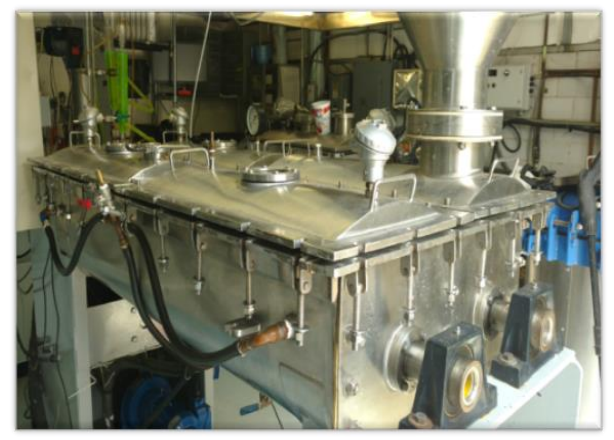

C

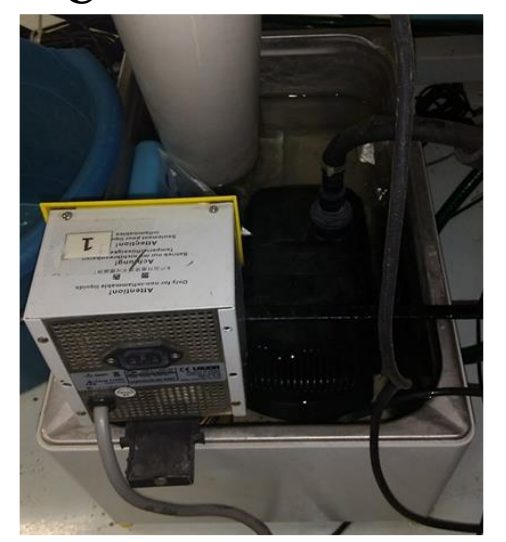

B

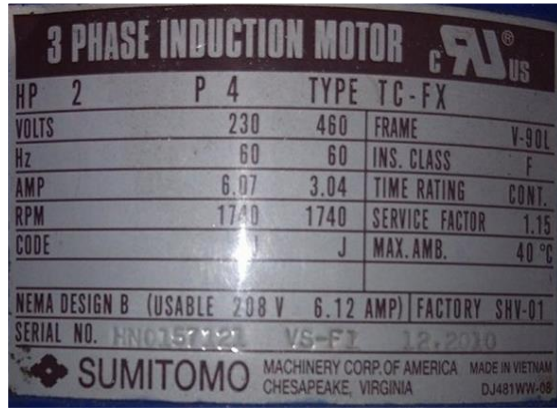

$\mathbf{D}$

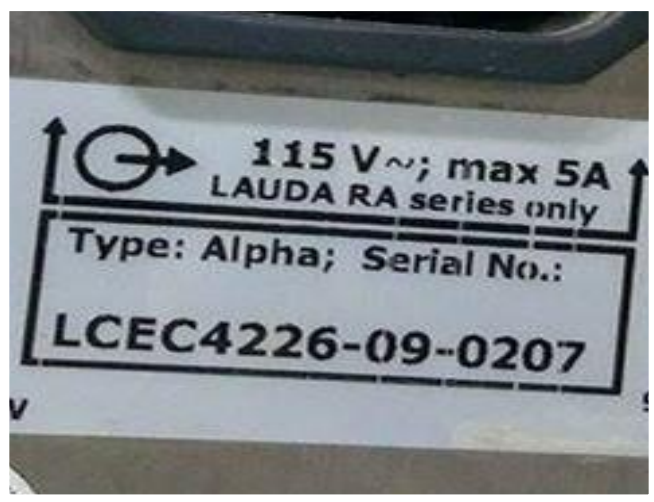

Figura 5.4. Reactor utilizado en la etapa de fermentación

Los cálculos de consumo de energía en esta etapa se realizaron con la información de la placa de los equipos (Figura 5.4B, D). Adicionalmente, se realizaron mediciones de amperaje y voltaje del biorreactor, calentador y la bomba que recircula el agua, por medio de un amperímetro de gancho con los equipos con carga (Figura 5.5), es decir, durante la fermentación de la FORSU.
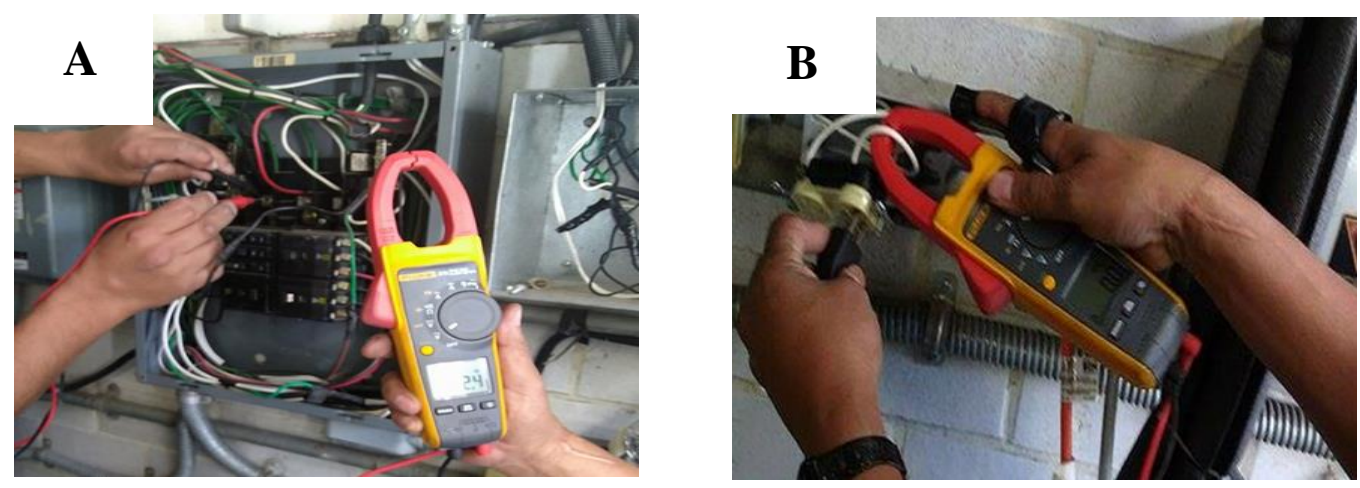

Figura 5.5. Medición de amperaje del reactor

Metodología: Análisis energético y ambiental de la producción de bio-etanol a partir de la FORSU. T. P. Mendoza Tinoco 
Una vez obtenidos los datos se utilizó la Ecuación 5.3, para el cálculo del consumo biorreactor. La bomba que recircula el agua funciona con un motor monofásico por lo que se utilizó el cálculo de consumo energético con la Ecuación 5.3 de motor monofásico.

$$
\boldsymbol{P}(\boldsymbol{w})=\boldsymbol{V} \boldsymbol{L}-\boldsymbol{N} * \boldsymbol{I} * \boldsymbol{F P} \text { Ec. } 5.3
$$

Donde:

$\mathrm{P}(\mathrm{W})$ : potencia en Watts

VL-N: voltaje de línea a neutro en voltios (V)

I: corriente en línea en amperios (A)

FP: factor de potencia

\subsubsection{Etapa V. Destilación}

En esta etapa, se consideró una destilación simple. En la destilación simple, se calienta el caldo fermentado a $78^{\circ} \mathrm{C}$, para obtener una concentración del $90 \%$ de producto destilado. Se calculó la energía necesaria para destilar el caldo fermentado considerando una composición de 30\% de bio-etanol, y 70\% de humedad (agua). Se consideraron las características físico-químicas (poder calorífico $\left(\mathrm{k} \mathrm{cal} / \mathrm{kg}{ }^{\circ} \mathrm{C}\right.$ )) del agua para simplificar el cálculo. Para el cálculo de consumo energético en la etapa de destilación se consideró la Ecuación 5.2, sustituyendo los valores para cada sustancia.

\subsection{Análisis de ciclo de vida para la producción de bio-etanol a partir de FORSU a nivel piloto}

La información del proceso de producción de bio-etanol a nivel piloto se suministró al programa Aspen plus 7.3, para simular el proceso de producción de bio-etanol considerando las etapas antes mencionadas. El proceso de simulación inicia con la selección de los equipos involucrados en el proceso de producción, similar a lo utilizado experimentalmente en la planta piloto 4 para poder simular las mismas condiciones del proceso. 
En la Figura 5.6, se presenta el diagrama de flujo del proceso, donde se pueden observar las siguientes etapas: disminución de partícula, explosión a vapor, fermentación y destilación.

\section{Producción de etanol a partir de FORSU.}

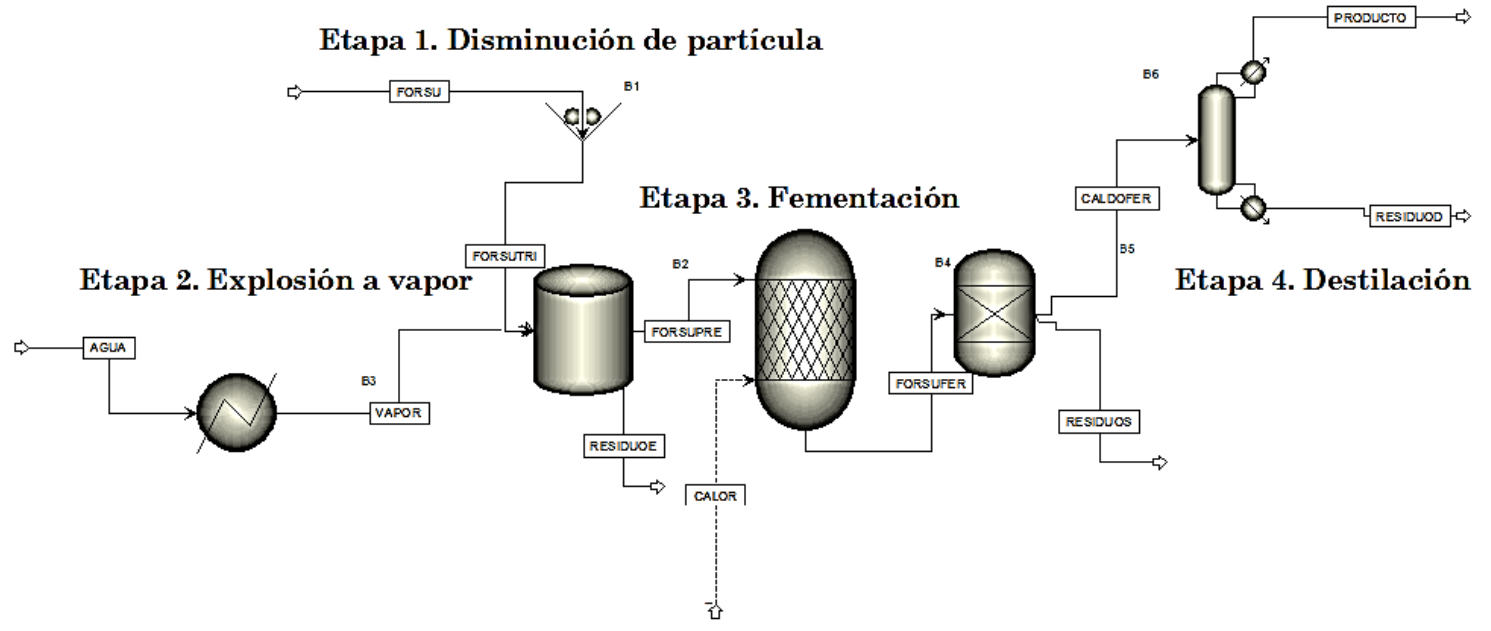

Figura 5.6. Diagrama de flujo del proceso de producción

El diagrama de flujo del proceso presenta las siguientes siglas que corresponden a lo considerado en cada etapa: FORSU: fracción orgánica de los residuos sólidos urbanos, FORSUTRI: fracción orgánica de los residuos sólidos urbanos triturada, AGUA: agua que se suministra a la caldera, VAPOR: producto dela caldera, RESIDUOE: vapor liberado después de la explosión a vapor, FORSUPRE: fracción orgánica de los residuos sólidos urbanos después del pretratamiento térmico, CALOR: calor suministrado en la fermentación, FORSUFER: fracción orgánica de los residuos sólidos urbanos después de la fermentación, RESIDUOS: residuos no fermentados, CALDOFER: caldo fermentado, PRODUCTO: bioetanol destilado, RESIDUOO: residuos del destilado.

Con los equipos seleccionados, se realizarón las conexiones de entrada y salida de materia y/o energía, las cuales, fueron introducidas de acuerdo a la información obtenida en el inventario. En una etapa posterior, se introdujeron los siguientes datos de la simulación al programa: las condiciones de operación, la capacidad de la planta y la composición de la materia prima.

En la Tabla 5.2, se muestra la composición de la materia prima (FORSU) utilizada para la simulación.

Metodología: Análisis energético y ambiental de la producción de bio-etanol a partir de la 


\begin{tabular}{cc} 
Tabla 5.2. Compuestos considerados en la simulación (\% \\
\hline Compuesto & Inicial \\
\hline Agua & 70.00 \\
Carbohidratos & 14.45 \\
Cenizas & 2.56 \\
Almidón & 5.00 \\
Proteínas & 7.99 \\
\hline
\end{tabular}

Fuente:(Kiran y col., 2014)

Los carbohidratos considerados fueron: sacarosa, fructuosa y glucosa, datos obtenidos a partir del análisis por HPLC. Los datos de proteínas, cenizas y almidón fueron estimados a partir de trabajos previos (Kiran, Trzcinski, Ng, y Liu, 2014b).

Tomando en cuenta la capacidad de la planta piloto 4 (50 $\mathrm{kg}$ de FORSU al día), se consideró una capacidad de planta de 9 ton/año de FORSU en base húmeda, con una producción de 498.50 L de bio-etanol al año, considerando un rendimiento de producción de $36.93 \mathrm{~g}$ de bio-etanol/kgMH por lote. Para el cálculo de los coeficientes de actividad se utilizó el modelo termodinámico no aleatorio de dos líquidos (NRTL) con el que se puede calcular los estados de equilibrio de un sistema, ya sea liquido-vapor o solido-liquido (Cardona, Sánchez, Montoya, y Quintero, 2005a).

Las propiedades fisicoquímicas de las de proteína y el almidón se obtuvieron del trabajo de producción de bio-etanol a partir de maíz elaborado por el laboratorio Nacional de Energías Renovables de Estados Unidos, debido a la similitud en la composición que se empleó en este trabajo, ya que dentro de su composcision inicial de la materia prima se considera almidon, cenizas, proteínas y carbohidratos, también sirvió como base para establecer las condiciones de operación de los equipos (NERL, 2011).

En la Tabla 5.3, se muestran las condiciones de operación que se consideraron para llevar a cabo la simulación.

Metodología: Análisis energético y ambiental de la producción de bio-etanol a partir de la 
Tabla 5.3. Condiciones de operación por etapa y equipos

\begin{tabular}{|c|c|c|}
\hline Etapa & $\begin{array}{l}\text { Equipo utilizado } \\
\text { en la simulación }\end{array}$ & Especificaciones \\
\hline \multirow{2}{*}{$\begin{array}{l}\text { Disminución de } \\
\text { partícula }\end{array}$} & \multirow{2}{*}{ Crusher } & Diámetro máximo de partícula: $6 \mathrm{~cm}$ \\
\hline & & Bon Word Index: $43 \mathrm{~kW} \mathrm{h/Ton}$ \\
\hline \multirow{3}{*}{$\begin{array}{l}\text { Explosión a } \\
\text { vapor }\end{array}$} & \multirow{2}{*}{ Heater } & Temperatura: $138.39^{\circ} \mathrm{C}$. \\
\hline & & Presión: 1 atm \\
\hline & \multirow[t]{2}{*}{ Mixer } & Presión: 2.6 bar \\
\hline \multirow{4}{*}{ Fermentación } & & Temperatura: $30^{\circ} \mathrm{C}$, \\
\hline & \multirow[t]{3}{*}{ Rstoic } & $\begin{array}{l}\text { Reacción: } \\
\mathrm{C}_{6} \mathrm{H}_{12} \mathrm{O}_{6} \rightarrow 2 \mathrm{C}_{2} \mathrm{H}_{5} \mathrm{OH}+2 \mathrm{CO}_{2}\end{array}$ \\
\hline & & (Conversión 51 \%) \\
\hline & & Temperatura: $78^{\circ} \mathrm{C}$ \\
\hline \multirow[t]{2}{*}{ Destilación } & \multirow[t]{2}{*}{ Radfrac } & Número de etapas :17 \\
\hline & & Relación de reflujo : 0.39 \\
\hline
\end{tabular}

Con la finalidad de simplificar la simulación, se modificó el biorreactor utilizado en la etapa de fermentación y se seleccionó un bioreactor estequiométrico. Con el uso del biorreactor estequiométrico se permite simular la etapa de fermentación considerando el porcentaje de conversión teórico en la producción de bio-etanol (51\%) y no se requiere establecer un tiempo de retención u operación. En este caso se puede omitir el tiempo de operación, ya que se busca determinar los impactos ambientales provocados y no el consumo energético a partir de esta simulación.

En la etapa de destilación, se calculó el número de etapas por el método McCabe Thiele, a partir de la concentración al inicial de bio-etanol hasta obtener una concentración del 90 $\%$ y obtener la relación de reflujo. Una vez introducidos todos los datos requeridos se corrió la simulación para obtener: un resumen de las entradas y salidas de materia, con lo que, se pudo cuantificar las entradas de materia prima, residuos y de producto (Anexo B).

\subsubsection{Evaluación de impacto ambiental}

Con la información obtenida en la simulación se analizaron los impactos ambientales con el programa WAR. En el cual, se exportó la información sobre los flujos de materia y energía consumida y se realizó la valoración de las 8 categorías de impacto con el valor más alto (10). Con ayuda del programa WAR, se evaluaron los impactos generados por el proceso. El programa se enfoca en los impactos generados por los compuestos, productos, residuos 
del proceso y por la fuente que suministra la energía para desarrollar el proceso de producción. Como fuente de suministro energético, se consideró una central termoeléctrica, cuyo funcionamiento es mediante el uso de hidrocarburos (diésel, combustóleo, etc.) (Ramos y Montenegro, 2012), la cual suministra a la Ciudad de México.

Suministrados todos los datos al programa WAR, se analizaron los compuestos vertidos y con ayuda de una base de datos incorporada en el programa se determinaron cuáles son los potenciales impactos ambientales del proceso. El programa funciona de acuerdo a una base de datos que contiene los posibles impactos que puede provocar un cierto elemento con base en estudios realizados por la agencia de protección ambiental de los Estados Unidos (EPA), dando como resultado un resumen de los $\mathrm{Kg}$ de contaminante por unidad de tiempo y por unidad de producto.

\subsection{ACV para la producción de bio-etanol a nivel industrial}

Caso de estudio II: Al obtener los resultados del ACV a nivel piloto, se realizó el mismo análisis en un caso real. Se utilizaron los mismos datos de composición y condiciones de operación que en la primera simulación (Tabla 5.3). El caso de estudio seleccionado fue la planta de compostaje del Bordo Poniente que recibe grandes cantidades de residuos orgánicos provenientes del Valle de México.

\subsubsection{Descripción del caso de estudio}

En la Ciudad de México se opera una la planta de compostaje, ubicada en el sitio Bordo Poniente IV Etapa, en un lugar cercano del relleno sanitario de Bordo Poniente dentro de los terrenos federales del Estado de México y en los límites de la Ciudad de México, con una superficie de $6000 \mathrm{~m}^{2}$. La planta trabaja los 365 días del año de 7 a 22 horas, recibe 4828.31 ton/día de FORSU (Saucedo,2012) y produce diariamente alrededor de 2500 toneladas de composta (Morillas, 2014).

En esta tesis se propone utilizar los residuos orgánicos (FORSU) que ingresan a la planta, para la producción de bio-etanol, el cual, podría ser distribuido para su uso en el trasporte, obteniendo uno de los primeros centros de producción de biocombustibles en la Ciudad de México. La selección de este caso de estudio se debió a la facilidad de la obtención de materia prima, el área disponible y que se cuenta con la etapa de molienda, considerada importante para la producción de bio-etanol. La implementación de este proyecto implicaría 
una inversión económica y energética elevada, estos aspectos no son analizados en el presente trabajo, donde el único objetivo es dar un panorama general sobre la viabilidad de este tipo de acciones en sitios de disposición final en términos de aspectos ambientales y energéticos.

\subsubsection{Simulación y análisis de datos}

Se realizó una simulación con una capacidad de planta de 8.42 × $10^{5}$ Ton/año, con una producción de $4.67 \times 10^{4} \mathrm{~m}^{3} /$ año de bio-etanol. Se utilizaron las mismas condiciones de operación y equipos planteados a escala planta piloto. Con los datos obtenidos de la simulación, se evaluaron las 8 categorías de impacto con el programa WAR.

Metodología: Análisis energético y ambiental de la producción de bio-etanol a partir de la 


\section{Resultados y discusión}

\subsection{Determinación de la TRE para la producción de bio-etanol a partir de FORSU a nivel piloto}

La estimación de la tasa de retorno energético inicialmente se pretendía realizar en base a los flujos de energía obtenidos por una simulación del proceso que se llevó a cabo en el programa Aspen plus en la cual se intentó imitar los equipos y condiciones de operación de la planta piloto, las etapas simuladas fueron: disminución de partícula, explosión a vapor, fermentación y destilación. Sin embargo, la simulación no ayudó a determinar una TRE fiable, debido a que el programa no contiene algunos de los equipos utilizados, especialmente en la etapa de fermentación, pero los resultados de los flujos de materia obtenidos sirvieron para determinar los impactos ambientales que se verán en el siguiente apartado.

En una etapa preliminar, a partir de la simulación realizada con el programa Aspen plus se obtuvo una TRE de 5:1 (ver Anexo E), esta estimación fue descartada debido a que no se simularon los mismo equipos en las etapas del proceso de producción de bio-etanol y este resultado puede ser incorrecto. Las principal diferencia fue en la etapa de fermentación, en la cual, se utilizó un biorreactor estequiométrico que no cuenta con una agitación constante y no se define un tiempo de operación. Sin embargo, esta simulación se utilizó como una herramienta para determinar los impactos ambientales en el proceso. Con las mediciones realizadas, en cada etapa se obtuvieron las estimaciones energéticas de consumo por equipo. A continuación se presentan los resultados a nivel piloto, considerando la información de fabricante a través de la placa del equipo y las mediciones reales obtenidas con el amperímetro de gancho.

Resultados y discusión: Análisis energético y ambiental de la producción de bio-etanol a partir 


\section{Etapa 1. Disminución de partícula}

En la Tabla 6.1, se muestran los datos obtenidos a partir de las mediciones del triturador utilizado en la etapa de disminución de partícula.

Tabla 6.1. Amperaje de línea a neutro

\begin{tabular}{llll}
\hline \multicolumn{2}{l}{ Sin carga } & \multicolumn{2}{l}{ Con carga } \\
\hline L1 & 3.3 & L1 & 3.5 \\
L2 & 3.4 & L2 & 3.6 \\
L3 & 3.4 & L3 & 3.6 \\
\hline
\end{tabular}

De acuerdo a las mediciones realizadas al motor trifásico utilizado en esta etapa se obtuvieron los valores de amperaje (A) sin carga y con carga como se muestran en la Tabla 6.1. Las mediciones sin carga se realizaron para tener las variaciones de arranque antes de que el equipo esté operando. Las mediciones se compararon con el consumo real del equipo en operación. El valor tomado para el cálculo del consumo energético fue de 3.6 A.

En la Tabla 6.2, se muestran los resultados del consumo energético a partir de los datos obtenidos de la placa del equipo y reales a las condiciones de trabajo y usando la Ecuación 5.1 .

Tabla 6.2. Consumo energético de la etapa de disminución de partícula

\begin{tabular}{ccc}
\hline \hline \multicolumn{3}{c}{ Datos } \\
\hline Variable & \multicolumn{2}{c}{ Lectura } \\
HP & 3.00 & 3.00 \\
V & 208 & 224 \\
A & 8.50 & 3.60 \\
Fp & 0.82 & 0.82 \\
$\sqrt{3}$ & 1.73 & 1.73 \\
& & \\
Consumo energético \\
W & 2508.08 & 1149.06 \\
H & 0.25 & 0.25 \\
kW h & $\mathbf{0 . 6 2}$ & $\mathbf{0 . 2 8}$
\end{tabular}

Resultados y discusión: Análisis energético y ambiental de la producción de bio-etanol a partir de la FORSU. T. P. Mendoza Tinoco 
Se observa que el consumo energético real $(0.28 \mathrm{~kW} \mathrm{~h})$ es menor comparado con lo indicado en la placa del fabricante $(0.62 \mathrm{~kW} \mathrm{~h})$, esto es debido a que las condiciones reportadas en la placa son a la máxima potencia que puede alcanzar el equipo. Sin embargo, la FORSU al ser un material blando, comparada a otros materiales usualmente triturados en este tipo de equipos, como por ejemplo madera y gravilla, no requiere la potencia reportada en la placa. Para disminuir en el consumo energético en la etapa de disminución de partícula, es necesario disminuir los tiempos muertos de funcionamiento del equipo, por lo que es necesario suministrar la materia prima constantemente y optimizar las condiciones de operación.

\section{Etapa 2. Explosión a vapor}

En la Tabla 6.3, se muestran las mediciones de voltaje (V) y amperaje (A), obtenidas del tablero de distribución de la caldera.

Tabla 6.3. Voltaje y amperaje de la bomba

\begin{tabular}{cccc}
\hline \multicolumn{2}{c}{ Voltaje en operación (L-L) } & \multicolumn{2}{c}{ Amperaje en operación } \\
\hline L1 & 222.20 & L1 & 5.60 \\
L2 & 223.90 & L2 & 4.50 \\
L3 & 224.40 & L3 & 5.50 \\
\hline
\end{tabular}

Se obtuvieron valores variables debido a que se utiliza corriente alterna, en ella la magnitud y dirección varían cíclicamente. Con esto consigue una transmisión más eficiente de la energía. Se seleccionaron las mayores lecturas obtenidas: 224.40 V y 5.60 A, las cuales se utilizaron para el cálculo del consumo energético de la caldera.

En la Tabla 6.4, se muestran los resultados obtenidos del consumo de energía en la etapa de explosión a vapor.

Resultados y discusión: Análisis energético y ambiental de la producción de bio-etanol a partir 
Tabla 6.4. Consumo energético de la caldera.

\begin{tabular}{ccc}
\hline & Placa & Real \\
\hline HP & 3.00 & 3.00 \\
V & 220.00 & 224.40 \\
A & 8.40 & 5.60 \\
FP & 0.87 & 0.87 \\
& & 1.73 \\
$\sqrt{3}$ & & \\
& & \\
\hline W & 2781.42 & 1891.36 \\
H & 0.25 & 0.25 \\
kW h & $\mathbf{0 . 6 9}$ & $\mathbf{0 . 4 7}$
\end{tabular}

Además del consumo de la caldera, se consideró para esta etapa el consumo de gas utilizado para calentar el agua, para el cual se utilizó la Ecuación 5.2. Esta ecuación considera el flujo de la sustancia a calentar $(0.18 \mathrm{~kg} / 0.25 \mathrm{~h})$, el poder calorífico de la sustancia a calentar $\left(1 \mathrm{kcal} / \mathrm{kg}^{\circ} \mathrm{C}\right)$ y la diferencia en la temperatura inicial y final $\left(139.98^{\circ} \mathrm{C}\right.$ $20{ }^{\circ} \mathrm{C}$ ), obteniendo un calor térmico (Q) de $0.025 \mathrm{~kW}$ h. Realizando la sumatoria de los dos valores de la caldera y el uso de gas $(0.47 \pm 0.03 \mathrm{~kW} h)$ se obtiene un consumo total de 0.49 $\mathrm{kW}$ h en la etapa de explosión a vapor.

\section{Etapa 3. Fermentación}

En la etapa de fermentación se consideraron tres equipos (biorreactor, calentador y bomba de recirculación). En la Tabla 6.5, se muestran el consumo energético del reactor utilizado en la etapa de fermentación. 
Tabla 6.5. Consumo energético del reactor

\begin{tabular}{ccc}
\hline & DATOS & \\
\hline Variable & Lectura & Lectura \\
& Placa & Real \\
Hp & 2.00 & 2.00 \\
V & 230.00 & 225.90 \\
A & 6.07 & 1.00 \\
FP & 0.85 & 0.85 \\
$\sqrt{3}$ & 1.73 & 1.73 \\
& & \\
\hline W & 2052.96 & 376.30 \\
H & 24.00 & 24.00 \\
kW h & $\mathbf{4 9 . 2 7}$ & $\mathbf{9 . 0 3}$ \\
\hline
\end{tabular}

En el uso del biorreactor se obtuvo una potencia de $9.03 \mathrm{~kW} \mathrm{~h}$ (Tabla 6.5), donde el consumo indicado en la placa es casi cuatro veces mayor a la real $(49.27 \mathrm{~kW} \mathrm{~h})$, esto es debido a que los valores reportados en las placas de los equipos son en condiciones estándar o máximas. Los datos de la placa reportan un amperaje de 6 A 1740 RPM (ver Figura 5.4B), pero el equipo opera realmente a 0.75 RPM, por lo que el consumo energético es menor. La ventaja de realizar mediciones con los equipos en operación es que se puede estimar el consumo energético en tiempo real.

El segundo equipo considerado en la producción de bio-etanol a partir de la FORSU es el calentador de agua de recirculación en la chaqueta del reactor. En la Tabla 6.6, se muestran los resultados del consumo energético del calentador de agua utilizado en la etapa de fermentación.

Resultados y discusión: Análisis energético y ambiental de la producción de bio-etanol a partir de la FORSU. T. P. Mendoza Tinoco 
Tabla 6.6. Consumo energético del calentador

\begin{tabular}{|c|c|c|c|}
\hline \multicolumn{2}{|r|}{ Placa } & \multicolumn{2}{|c|}{ Real } \\
\hline & & $\mathrm{T} 1(0-30 \mathrm{~min})$ & $\mathrm{T} 2(30-24 \mathrm{hr})$ \\
\hline V & 115.00 & 127.40 & 127.40 \\
\hline A & 5.00 & 7.50 & 0.30 \\
\hline $\mathrm{H}$ & 24.00 & 0.50 & 23.50 \\
\hline $\mathrm{W}$ & 575.00 & 955.50 & 650 \\
\hline kW h & 13.80 & 0.47 & 0.89 \\
\hline Total & 13.80 & \multicolumn{2}{|c|}{1.36} \\
\hline
\end{tabular}

Se realizaron mediciones a diferentes tiempos, la primera fue tomada al momento de encender el calentador donde se obtuvo una lectura de 8 A, la segunda medición se realizó a los 30 minutos, tiempo en el que el equipo sube la temperatura del agua de $20^{\circ} \mathrm{C}$ a $30^{\circ} \mathrm{C}$ y la tercera cuando cuando se alcanza una temperatura estable del agua a $30^{\circ} \mathrm{C}$. En la Tabla 6.6 , se muestra que el calentador tiene una potencia de $1.36 \mathrm{~kW} \mathrm{~h}$, valor menor a lo obtenido con los datos reportados en la placa del equipo.

En la Tabla 6.7, se muestran los resultados obtenidos para la bomba de agua utilizada en la etapa de fermentación.

Tabla 6.7. Consumo energético de la bomba

\begin{tabular}{ccc}
\hline & Placa & Real \\
\hline Hp & 0.50 & 0.50 \\
V & 127.00 & 127.40 \\
A & 1.06 & 1.30 \\
Fp & 0.85 & 0.85 \\
W & 114.42 & 140.77 \\
H & 24.00 & 24.00 \\
$\mathbf{k W ~ h}$ & $\mathbf{2 . 7 4}$ & $\mathbf{3 . 3 7}$ \\
\hline
\end{tabular}

Se obtuvo un valor de $3.37 \mathrm{~kW}$ h a partir del cálculo de consumo energético de la bomba (tercer equipo) que recircula el agua a través de la chaqueta del biorreactor. Sumando las potencias de los tres equipos considerados en el proceso se obtiene un consumo total de $15.77 \mathrm{~kW} \mathrm{~h}$, en este caso el biorreactor es el equipo que aporta a un mayor consumo de energía a esta etapa. En el proceso de producción de bio-etanol, la etapa de fermentación es la de mayor consumo de energía debido a los tiempos de operación de los equipos.

Resultados y discusión: Análisis energético y ambiental de la producción de bio-etanol a partir de la FORSU. T. P. Mendoza Tinoco 


\section{Etapa 4. Destilación}

La etapa de destilación, es considerada una de las que tiene un mayor consumo energético ya que el proceso de separación etanol-agua. En la literatura se ha reportado la separación etanol-agua por destilación triple (Destilación del fermentado a bio-etanol crudo ( $45 \% \mathrm{v} / \mathrm{v}$ ), rectificación a $96 \%$ v/v y deshidratación a $99.9 \%$ con tamices moleculares), para llegar a una concentración del 99\% de bio-etanol, se tendría un consumo energético promedio de $1.66 \mathrm{~kW} \mathrm{h/L} \mathrm{de} \mathrm{bio-etanol} \mathrm{(Abril} \mathrm{y} \mathrm{Navarro,} \mathrm{2012).} \mathrm{Sin} \mathrm{embargo,} \mathrm{debido} \mathrm{a} \mathrm{su} \mathrm{alto} \mathrm{consumo}$ energético se han considerado otras alternativas de destilación.

Para disminuir se considero una destilación simple con la ayuda de un compuesto químico (sales de sulfato) para desidratar la mezcla y obtener un grado de pureza del $99 \%$.

$$
\begin{gathered}
\text { QEtanol }=2130.3 \mathrm{~g} * \frac{0.58 \mathrm{cal}}{\mathrm{g}^{\circ} \mathrm{C}} *\left(78^{\circ} \mathrm{C}-20^{\circ} \mathrm{C}\right)=71663.29 \mathrm{cal} \text { Ec. } 6.2 \\
Q \text { Agua }=4970.7 \mathrm{~g} * \frac{1 \mathrm{cal}}{\mathrm{g}^{\circ} \mathrm{C}} *\left(78{ }^{\circ} \mathrm{C}-20^{\circ} \mathrm{C}\right)=288300.60 \mathrm{cal} \mathrm{Ec} 6.3 \\
Q T=359963.898 \mathrm{cal} * \frac{1 \mathrm{kcal}}{1000 \mathrm{cal}} * \frac{1 \mathrm{~kW} \mathrm{~h}}{860 \mathrm{kcal}}=0.41 \mathrm{kw} \text { Ec. } 6.4
\end{gathered}
$$

En la etapa de destilación, se obtuvo el consumo energético requerido para llevar el caldo fermentado (mezcla azeotrópica) de $20^{\circ} \mathrm{C}$ a $78^{\circ} \mathrm{C}$, punto de evaporación del bio-etanol. El cálculo del consumo energético se realizó con las Ec. 6.2, 6.3 y 6.4, obteniéndose un consumo total de $0.41 \mathrm{~kW}$ h para la producción de $2.77 \mathrm{~L}$ de bio-etanol, rendimiento obtenido a partir de la fermentación de $50 \mathrm{~kg}$ de FORSU (36.93 g de bio-etanol/kg de FORSU).

Resultados y discusión: Análisis energético y ambiental de la producción de bio-etanol a partir 
En la Tabla 6.8, se muestran los resultados del consumo energético total del proceso considerando la energía en placa y real.

Tabla 6.8. Energía invertida por etapa

\begin{tabular}{ccc} 
Etapa & $\begin{array}{c}\text { Consumo de energía placa }(\mathbf{k W h} / \mathbf{5 0} \\
\mathbf{k g} \text { de FORSU) }\end{array}$ & $\begin{array}{c}\text { Consumo de energía real }(\mathbf{k W h} / \mathbf{5 0} \mathbf{~ k g} \\
\text { FORSU) }\end{array}$ \\
\hline $\begin{array}{c}\text { Disminución de partícula } \\
\text { Explosión a vapor }\end{array}$ & 0.62 & 0.28 \\
Caldera & 0.69 & 0.47 \\
Consumo de gas & 0.02 & 0.02 \\
Fermentación & & \\
Reactor & 49.27 & 9.03 \\
Bomba & 2.74 & 3.37 \\
Calentador & 13.80 & 1.37 \\
Destilación & 0.44 & 0.44 \\
Total & $\mathbf{6 7 . 5 8}$ & $\mathbf{1 4 . 9 8}$ \\
MJ & $\mathbf{2 4 1 . 6 6}$ & $\mathbf{5 3 . 9 2}$ \\
\hline
\end{tabular}

Realizando la sumatoria de consumos energéticos de las etapas involucradas se obtiene un valor de $67.59 \mathrm{~kW}$ h a partir de la información obtenida de las placas de los fabricantes y $14.98 \mathrm{~kW}$ h para el real. Los valores obtenidos de las lecturas reales fueron utilizados para determinar la tasa de retorno energético. Como se ha mencionado, los datos reportados en las placas de los equipos muestran la potencia máxima de consumo y no los consumos reales. Sin embargo, nos permitió conocer la diferencia entre uno y otro, además de servir como punto de comparación para detectar errores en las mediciones realizadas. Los valores tanto de energía invertida como energía obtenida fueron convertidos a unidades MJ para para que en el análisis adimensional las unidades se cancelaran obteniendo una TRE sin unidades. El valor de consumo energético real, fue convertido a MJ con un factor de conversión ( $1 \mathrm{~kW} \mathrm{~h}$ es igual a 3.6 MJ), obteniendo 53.92 MJ. Para el cálculo de la energía retornada o útil, se utilizó el poder calorífico del bio-etanol (23.60 MJ/L de bio-etanol) y la producción de bioetanol a partir de los $50 \mathrm{~kg}$ de FORSU (2.77 L de bio-etanol), obteniéndose un valor de 65.37 MJ.

En la ecuación 6.5 se muestra la tasa de retorno obtenida. 


$$
\mathrm{TRE}=\frac{65.37 \mathrm{MJ}}{53.92 \mathrm{MJ}}=\mathbf{1 . 2 1} \text { Ec. } 6.5
$$

La TRE obtenida fue de 1.21 por unidad de energía invertida para un proceso por lote de $50 \mathrm{~kg}$ de FORSU. Las TRE reportadas para la producción de bio-combustibles se encuentran en un rango de energía de 0.60-4.00 (Hammerschlag, 2006). Esto ubica nuestra técnica en el promedio de los bio-combustibles actuales. Sin embargo, este análisis no es del todo comparable ya que los datos obtenidos en este trabajo fueron a nivel piloto, y los reportados son a nivel industrial. Para hacer este análisis más comparativo, se tendrían que realizar otras consideraciones, las cuales aumentaría la TRE obtenida a partir del uso de la FORSU como sustrato. La capacidad de los equipos considerados en la simulación a escala piloto, diminuyen el consumo energético por litro de etanol. Si las etapas de crecimiento de microorganismos y esterilización se hubieran considerado en la simulación de proceso, se hubiese obtenido una TRE calculada menor, ya que estas etapas tienen un consumo energético considerable de $1.14 \mathrm{~kW}$ h y $3.78 \mathrm{~kW}$ h (ver Anexo A), respectivamente. Estas etapas podrían considerarse en simulaciones posteriores a escala industrial.

Dentro de las alternativas para aumentar la TRE se menciona en aumentar la carga de la FORSU y el tamaño del bioreactor con la finalidad de recuperar una concentración mayor de bio-etanol, así como, realizar la agitación en el biorreactor de manera intermitente.

El valor obtenido en esta investigación es menor al deseable $(\geq 5)$, para que el proceso sea energéticamente viable. Sin embargo, al tratarse de un proceso donde se aprovechan residuos (FORSU) que no compiten con la industria alimentaria y no utiliza químicos con altos impactos ambientales, tiene ventajas ante las producciones convencionales de bio-etanol. Dentro de las ventajas se pueden mencionar, la disminución de impactos ambientales, disminución de uso de agua, no requiere una etapa agrícola, etc. Los procesos pueden ser optimizados desde un punto de vista técnico y operario, como por ejemplo: implementando fuentes de energía renovables en el proceso, ya sea trituradores manuales, calentadores solares y destiladores solares. También, la producción de bio-etanol en México es un proceso que está en vías de desarrollo, por lo que todavía se pueden optimizar los rendimientos de producción y tiempos de operación de los equipos, principalmente, en la etapa de fermentación.

Resultados y discusión: Análisis energético y ambiental de la producción de bio-etanol a partir de la FORSU. T. P. Mendoza Tinoco 


\subsection{ACV para la producción de bio-etanol a partir de FORSU a nivel piloto}

Los resultados que se pueden obtener a partir del programa WAR son muy variables, en primer lugar se pueden realizar diferentes análisis cambiando el valor que se da inicialmente a cada categoría, esto refleja la importancia que se está dando a las categorías y puede ser de gran ayuda en la creación de diferentes escenarios, los valores van de 1 a 10. Al modificar los valores de cada categoría se observó que no existe una diferencia significativa en los resultados, por lo cual, la valoración se mantuvo en 10 para cada categoría. Otro de los aspectos que se pueden modificar para realizar diferentes análisis es considerar el flujo del producto y la fuente de energía del proceso, además, de dar datos totales de impacto o individuales por cada categoría.

También, con el programa se pueden obtener resultados para dos índices: el índice de salida y el de generación, los cuales, reportan los posibles impactos por hora y por unidad de producto. En el análisis de este caso de estudio, solo se contemplaron los resultados por unidad de producto, ya que al realizar el análisis para ambos casos se obtiene un resultado similar en los impactos del proceso. El uso de los resultados por unidad de producto nos da un panorama de cuáles son los posibles impactos que pueden ser provocados por la producción de un litro de bio-etanol.

En la Figura 6.1, se muestran los resultados de los impactos provocados por unidad de producto, después de la producción de bio-etanol a nivel piloto, para las categorías de impacto: Potencial de Toxicidad Humana por Ingestión (HTPI), Potencial de Toxicidad Humana por Exposición (HTPE), Potencial de Toxicidad Terrestre (TTP), Potencial de Toxicidad Acuática (ATP), Potencial de Calentamiento Global (GWP), Potencial de Deterioro de la capa de Ozono (ODP), Potencial de Formación de Smog (PCOP) y Potencial de Acidificación (AP), solo considerando el flujo de producto.

Resultados y discusión: Análisis energético y ambiental de la producción de bio-etanol a partir 


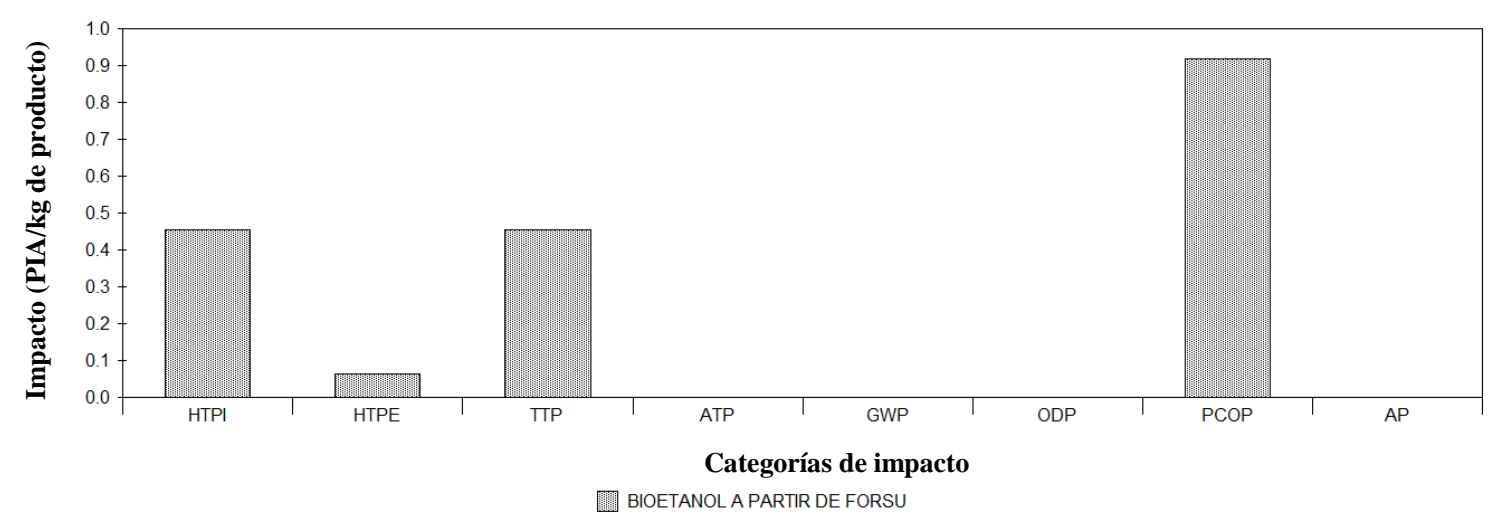

Figura 6.1. PIA después del proceso por unidad de producto

Para este índice se obtuvieron los siguientes resultados: $1.71 \times 10^{-4}$ (ATP), $0.56 \times 10^{-4}$

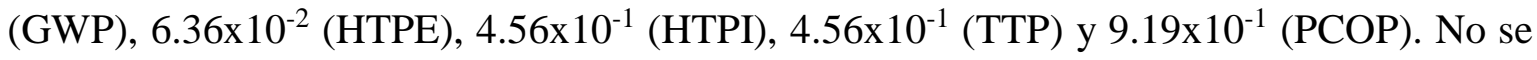
observó un impacto en las categorías de ODP y AP. La categoría de formación de smog es la que representa un mayor impacto, debido a la liberación del bio-etanol por su combustión al medio ambiente. El bio-etanol reacciona con otros contaminantes como el dióxido de carbono o con los componentes naturales de la atmósfera y junto a la radiación solar forma el ozono (Baird, 2001). Se ha identificado una gran número sustancias que participan en complejos procesos de naturaleza fotoquímica, algunos de ellos son: aldehídos, cetonas, ácidos, peróxido de hidrógeno, nitrato de peroxiacetilo, radicales libres y otras de diverso origen como sulfatos $\left(\mathrm{SO}_{\mathrm{x}}\right)$ y nitratos $\left(\mathrm{NO}_{\mathrm{x}}\right)$ (Rojas y col., 2002). Estos compuestos podrían reaccionar con el bio-etanol liberado al medio ambiente y formar smog. Otra de las categorías en las cuales se observó un impacto es la toxicidad humana por ingestión, esto es debido a que dosis grandes de bio-etanol provocan envenenamiento alcohólico, mientras que su ingestión constante, es responsable del alcoholismo. La ingestión constante de grandes cantidades de bio-etanol provoca daños en el cerebro, hígado y riñones, que conducen a la muerte (Aburto y col., 2008).

En la Figura 6.2, se presentan los resultados de los posibles impactos ambientales durante la generación de bio-etanol para las 8 categoría (HTPI, HTPE, TTP, ATP, GWP, ODP, PCOP y AP), considerando solamente el flujo de producto. 


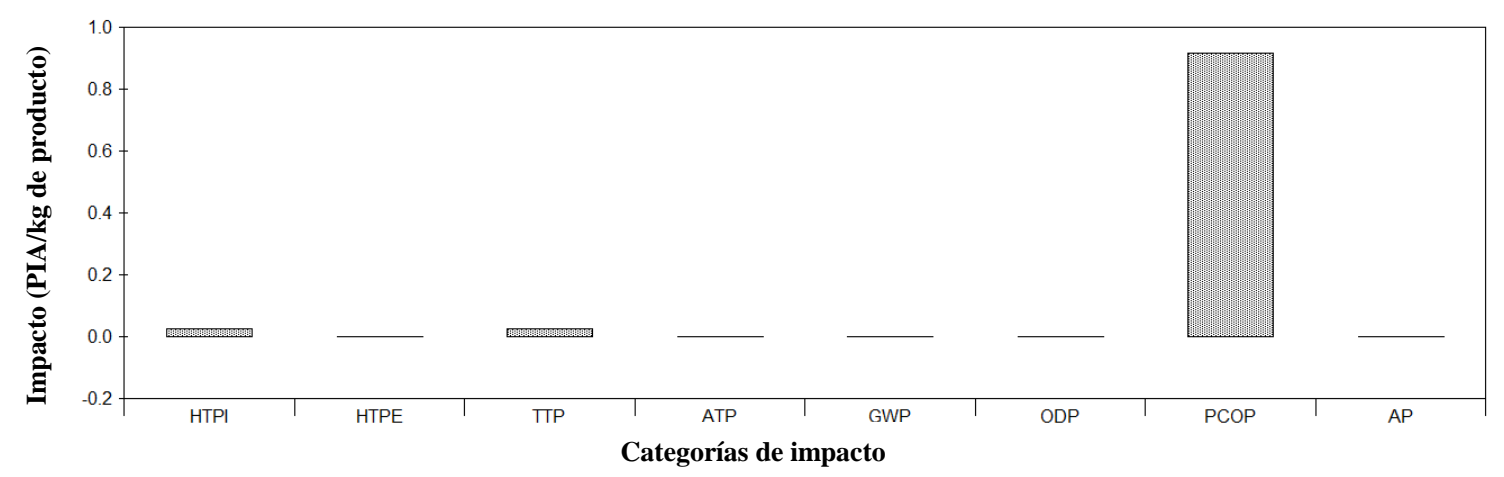

DIOETANOL A PARTIR DE FORSU

Figura 6.2. PIA durante el proceso por unidad de producto

En la generación de impactos por unidad de producto se reflejan los impactos ambientales que pueden ocurrir durante el proceso de producción, de los cuales se obtuvieron los valores de: $-6.24 \times 10^{-5}$ (ATP), $2.95 \times 10^{-4}$ (HTPE), $4.56 \times 10^{-4}$ (GWP), $2.65 \times 10^{-2}$ (HTPI), $2.65 \times 10^{-2}$ (TTP) y $9.19 \times 10^{-1}$ (PCOP). En este índice se puede observar que al igual que en el índice de salida, el mayor impacto es la formación de smog (PCOP). El ATP, presenta valor negativo lo que significa que alguno de los compuestos es trasformado en uno menos dañino para el ambiente, reduciendo la toxicidad acuática. El dióxido de carbono $\left(\mathrm{CO}_{2}\right)$, subproducto de la producción de bio-etanol en la etapa de fermentación, contribuye directamente a la categoría de calentamiento global, siendo uno de los principales gases de efecto invernadero generado. $\mathrm{El} \mathrm{CO}_{2}$, en grandes cantidades, llega a la atmósfera impidiendo la salida de los rayos UV que entran a la tierra, provocando un aumento en el calentamiento global.

En las Figuras 6.3 y 6.4, se presentan los resultados de los posibles impactos ambientales por salida y generación por unidad de producto, respectivamente, donde se incluye el uso de energía para las 8 categorías de impacto.

Resultados y discusión: Análisis energético y ambiental de la producción de bio-etanol a partir 


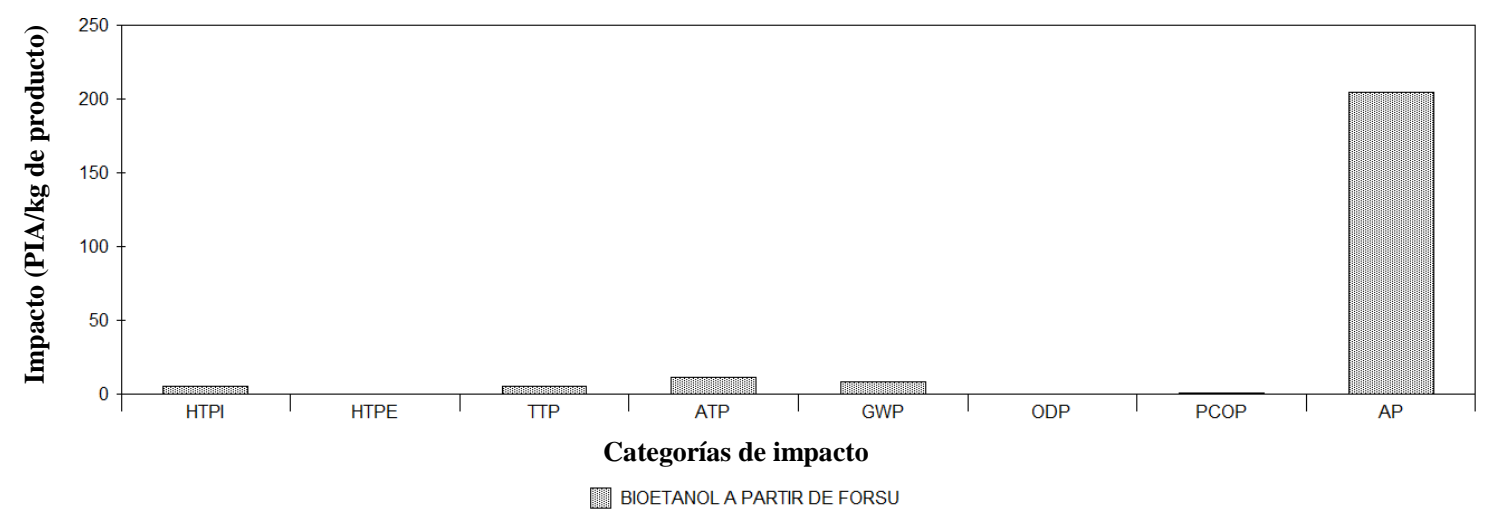

Figura 6.3. PIA después del porceso por unidad de producto incluyendo el uso de energía

En el índice de salida se observa un claro aumento en los impactos analizados, debido a la consideración de la energía. Para cada impacto se obtuvieron los siguientes resultados:

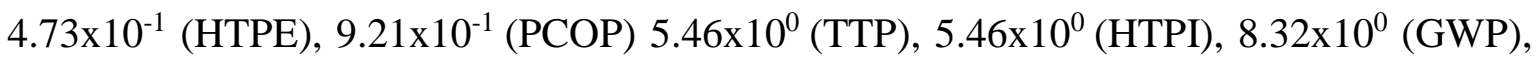
$1.9 \times 10^{1}$ (ATP), y $2.05 \times 10^{2}$ (AP). Todas las categorías aumentaron excepto la de formación de smog, en comparación a los impactos reportados en los que solo se consideró el flujo del producto. La categoría con mayor impacto fue la de acidificación, esto es debido a que se consideró el uso de diésel, como el combustible que se utiliza en la central eléctrica de la CDMX y contribuye a estas categorías por sus altas concentraciones de azufre. La categoría de potencial de acidificación, está relacionada con la emisión de compuestos sulfurados que forman la lluvia ácida. Por otro lado, el $\mathrm{CO}_{2}$ producido a partir del uso de diésel, contribuye a la categoría de calentamiento global, debido a que es un gas de efecto invernadero y en las categorías de toxicidad acuática, terrestre y humana. Los estudios epidemiológicos demuestran que la exposición a diferentes contaminantes ambientales, incluso a niveles por debajo de las normas internacionales, se asocian con un incremento en la incidencia de asma, severidad en el deterioro de la función pulmonar y a un aumento en la gravedad en las enfermedades respiratorias en niños y adolescentes (Romero, 2006).

Resultados y discusión: Análisis energético y ambiental de la producción de bio-etanol a partir de la FORSU. T. P. Mendoza Tinoco 


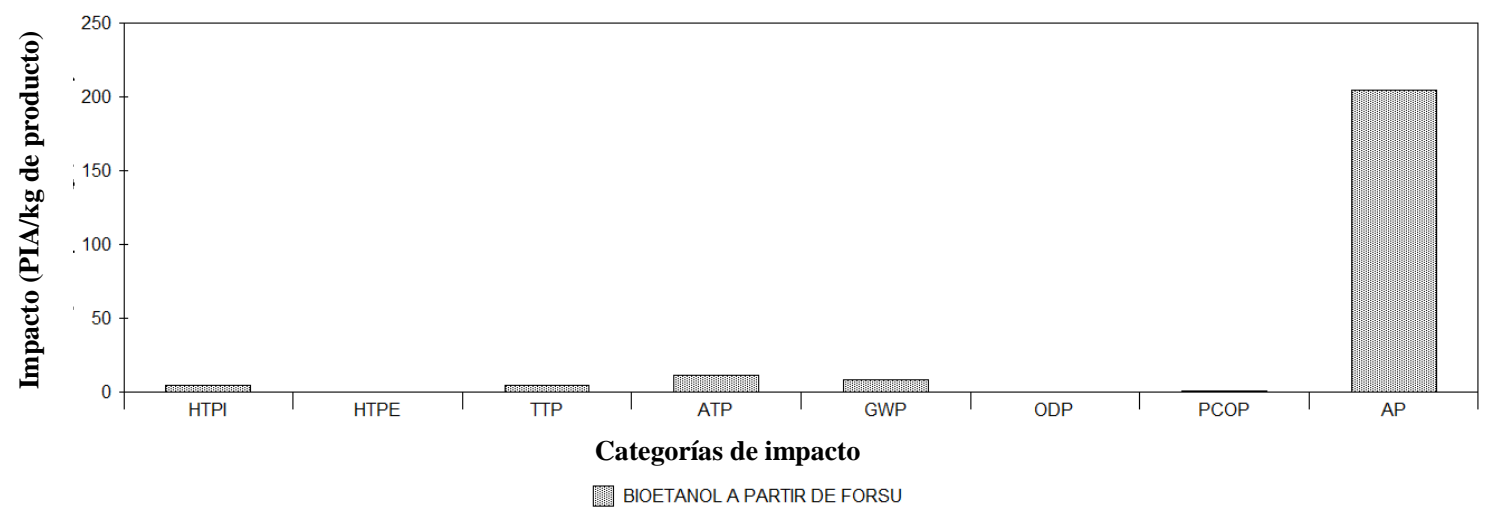

Figura 6.4. PIA durante el proceso por unidad de producto incluyendo el uso de energía

En el índice de generación por unidad de producto donde se considera la energía se

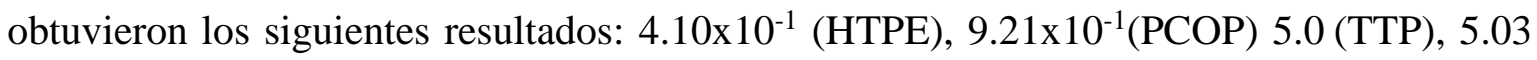

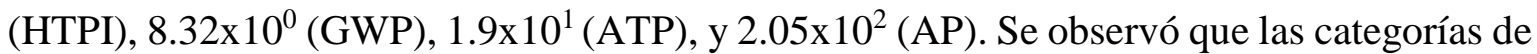
toxicidad acuática, calentamiento global, formación de smog y acidificación se mantuvieron con los mismos valores, comparados con el índice anterior. Por el contrario, se observa una disminución de impactos en las categorías de toxicidad humana, y terrestre, debido a que este índice refleja la exposición o liberación de bio-etanol en los impactos provocados durante el proceso. En la Figura 6.5, se muestra una comparación de los impactos provocados por el proceso y por la fuente de energía en las 8 categorías de impacto. Solo se consideró el índice de salida ya que los resultados son más significativos.

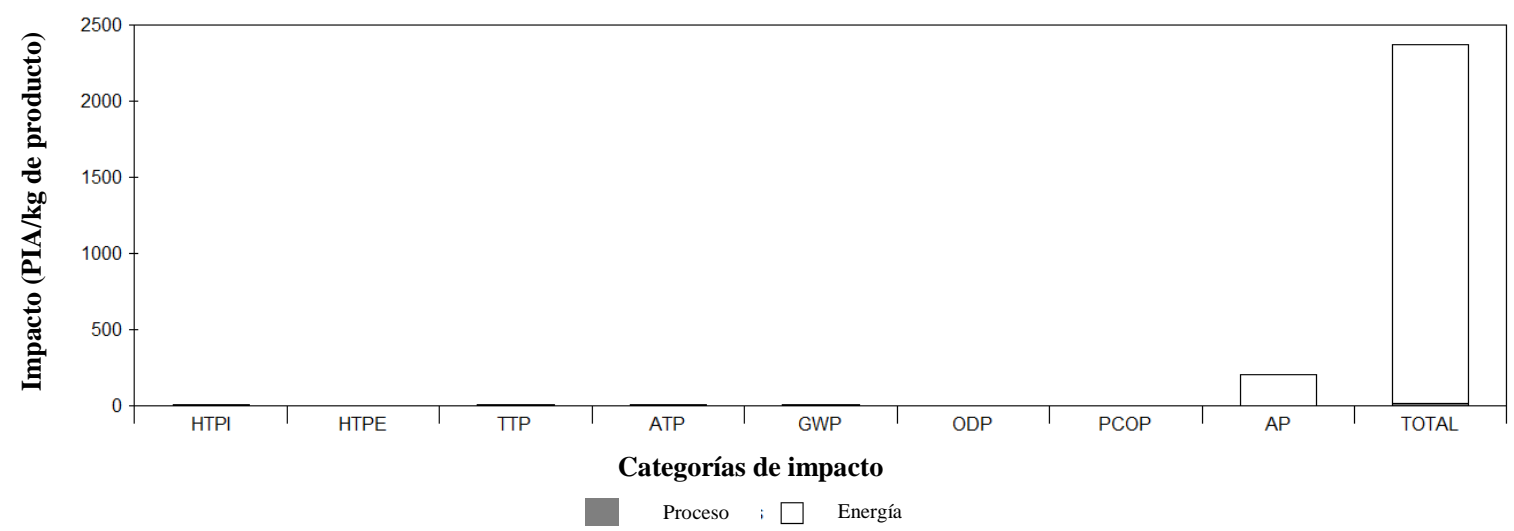

Figura 6.5. Comparación de impactos ambientales del proceso vs el uso de energía

Al comparar los impactos provocados por el proceso y el uso de energía se pudo observar que el uso de energía contribuye al aumento en los impactos en las diferentes categorías analizadas. Estos resultados concuerdan con el análisis energético realizado en esta 
investigación a escala piloto. El proceso no es energéticamente sustentable y provoca mayores impactos, aunque los impactos no pueden ser definidos como altos o bajos ya que por más mínimo que sea un impacto, influye en el deterioro en el medio ambiente, pero si se puede definir como mitigables o no mitigables.

Los impactos provocados por la producción de bio-etanol descrita en esta investigación pueden ser mitigables. La toxicidad humana y formación de smog que son causados por el bio-etanol no serían provocadas, ya que al ser el producto principal, se aprovechará al máximo evitando que este sea un residuo. Los impactos como toxicidades terrestres y acuáticas provocadas por los residuos que salen del sistema pueden evitarse si la FORSU resultante del proceso es composteada, en específico, por el proceso de lombricosposta esta técnica disminuye los lixiviados y produce un fertilizante, por lo que el material estará enriquecido química y biológicamente. Los abonos orgánicos pueden satisfacer la demanda de nutrientes de los cultivos, reduciendo significativamente el uso de fertilizantes químicos y mejorando las características de los vegetales consumidos, además, los abonos orgánicos mejoran las características de suelos que han sido deteriorados por el uso excesivo de agroquímicos y su sobre-explotación, lo que contribuiría a reducir estos impactos ambientales (Olivares y col, 2012).

Finalmente, el impacto ambiental pueden ser mitigado realizando cambios en el proceso de producción como el tratamiento de residuos y captura de $\mathrm{CO}_{2}$ a través del cultivo de micro algas en condiciones auxótrofas. Con esto se evitaría que sean liberados al medio ambiente sin ningún tratamiento previo para disminuirlos o neutralizarlos.

Por otro lado, los impactos provocados por el uso de energía, pueden ser reducidos al disminuir los tiempos de operación de los equipos y con la implementación de fuentes de energía renovables. El proceso analizado a nivel piloto resulta amigable con el medio ambiente debido a que las descargas de residuos son mínimas y los compuestos liberados no contribuyen a las categorías de mayor importancia en el análisis de ciclo de vida que son potencial de calentamiento global y deterioro de la capa de ozono. La única categoría de impacto en la atmósfera, es el potencial de acidificación.

Resultados y discusión: Análisis energético y ambiental de la producción de bio-etanol a partir de la FORSU. T. P. Mendoza Tinoco 


\subsection{ACV para la producción de bio-etanol a partir de la FORSU a nivel industrial}

En el caso de estudio de la plata de compostaje de Bordo Poniente (PCBP), se realizó un análisis de los impactos generados en la producción de bioetanol a escala industrial. A cada categoría se le asignó un valor de 10. Con la metodología planteada para el cálculo del consumo energético a nivel piloto $\left(1.08 \times 10^{3} \mathrm{MJ}\right.$ h), se calculó el consumo a nivel industrial dando un valor de $1.01 \times 10^{8} \mathrm{MJ}$ h. Este aumento en el consumo energético es debido al aumento de la escala y a la baja eficiencia en la producción de bio-etanol.

En la Figura 6.6, se muestran los resultados de los impactos provocados por unidad de producto, después de la producción de bio-etanol a nivel industrial, para las categorías de impacto: HTPI, HTPE, TTP, ATP, GWP, ODP, PCOP y AP, en las cuales solo se consideró el flujo de producto.

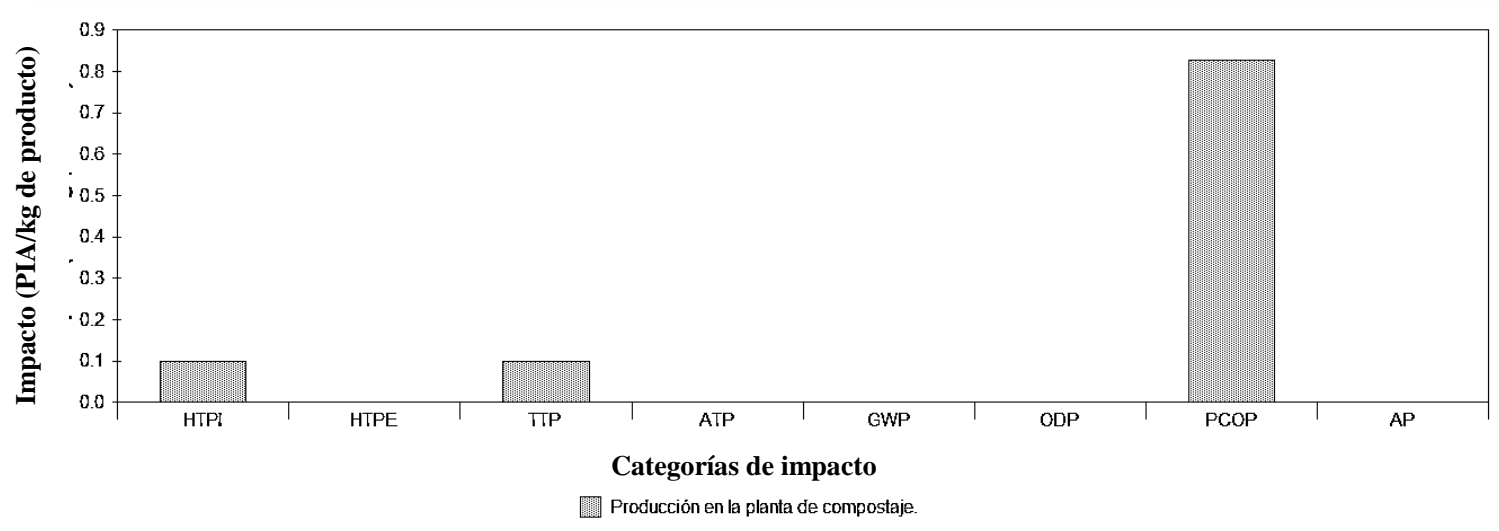

Figura 6.6. Índice después del proceso por unidad de producto para la PCBP.

Los resultados obtenidos a nivel industrial para el índice de salida son: $1.01 \times 10^{-4}$ (ATP),

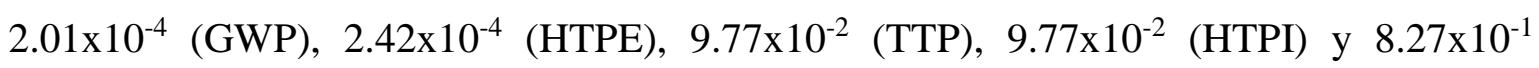
(PCOP). Los impactos a nivel industrial disminuyeron para las categorías de ATP, HTPE, TTP, HTPI y PCOP. La única categoría que aumentó su valor fue el calentamiento global, debido a la formación en mayor cantidad de $\mathrm{CO}_{2}$ como subproducto del bio-etanol. Esto refleja que los impactos ambientales provocados después del proceso se disminuyen. Cuando se tiene una mayor producción de bio-etanol se observa una disminución de los impactos a nivel industrial.

Resultados y discusión: Análisis energético y ambiental de la producción de bio-etanol a partir 
En la Figura 6.7, se presentan los resultados de los posibles impactos ambientales durante la generación de bio-etanol para las 8 categoría (HTPI, HTPE, TTP, ATP, GWP, ODP, PCOP y AP) considerando solamente el flujo de producto.

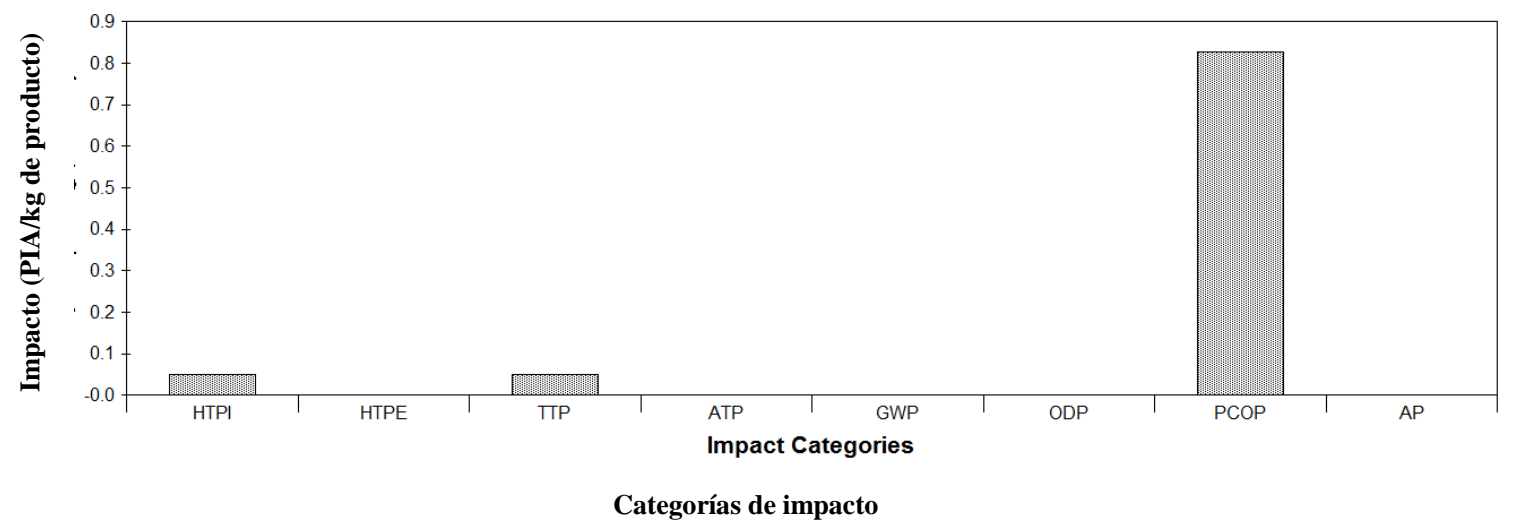

Figura 6.7. Índice durante el proceso por unidad de producto para la PCBP

Para el índice de generación por unidad de producto se obtuvieron los siguientes valores:

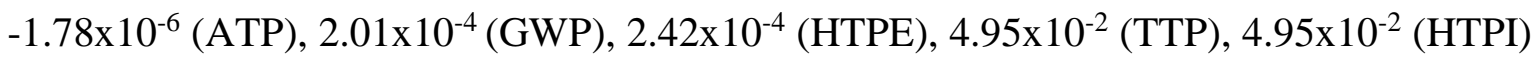
y $8.27 \times 10^{-1}$ (PCOP). Las categorías que aumentaron a nivel industrial comparado con las de nivel piloto fueron TTP y HTPI, debido a la cantidad de producto que se obtuvo.

En la Figura 6.8, se muestra una comparación de los impactos provocados por el proceso y por la fuente de energía en las 8 categorías de impacto, donde sólo se consideró el índice de salida ya que presenta los resultados más significativos.

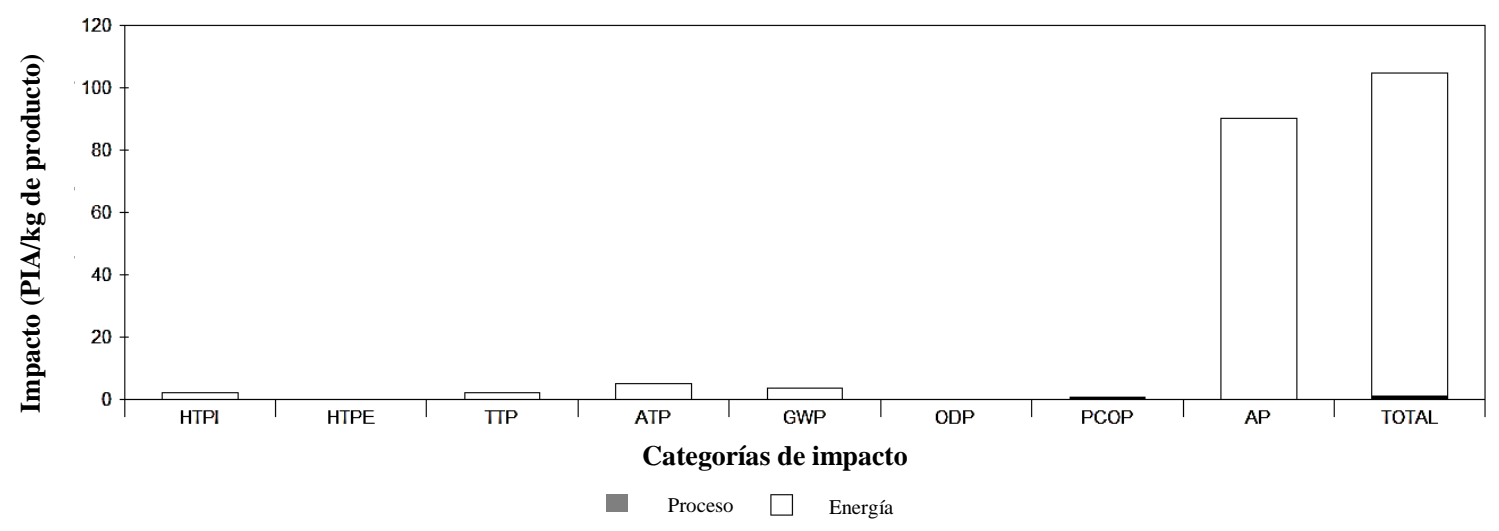

Figura 6.8. Comparación de impactos ambientales del proceso vs el uso de energía a nivel industrial 
Se puede observar que los impactos aumentan cuando se considera el uso de energía. Los impactos provocados por el proceso son insignificantes comparados con los producidos por el uso de energía, sin embargo, es menor el impacto generado a escala industrial que a nivel piloto.

En la Figura 6.9, se comparan los impactos en el índice de salida por unidad de tiempo, de los procesos que utilizan como otras materia primas además de la FORSU, maíz y caña de azúcar en base a la investigación realizada por Montoya y col. (2006).

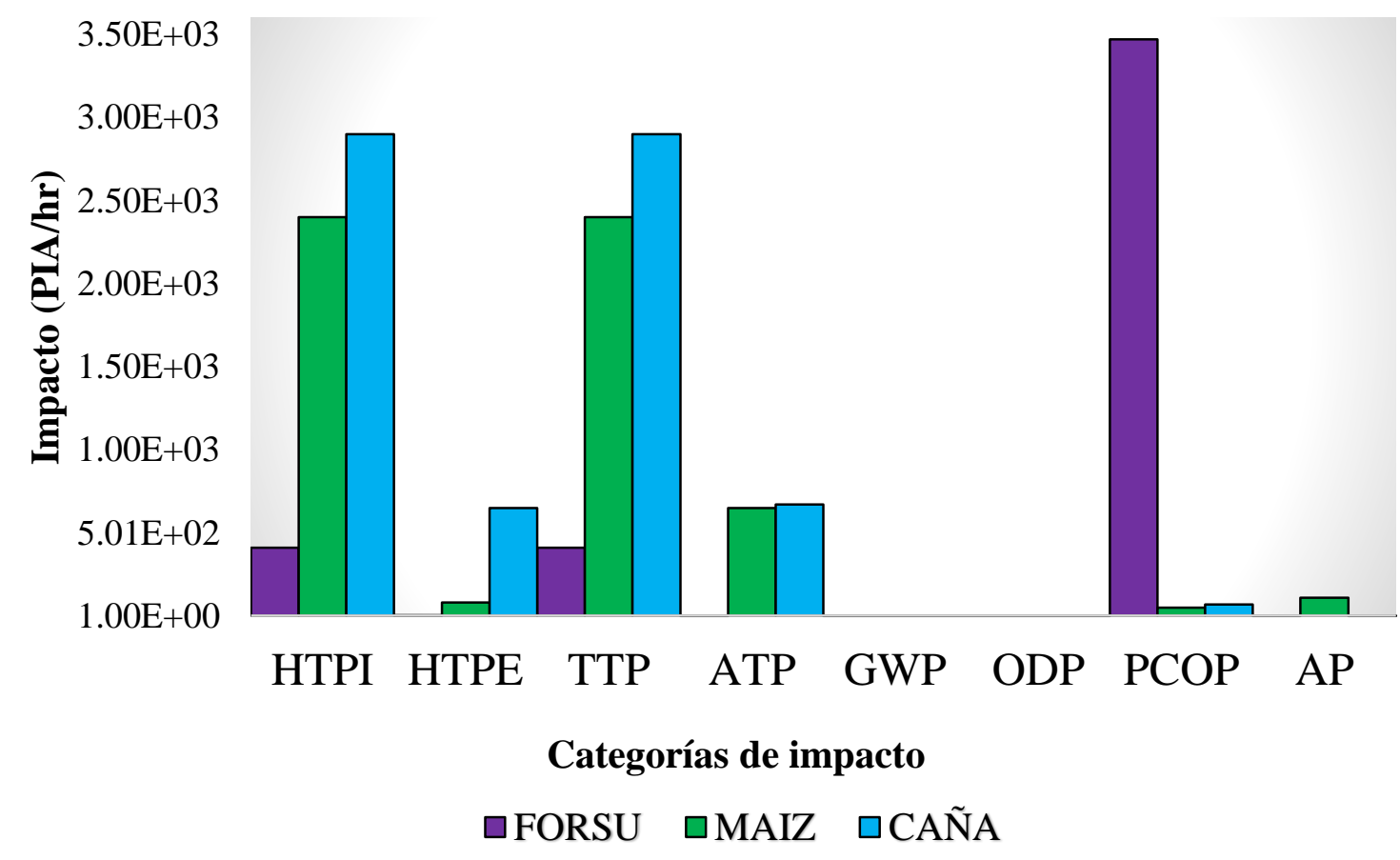

Figura 6.9. Índice después del proceso por unidad de tiempo FORSU vs maíz y caña de azúcar

Montoya y col. (2006), evaluaron la producción de bio-etanol a partir de caña de azúcar y maíz. En la Figura 6.9, se puede observar que se obtienen menores impactos de salida al utilizar la FORSU como sustrato, esto puede ser debido a que no se utiliza una hidrólisis ácida en el proceso planteado y no se generan inhibidores como el hidroximetilfurfural (HMF).Los contaminantes del proceso (HMF), podrían contribuir a la formación de otros contaminantes y tener mayor impacto de salida. Pero en la categoría de formación de smog (PCOP), relacionado con la generación de producto, es mucho mayor para el uso de FORSU. En la producción de bio-etanol se observó que con la FORSU se obtuvo una producción de $4.67 \times 10^{7} \mathrm{~L} / a n ̃ o$, mientras que para los casos de maíz y caña azúcar se tiene una producción

Resultados y discusión: Análisis energético y ambiental de la producción de bio-etanol a partir de la FORSU. T. P. Mendoza Tinoco 
de $1.96 \times 10^{5}$ L/año, esto es debido a que la capacidad de plata para el aprovechamiento de la FORSU es mayor a las utilizadas para el aprovechamiento del maíz y de la caña de azúcar. En la tabla 6.9, se resumen los valores exactos en el índice de salida por unidad de tiempo para la FORSU, maíz y caña de azúcar.

Tabla 6.9 Índice de salida por unidad de tiempo para la FORSU, maíz y caña de azúcar.

\begin{tabular}{cccc}
\hline Categoría & FORSU & Maíz* & Caña de azúcar* \\
\hline HTPI & $4.10 \times 10^{2}$ & $2.40 \times 10^{3}$ & $2.90 \times 10^{3}$ \\
HTPE & $1.02 \times 10^{0}$ & $8.00 \times 10^{1}$ & $6.50 \times 10^{2}$ \\
TTP & $4.10 \times 10^{-2}$ & $2.40 \times 10^{3}$ & $2.90 \times 10^{3}$ \\
ATP & $4.22 \times 10^{-1}$ & $6.50 \times 10^{2}$ & --- \\
GWP & $8.44 \times 10^{-1}$ & --- & --- \\
ODP & --- & --- & --- \\
PCOP & $3.47 \times 10^{3}$ & $5.00 \times 10$ & $7.00 \times 10^{1}$ \\
AP & --- & $1.10 \times 10^{2}$ & $6.70 \times 10^{2}$ \\
\hline
\end{tabular}

*Fuente: Montoya y col., 2016

Si se llegara a producir bio-etanol a partir de la FORSU que se genera al año en México, la cual es aproximadamente de $2.53 \times 10^{7}$ ton/año, se podría llegar a producir $1.4 \times 10^{6} \mathrm{~m}^{3} \mathrm{de}$ bio-etanol al año lo que representa el $5.50 \%$ de la gasolina Magna producida anualmente $\left(2.55 \times 10^{7} \mathrm{~m}^{3}\right)$ en el país. Por que la única alternativa de uso sería iniciar con la dilución de las gasolinas. El costo por la obtención de la FORSU comparado con el de otras materias primas es de $\$ 5.4 / \mathrm{L}$, mientras que la de maíz y caña de azúcar es de $\$ 133 / \mathrm{L}$ y $\$ 8.8 / \mathrm{L}$, respectivamente (Aburto, Martínez, y Murrieta, 2008b). Esto resultaría una ventaja al momento de seleccionar el sustrato para la generación de bio-etanol en México.

Resultados y discusión: Análisis energético y ambiental de la producción de bio-etanol a partir 


\section{Conclusiones}

Por medio del inventario elaborado se logró definir los límites del sistema, las etapas más relevantes a analizar y fue una herramienta para comprender más a fondo el proceso metodológico de la producción de bio-etanol.

Con la tasa de retorno energético obtenida (1.21:1) se determinó que el proceso de producción de bio-etanol a partir de la FORSU no es considerado viable ya que tiene una tasa de retorno energético menor a 5, a las condiciones operacionales planteadas en el proceso.

Se requiere una optimización en los tiempos de operación, así como, en el rendimiento de producción para hacer el proceso energéticamente viable. Aunque la FORSU presenta un rendimiento mayor (55 L/Ton $\mathrm{MH}$ ) a lo reportado para otros procesos, aun no puede competir con la energía recuperada de los hidrocarburos.

Con el análisis ambiental realizado en los dos casos de estudio (nivel piloto e industrial), se pudo determinar que a nivel piloto los impactos ambientales son mayores, en las categorías de toxicidad humana y calentamiento global.

La fermentación es una de las etapas con mayor consumo energético y por lo tanto con un mayor impacto ambiental.

A nivel industrial, aunque la energía invertida aún es elevada, se tiene una mayor obtención de bio-etanol que ayuda a disminuir los impactos ambientales.

El uso del programa WAR y Aspen plus, solo es aplicable cuando los límites del sistema están ubicados al inicio y final del proceso de producción, es decir, que no se consideran la obtención de la materia prima, distribución y uso, como es el caso de este estudio.

La metodología de simulación empleada en esta investigación sirve como soporte para el diseño del proceso de producción de bio-etanol.

Con el uso de los softwares, se pudo determinar las modificaciones necesarias para mejorar el impacto ambiental y el consumo energético del proceso de producción de bioetanol.

En México, con el uso de la FORSU se podrán valorizar los residuos y darles un tratamiento adecuado.

Conclusiones: Análisis energético y ambiental de la producción de bio-etanol a partir de la 
A partir de la FORSU que se genera al año en México, se podría llegar a producir $1.4 \times 10^{6}$ $\mathrm{m}^{3}$ de bio-etanol al año, por lo que podría ser utilizada diluida en los combustibles convencionales.

El bioproceso objeto de esta tesis puede ser mejorado, empleando fuentes de energía renovables, así como optimizar los rendimientos de producción y condiciones de operación de los equipos, principalmente, en la etapa de fermentación.

Es necesario informar a la población en general, sobre las técnicas en desarrollo para el aprovechamiento de los residuos y lograr una mayor separación de estos. 


\section{Referencias}

1. Abril, A., y Navarro, E. A. (2012b). Etanol a partir de biomasa lignocelulósica. Aleta.

2. Aburto, J., Martínez, T., y Murrieta, F. (2008b). Evaluación técnico-económica de la producción de bioetanol a partir de residuos lignocelulósicos. Tecnología, Ciencia, Educación, 23(1).

3. Baird, C. (2001). Química ambiental. Reverté.

4. Ballenilla, M., y Ballenilla, F. (2007). La tasa de retorno energético. Revista Ecologista, (55).

5. Bravo, E. (2006). Biocombustibles, cultivos energéticos y soberanía alimentaria: encendiendo el debate sobre biocombustibles. Acción Ecológica, Quito, Ecuador.

6. Callejas, E. S., y Quezada, V. G. (2009). Los biocombustibles. El Cotidiano, 157(157), 75-82.

7. Callejas Salinas, E., y Gasca Quezada, V. (2009). Los biocombustibles.

8. Camargo, F. G., y Schweickardt, G. A. (2016). Estimación de la tasa de retorno energético: Análisis comparativo de las metodologías disponibles en la actualidad. Maskana, 65-73.

9. Cardona, C. A., Sánchez, Ó. J., Montoya, M. I., y Quintero, J. A. (2005a). Simulación de los procesos de obtención de etanol a partir de caña de azúcar y maíz. Scientia et technica, 2(28).

10. Castello, L. (2008). Biocombustibles y seguridad alimentaria. FAO, ed., FAO.

11. Castillo-Hernández, P., Mendoza-Domínguez, A., y Caballero-Mata, P. (2012). Análisis de las propiedades fisicoquímicas de gasolina y diesel mexicanos reformulados con Etanol. Ingeniería, investigación y tecnología, 13(3), 293-306.

12. Dutta, K., Daverey, A., y Lin, J.-G. (2014). Evolution retrospective for alternative fuels: First to fourth generation. Renewable energy, 69, 114-122.

13. El estado mundial de la agricultura y la alimentación 2008.

14. Fernández-Linares, L. C., Montiel-Montoya, J., Millán-Oropeza, A., y BadilloCorona, J. A. (2012). Producción de biocombustibles a partir de microalgas. Ra Ximhai, 8(3b), 101-115.

15. García, J. M., y García, J. (2006). Biocarburantes líquidos: biodiesel y bioetanol. Informe de Vigilancia Tecnológica.

Referencias: Análisis energético y ambiental de la producción de bio-etanol a partir de la FORSU. T. P. Mendoza Tinoco 
16. Gracida Rodríguez, J. N., y Pérez-Díaz, B. (2014). Factores previos involucrados en la producción de bioetanol, aspectos a considerar. Revista internacional de contaminación ambiental, 30(2), 213-227.

17. Hammerschlag, R. (2006b). Ethanol's energy return on investment: A survey of the literature 1990-Present. Environmental Science y Technology, 40(6), 17441750.

18. Kiran, E. U., Trzcinski, A. P., Ng, W. J., y Liu, Y. (2014a). Bioconversion of food waste to energy: a review. Fuel, 134, 389-399.

19. Lobo Garcia de Cortazar, A., Hernández-Berriel, M. del C., y Mañón-Salas, M. del C. (2016). Biorrellenos: perspectivas tras dos décadas de experiencias en el mundo.

20. Montoya, M. I., Quintero, J. A., Sánchez, O. J., y Cardona, C. A. (2006). Evaluación del impacto ambiental del proceso de obtención de alcohol carburante utilizando el algoritmo de reducción de residuos. Revista Facultad de Ingeniería Universidad de Antioquia, 36, 85-95.

21. Morillas, A. V. (2014). Caracterización de la composta producida en la planta de bordo poniente.

22. Murphy, D. J., y Hall, C. A. (2010). Year in review-EROI or energy return on (energy) invested. Annals of the New York Academy of Sciences, 1185(1), 102118.

23. Naik, S. N., Goud, V. V., Rout, P. K., y Dalai, A. K. (2010). Production of first and second generation biofuels: a comprehensive review. Renewable and Sustainable Energy Reviews, 14(2), 578-597.

24. Naranjo, C., y SAS, G. S. A. (2013). Análisis de ciclo de vida. Universidad Pontificia Bolivariana. Recuento histórico. Comunicación personal.

25. Olivares-Campos, M. A., Hernández-Rodríguez, A., Vences-Contreras, C., Jáquez-Balderrama, J. L., y Ojeda-Barrios, D. (2012). Lombricomposta y composta de estiércol de ganado vacuno lechero como fertilizantes y mejoradores de suelo. Universidad y ciencia, 28(1), 27-37.

26. Papong, S., Rewlay-ngoen, C., Itsubo, N., y Malakul, P. (2017). Environmental life cycle assessment and social impacts of bioethanol production in Thailand. Journal of Cleaner Production, 157, 254-266.

Referencias: Análisis energético y ambiental de la producción de bio-etanol a partir de la FORSU. T. P. Mendoza Tinoco 
27. Pol, J. L. V., y Gómez, C. P. (2007). Los biocombustibles y su impacto en la crisis alimentaria. La crisis mundial de alimentos, alternativas para la toma de decisiones, Madrid, Fundación Alternativas/Observatorio de Política Exterior Española (OPEX)/Ministerio de Asuntos Exteriores y de Cooperación/Exlibris Ediciones, 29-51.

28. Ramos-Gutiérrez, L. de J., y Montenegro-Fragoso, M. (2012). La generación de energía eléctrica en México. Tecnología y ciencias del agua, 3(4), 197-211.

29. Robles Martínez, F. (2005). Generación de biogás y lixiviados en los rellenos sanitarios.

30. Rodríguez, B. R. (2003). El análisis del ciclo de vida y la gestión ambiental. Boletin iiE, 91-97.

31. Rojas, G. C., Rodríguez, C. M., Cervantes, S. C., y Morán-Pineda, M. (2002). Contaminación del aire urbano: efectos de la radiación solar. En XXVIII Congreso Interamericano de Ingeniería Sanitaria y Ambiental.

32. Romero Placeres, M., Diego Olite, F., y Álvarez Toste, M. (2006). La contaminación del aire: su repercusión como problema de salud. Revista cubana de higiene y epidemiologia, 44(2), 0-0.

33. Sánchez, Ó. J., y Cardona, C. A. (2005). Producción biotecnológica de alcohol carburante I: obtención a partir de diferentes materias primas. Interciencia, 30(11), $671-678$.

34. Sánchez, O. J., Cardona, C. A., y Sánchez, D. L. (2012). Análisis de ciclo de vida y su aplicación a la producción de bioetanol: Una aproximación cualitativa. Revista Universidad EAFIT, 43(146), 59-79.

35. Taherzadeh, M. J., y Karimi, K. (2007). Acid-based hydrolysis processes for ethanol from lignocellulosic materials: a review. BioResources, 2(3), 472-499.

36. US EPA, O. (s. f.-b). Waste Reduction Algorithm: Chemical Process Simulation for Waste Reduction [Data and Tools].

37. Uyazán, A. M., Gil, I. D., Aguilar, J. L., Rodríguez, G., y Caicedo, L. A. (2004). Deshidratación del etanol. Ingeniería e Investigación, 24(3).

38. Van Maris, A. J., Abbott, D. A., Bellissimi, E., van den Brink, J., Kuyper, M., Luttik, M. A.,.Pronk, J. T. (2006). Alcoholic fermentation of carbon sources in

Referencias: Análisis energético y ambiental de la producción de bio-etanol a partir de la FORSU. T. P. Mendoza Tinoco 
biomass hydrolysates by Saccharomyces cerevisiae: current status. Antonie Van Leeuwenhoek, 90(4), 391-418.

39. Vázquez, H. J., y Dacosta, O. (2007). Fermentación alcohólica: Una opción para la producción de energía renovable a partir de desechos agrícolas. Ingeniería, investigación y tecnología, 8(4), 249-259.

Referencias: Análisis energético y ambiental de la producción de bio-etanol a partir de la FORSU. T. P. Mendoza Tinoco 


\section{Anexos}

\section{A Anexo A. Inventario del proceso.}

\begin{tabular}{|c|c|c|c|c|c|c|c|c|c|}
\hline \multicolumn{4}{|c|}{ Objetivo de estudio: } & \multicolumn{6}{|c|}{ Conservación y crecimiento de microorganismos } \\
\hline \multicolumn{4}{|c|}{ Categoría : } & \multicolumn{6}{|c|}{ Equipo } \\
\hline \multicolumn{4}{|c|}{ Indicadores: } & \multicolumn{6}{|c|}{ Energía consumida por equipo y tiempo de trabajo por muestra } \\
\hline & & \multicolumn{8}{|c|}{ Especificaciones } \\
\hline No. & Equipo & $\begin{array}{c}\text { Consumo } \\
\text { de energía } \\
\text { por } \\
\text { equipo }(W) \\
\end{array}$ & $\begin{array}{c}\text { Tiempo de } \\
\text { trabajo por } \\
\text { equipo(h) }\end{array}$ & $\begin{array}{c}\text { Energía consumida } \\
\text { por hora }(\mathrm{kW} \mathrm{h})\end{array}$ & $\begin{array}{c}\text { Capacidad } \\
\text { del equipo } \\
\text { (L) }\end{array}$ & $\begin{array}{l}\text { Kg de FORSU/l } \\
\text { de bio-etanol }\end{array}$ & $\begin{array}{c}\text { Consumo de } \\
\text { energía por l de } \\
\text { bio-etanol }(\mathrm{kW})\end{array}$ & Fecha & Especificaciones \\
\hline 1 & $\begin{array}{c}\text { Calentador Laken Wood } \\
\text { Delongi }\end{array}$ & 1500 & 72 & 108 & 30000 & 18.05 & 0.06 & $22 / 02 / 2017$ & $\begin{array}{c}\text { La capacidad es considerara para realizar } \\
\text { el cálculo exacto de energía invertida por } \\
\text { volumen. La capacidad reportada es para } \\
\text { un cuarto con dimensiones de } 3 \times 4 \text { y } 2.5 \text { de } \\
\text { altura. }\end{array}$ \\
\hline 2 & $\begin{array}{l}\text { Centrifuga Beckham Coulter } \\
\text { modelo: Allegra } x-12 r\end{array}$ & 1872 & 0.30 & 0.5616 & 0.16 & 18.05 & --- & $23 / 02 / 2017$ & Dato recolectado en el sitio de estudio \\
\hline 3 & Autoclave vertical 241 & 2000 & 0.16 & 0.32 & 0.05 & 18.05 & --- & $24 / 02 / 2017$ & Dato recolectado en el sitio de estudio \\
\hline 4 & Ventilador Cyclone by lasko & 61 & 72 & 4.392 & 30000 & 18.05 & 0.0026 & $25 / 02 / 2017$ & \multirow{3}{*}{$\begin{array}{c}\text { La capacidad es considerara para realizar } \\
\text { el cálculo exacto de energía invertida por } \\
\text { volumen. La capacidad reportada es para } \\
\text { un cuarto con dimensiones de } 3 \times 4 \text { y } 2.5 \text { de } \\
\text { altura. }\end{array}$} \\
\hline 5 & Ventilador de techo 5 aspas & 80 & 72 & 5.76 & 30000 & 18.05 & 0.0034 & $26 / 02 / 2017$ & \\
\hline 6 & $\begin{array}{l}\text { Extractor de aire tipo } \\
\text { industrial } 30 \mathrm{~cm}\end{array}$ & 60 & 72 & 4.32 & 30000 & 18.05 & 0.0025 & $27 / 02 / 2017$ & \\
\hline 7 & Compresor & 1900 & 48 & 91.20 & 30000 & \multirow{2}{*}{$\begin{array}{l}18.05 \\
18.05\end{array}$} & 0.054 & $28 / 02 / 2017$ & Dato recolectado en el sitio de estudio \\
\hline 8 & $\begin{array}{l}\text { Parrilla de agitación hopala } \\
\text { estirar modelo: lms-1003 }\end{array}$ & 600 & 72 & 43.20 & 0.01536 & & 0.25 & 01/03/2017 & Dato recolectado en el sitio de estudio \\
\hline 9 & Luz & 75 & 48 & 3.6 & 30000 & 18.05 & 0.0021 & 02/03/2017 & \multirow{3}{*}{$\begin{array}{c}\text { La capacidad es considerara para realizar } \\
\text { el cálculo exacto de energía invertida por } \\
\text { volumen. La capacidad reportada es para } \\
\text { un cuarto con dimensiones de } 3 \times 4 \text { y } 2.5 \text { de } \\
\text { altura. }\end{array}$} \\
\hline 10 & Condensador & 170 & 48 & 8.16 & 30000 & \multirow{2}{*}{$\begin{array}{l}18.05 \\
18.05\end{array}$} & 0.0049 & 03/03/2017 & \\
\hline 11 & Evaporador & 1108 & 48 & 53.18 & 30000 & & 0.03 & $04 / 03 / 2017$ & \\
\hline \multirow[t]{2}{*}{12} & Balanza analítica explorer & 18 & 0.1 & 0.0018 & 0.00018 & \multirow[t]{2}{*}{18.05} & -- & $28 / 02 / 2017$ & \multirow[t]{2}{*}{ Dato recolectado en el sitio de estudio } \\
\hline & Total & & & 322.69 & & & 0.41 & & \\
\hline
\end{tabular}




\begin{tabular}{|c|c|c|c|c|c|c|c|c|c|}
\hline \multicolumn{3}{|c|}{ Objetivo de estudio: } & \multicolumn{7}{|c|}{ Conservación y crecimiento de microorganismos } \\
\hline \multicolumn{3}{|c|}{ Categoría : } & \multicolumn{7}{|c|}{ Insumos } \\
\hline \multicolumn{3}{|c|}{ Indicadores: } & \multicolumn{7}{|c|}{ Cantidad y tipo de insumos utilizados en la etapa } \\
\hline \multicolumn{10}{|c|}{ Especificaciones } \\
\hline No. & Insumo & Cantidad & \multicolumn{2}{|c|}{ Numero de muestras } & Cantidad total & \multicolumn{2}{|c|}{ Observaciones } & Fecha & Fuente \\
\hline 1 & Agua destilada & 50 & \multicolumn{2}{|c|}{4} & 200 & \multicolumn{2}{|c|}{$\begin{array}{l}\text { Utilizado para esterilizar } \\
\text { el material. }\end{array}$} & 03/03/2017 & $\begin{array}{c}\text { Dato recolectado en el sitio de } \\
\text { estudio }\end{array}$ \\
\hline 2 & Gas lp & ---- & & 4 & --- & \multicolumn{2}{|c|}{$\begin{array}{c}\text { Utilizado para esterilizar } \\
\text { el material. }\end{array}$} & 03/03/2017 & $\begin{array}{c}\text { Dato recolectado en el sitio de } \\
\text { estudio }\end{array}$ \\
\hline \multicolumn{3}{|c|}{ Objetivo de estudio: } & \multicolumn{7}{|c|}{ Conservación y crecimiento de microorganismos } \\
\hline \multicolumn{3}{|c|}{ Categoría : } & \multicolumn{7}{|c|}{ Sustancias/químicos } \\
\hline \multicolumn{3}{|c|}{ Indicadores: } & \multicolumn{7}{|c|}{ Cantidad y tipo de sustancia o químico utilizados en la etapa } \\
\hline \multicolumn{10}{|c|}{ Especificaciones } \\
\hline No. & Sustancia/ químico & Cantidad (gr) & $\begin{array}{l}\text { Numero de } \\
\text { muestras }\end{array}$ & $\begin{array}{c}\text { Cantidad total } \\
(\mathrm{gr} / \mathrm{l})\end{array}$ & & ciones & & & Fuente \\
\hline 1 & Glucosa & 1 & 4 & 4 & & & $24 / 0$ & 017 & Dato recolectado en el sitio de estudio \\
\hline 2 & Peptona de caseína & 0.175 & 4 & 0.7 & & & $25 / 0$ & 017 & Dato recolectado en el sitio de estudio \\
\hline 3 & Extracto de levadura & 0.15 & 4 & 0.6 & & & $26 / 0$ & 017 & Dato recolectado en el sitio de estudio \\
\hline 4 & Kh2po4 & 0.1 & 4 & 0.4 & $\begin{array}{l}\text { Se determinó } \\
\text { para fermen }\end{array}$ & $\begin{array}{l}\text { ntidad necesaria } \\
0 \mathrm{gr}(50 \mathrm{ml} \mathrm{de}\end{array}$ & $27 / 0$ & 017 & Dato recolectado en el sitio de estudio \\
\hline 5 & Mgso4-7h2o & 0.5 & 4 & 2 & $\begin{array}{l}\text { medio) de } \mathrm{m} \\
\text { considerando }\end{array}$ & $\begin{array}{l}\text { por duplicado } \\
\text { licroorganismos }\end{array}$ & $28 / 0$ & 017 & Dato recolectado en el sitio de estudio \\
\hline 6 & $($ nh4)2so4 & 0.025 & 4 & 0.1 & $\begin{array}{r}\text { saccharor } \\
\text { kluy }\end{array}$ & $\begin{array}{l}\text { cerevisiae y } \\
\text { yces nus }\end{array}$ & $01 / 0$ & & Dato recolectado en el sitio de estudio \\
\hline 7 & Agar & 2 & 4 & 8 & & & $02 / 0$ & 017 & Dato recolectado en el sitio de estudio \\
\hline 8 & Glicerol & & & & & & $03 / 0$ & 017 & Dato recolectado en el sitio de estudio \\
\hline 9 & Chaquiras & & & & & & $04 / 0$ & 017 & Dato recolectado en el sitio de estudio \\
\hline
\end{tabular}




\begin{tabular}{|c|c|c|c|c|c|}
\hline \multicolumn{3}{|c|}{ Objetivo de estudio: } & \multicolumn{3}{|r|}{ Conservación y crecimiento de microorganismos } \\
\hline \multicolumn{3}{|c|}{ Categoría : } & \multicolumn{3}{|r|}{ Residuos, emisiones y descargas } \\
\hline \multicolumn{3}{|c|}{ Indicadores: } & \multicolumn{3}{|c|}{ Tipo y cantidad de residuos, emisiones o descargas realizadas en esta etapa } \\
\hline \multicolumn{6}{|c|}{ Especificaciones } \\
\hline No. & $\begin{array}{c}\text { Residuos, emisión o } \\
\text { descarga }\end{array}$ & Cantidad & Fecha & Fuente & Especificaciones \\
\hline 1 & Descarga de aguas grises & 501 & 03/03/2017 & $\begin{array}{c}\text { Promedio de } 1 \text { en lavado } \\
\text { de trastes } \\
\text { www.whaterfootprint.co } \\
\text { m }\end{array}$ & Lavado de material de laboratorio para realizar la técnica de conservación y propagación \\
\hline 2 & Toalla de papel & $5 \mathrm{gr}$ & $04 / 04 / 2017$ & $\begin{array}{l}\text { Dato recolectado en el } \\
\text { sitio de estudio }\end{array}$ & Limpieza de área de trabajo \\
\hline 3 & Emisiones de $\mathrm{CO}_{2}(\mathrm{~kg})$ & 341.0779018 & $05 / 04 / 2017$ & $0.48 \mathrm{~kg} \mathrm{co} 2 / \mathrm{kW}$ & Emisiones por consumo de energía en la etapa \\
\hline
\end{tabular}




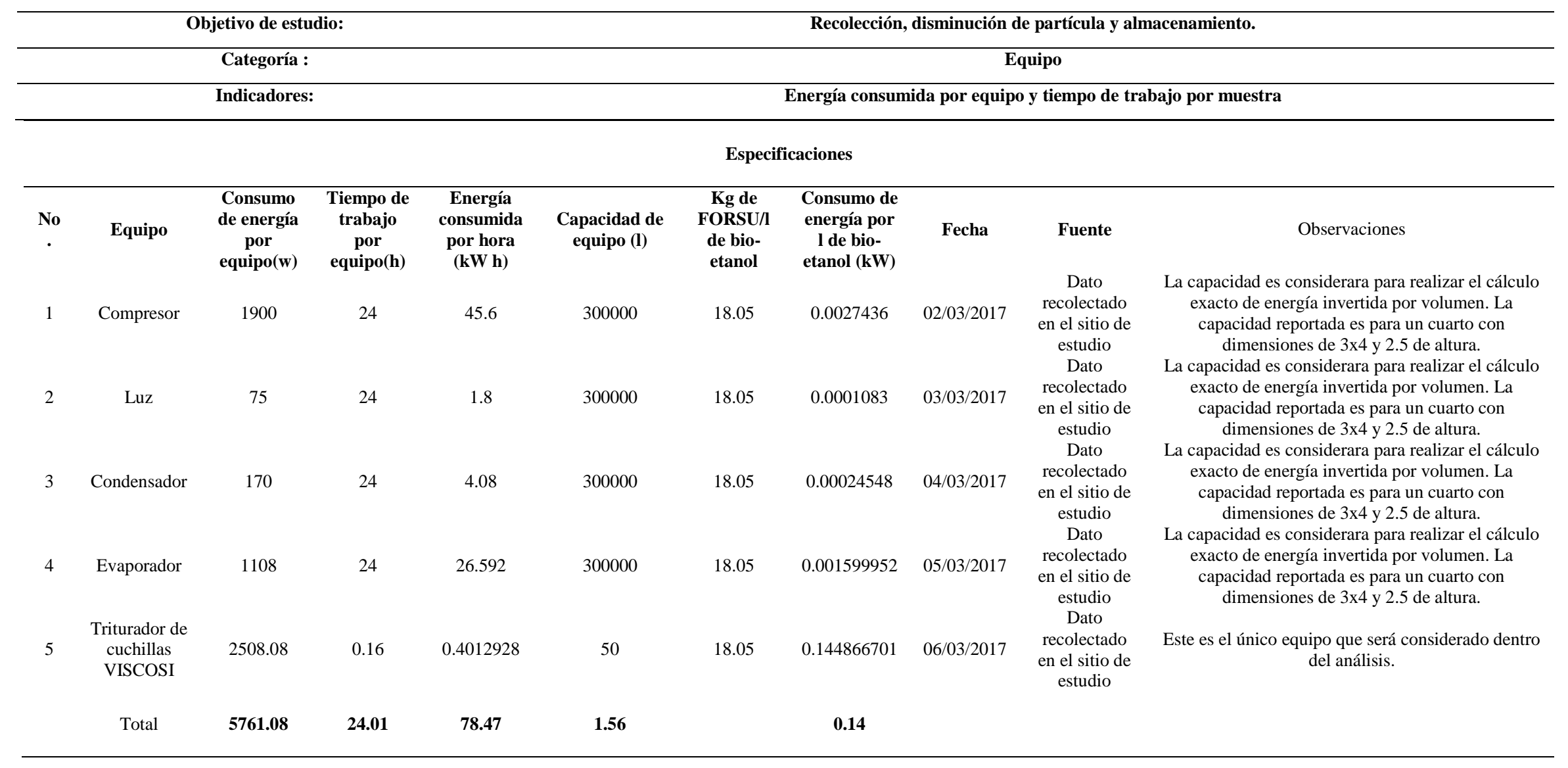




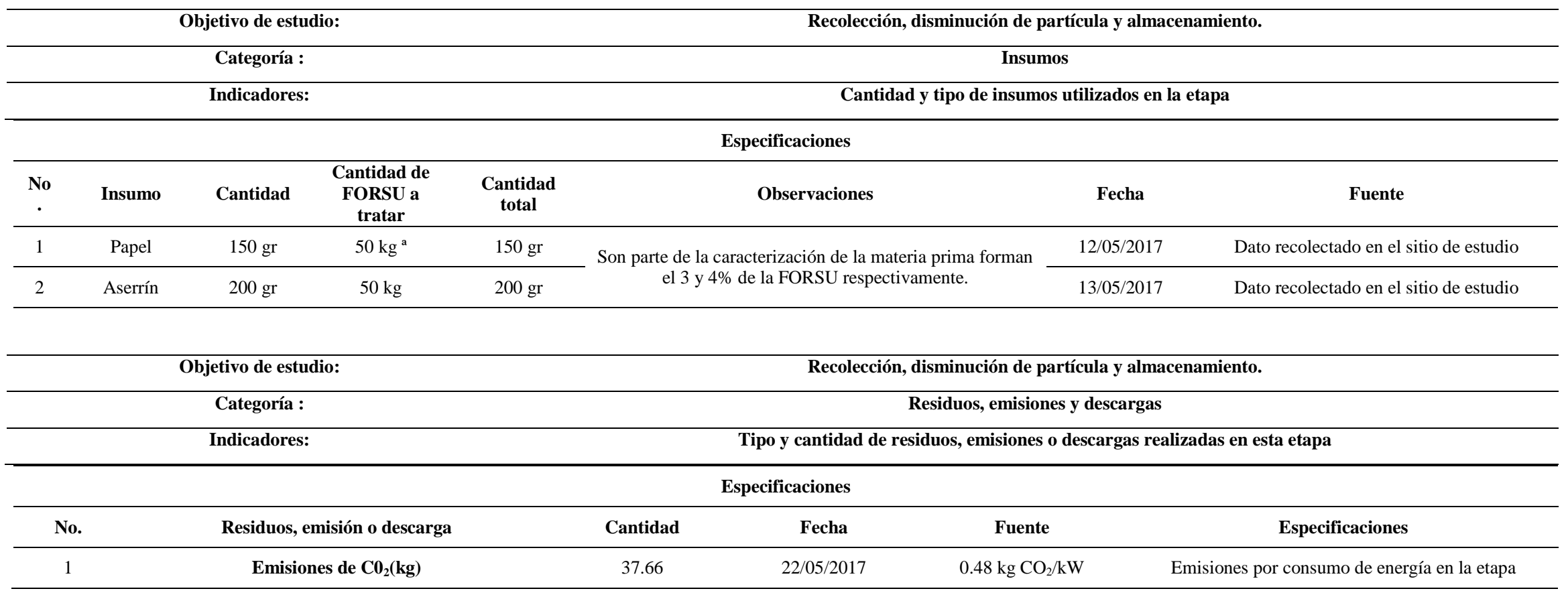




\begin{tabular}{|c|c|c|c|c|c|c|c|c|c|c|}
\hline \multicolumn{5}{|c|}{ Objetivo de estudio: } & \multicolumn{6}{|c|}{ Pretratamiento térmico (explosión a vapor) } \\
\hline \multicolumn{5}{|c|}{ Categoría : } & \multicolumn{6}{|c|}{ Equipo } \\
\hline \multicolumn{5}{|c|}{ Indicadores: } & \multicolumn{6}{|c|}{ Energía consumida por equipo y tiempo de trabajo por muestra } \\
\hline \multicolumn{11}{|c|}{ Especificaciones } \\
\hline No. & Equipo & $\begin{array}{c}\text { Consumo } \\
\text { de energía } \\
\text { por } \\
\text { equipo(w) }\end{array}$ & $\begin{array}{l}\text { Tiempo de } \\
\text { trabajo por } \\
\text { equipo(he) }\end{array}$ & $\begin{array}{c}\text { Energía } \\
\text { consumi } \\
\text { da por } \\
\text { hora } \\
(\mathbf{k W ~ h})\end{array}$ & $\begin{array}{l}\text { Capacidad de } \\
\text { equipo (l) }\end{array}$ & $\begin{array}{l}\text { Kg de } \\
\text { FORSU/l } \\
\text { de bio- } \\
\text { etanol }\end{array}$ & $\begin{array}{l}\text { Consumo de } \\
\text { energía por l } \\
\text { de bio-etanol } \\
\quad(\mathbf{k W})\end{array}$ & Fecha & Fuente & Observaciones \\
\hline 1 & $\begin{array}{l}\text { Caldera de } \\
\text { vapor: } \\
\text { Clayton de } \\
\text { México } \\
1995\end{array}$ & 2781.42 & 0.25 & 0.69 & 120 & 18.05 & 0.10 & $26 / 06 / 2017$ & $\begin{array}{c}\text { Dato } \\
\text { recolecta } \\
\text { do en el } \\
\text { sitio de } \\
\text { estudio }\end{array}$ & $\begin{array}{c}\text { Se realizó el cálculo con base en la ecuación de } \\
\text { potencias } \mathrm{p}=\mathrm{q}^{*} \mathrm{cp} \cdot *(\mathrm{t}-\mathrm{t} 0) \text {. Dónde: } \mathrm{q}=\text { caudal por } \\
\text { unidad de tiempo, } \mathrm{cp} .=\text { poder calorífico de la } \\
\text { sustancia a calentarte= temperatura final, } \\
\text { t0=temperatura inicial. }\end{array}$ \\
\hline 2 & $\begin{array}{c}\text { Autoclave } \\
\text { modificada } \\
1801\end{array}$ & 0 & 0.25 & 0 & 180 & 18.05 & 0 & $26 / 06 / 2017$ & $\begin{array}{l}\text { recolecta } \\
\text { do en el } \\
\text { sitio de } \\
\text { estudio }\end{array}$ & $\begin{array}{l}\text { La autoclave sirve como un contenedor por lo cual } \\
\text { no consume energía. }\end{array}$ \\
\hline 3 & $\begin{array}{l}\text { Balanza nbi } \\
\text { sm-60a }\end{array}$ & 460 & 0.03 & 0.01 & 50 & 18.05 & 0.0049 & $26 / 06 / 2017$ & $\begin{array}{l}\text { Dato } \\
\text { recolecta } \\
\text { do en el } \\
\text { sitio de } \\
\text { estudio }\end{array}$ & $\begin{array}{l}\text { Es necesaria para pesar la materia orgánica que se } \\
\text { tratara }\end{array}$ \\
\hline & Total & & & 0.70 & & & 0.10 & & & \\
\hline
\end{tabular}




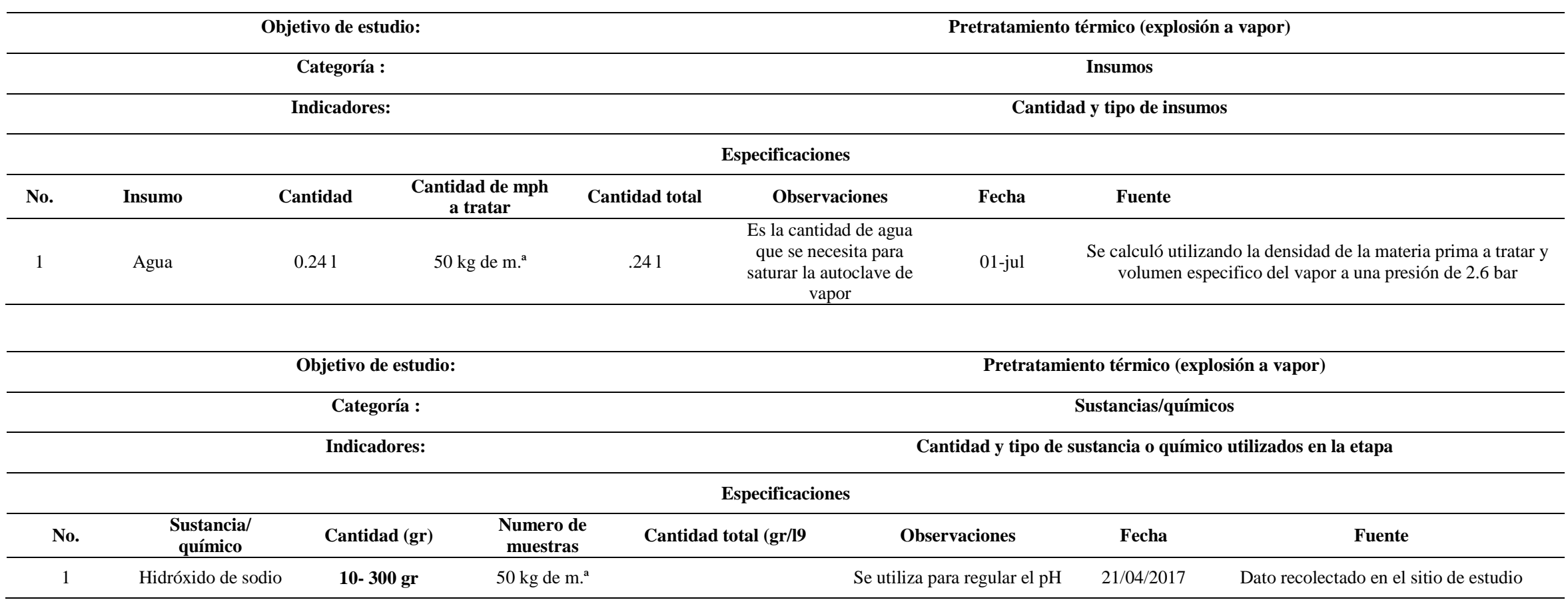

Objetivo de estudio:

$\begin{array}{r}\text { Objetivo de estu } \\ \hline \text { Categoría : }\end{array}$

Indicadores:
Pretratamiento térmico (explosión a vapor)

$$
\text { Residuos, emisiones y descargas }
$$

Tipo y cantidad de residuos, emisiones o descargas realizadas en esta etapa

\begin{tabular}{cccccc}
\hline & \multicolumn{4}{c}{ Especificaciones } \\
\hline No. & Residuos, emisión o descarga & Cantidad & Fecha & Fuente & Especificaciones \\
\hline 1 & Emisiones de $\mathrm{CO}_{2}$ & 0.34 & $22 / 05 / 2017$ & $0.48 \mathrm{~kg} \mathrm{CO}_{2} / \mathrm{kW}$ & Emisiones por consumo de energía en la etapa \\
\hline
\end{tabular}




\begin{tabular}{cc}
\hline Categoría : & Equipo \\
\hline Indicadores: & Energía consumida por equipo y tiempo de trabajo \\
\hline
\end{tabular}

Especificaciones

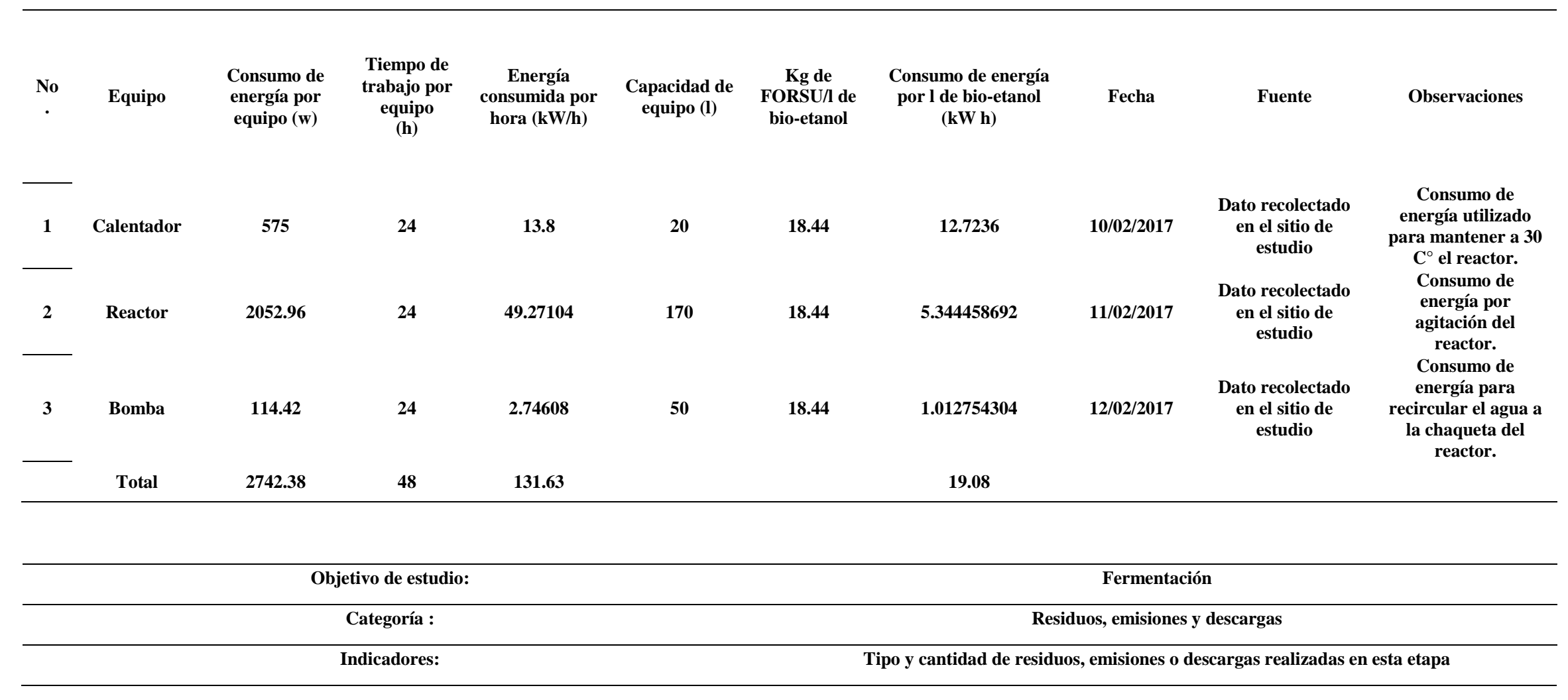




\section{Especificaciones}

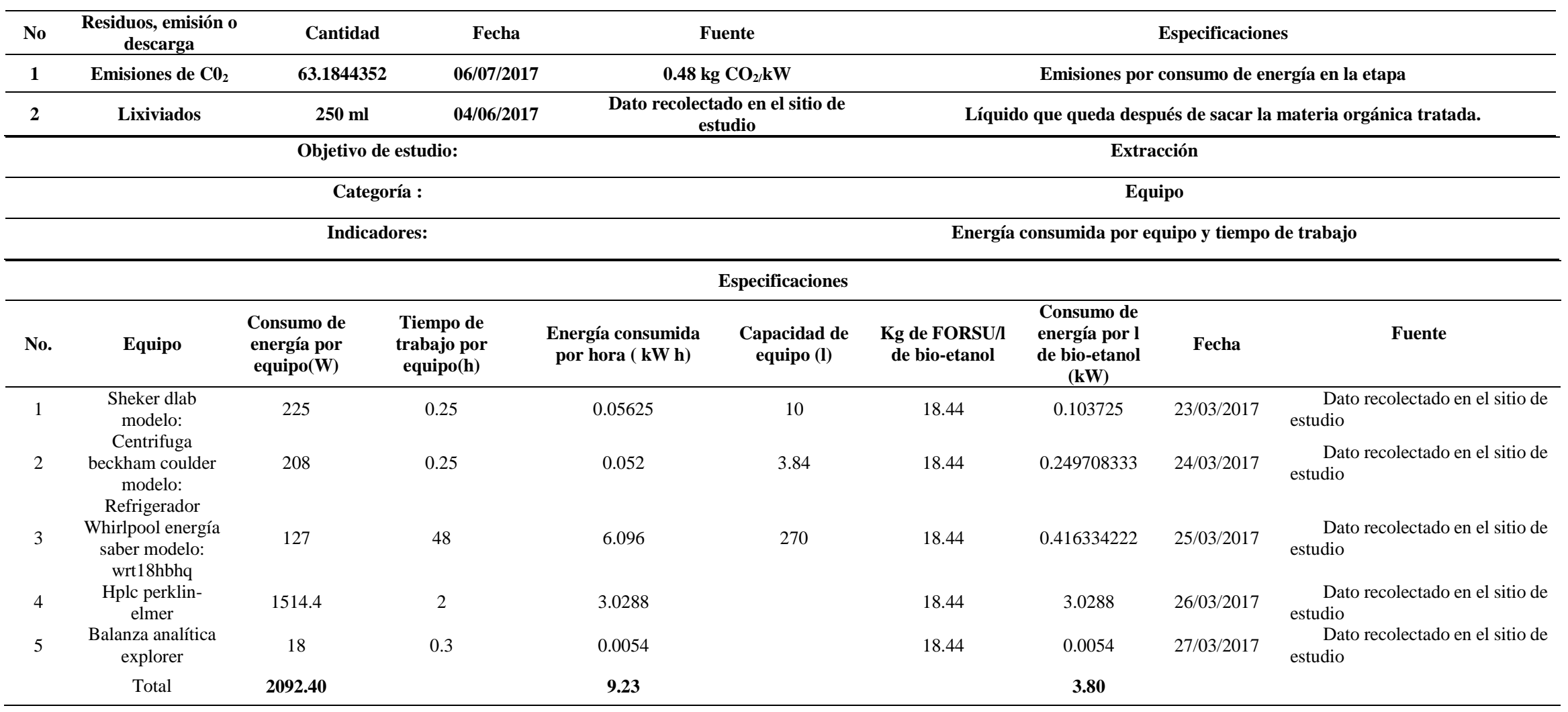

\begin{tabular}{ccc}
\hline Objetivo de estudio: & Extracción \\
\hline Categoría : & Insumos \\
\hline Indicadores: & Cantidad y tipo de insumos utilizados en la etapa \\
\hline
\end{tabular}




\begin{tabular}{cccccccc}
\hline No. & Insumo & Cantidad & $\begin{array}{c}\text { Cantidad de } \\
\text { FORSU a tratar }\end{array}$ & Cantidad total & Observaciones & Fspecificaciones & Fuente \\
\hline 1 & Agua destilada & 2001 & $50 \mathrm{~kg}$ & 2001 & $\begin{array}{c}\text { Se utiliza para lavar los sólidos y extraer la } \\
\text { mayor cantidad de bio-etanol producido. }\end{array}$ & $20 / 04 / 2017$ & Dato recolectado en el sitio de estudio \\
\hline
\end{tabular}

\begin{tabular}{cccccc}
\hline \multicolumn{7}{c}{ Objetivo de estudio: } & Extracción \\
\hline \multicolumn{7}{c}{ Categoría : } & Residuos, emisiones y descargas \\
\hline \multicolumn{7}{c}{ Indicadores: } & Tipo y cantidad de residuos, emisiones o descargas realizadas en esta etapa \\
\hline \multicolumn{7}{c}{ Cantidad } & Fecha & Fuente \\
\hline No. & Residuos, emisión o descarga & 4.434456 & $23 / 05 / 2017$ & $0.48 \mathrm{~kg}$ co $/ \mathrm{kW}$ & Especificaciones \\
\hline 1 & Emisiones de c02 & $\mathbf{4 0 ~} \mathbf{~ k g}$ & $24 / 05 / 2017$ & Dato recolectado en el sitio de estudio
\end{tabular}




\title{
9. B Anexo B. Reporte de simulación Aspen plus 7.3
}

\author{
TABLE OF CONTENTS
}

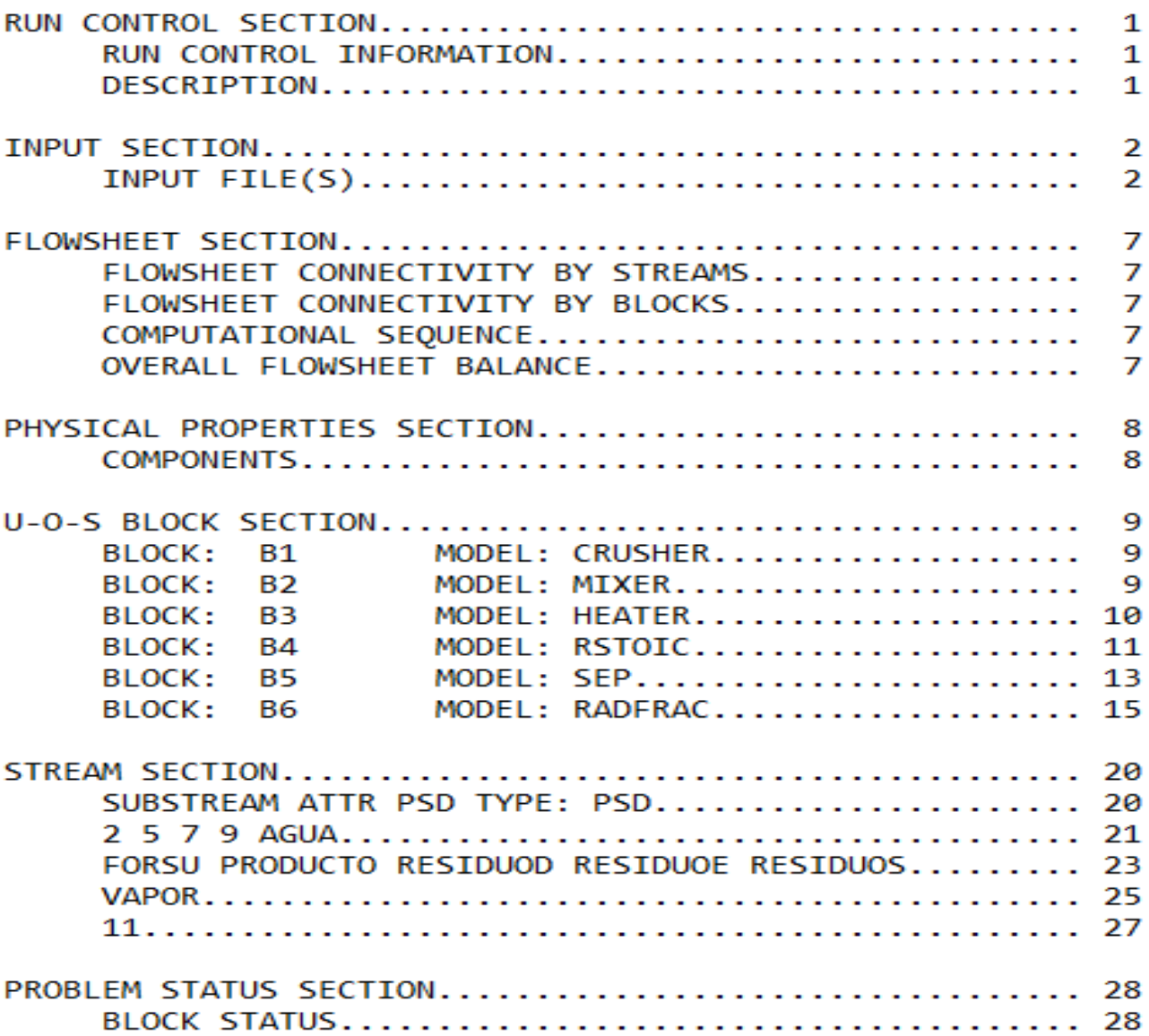

Anexos: Análisis energético y ambiental de la producción de bio-etanol a partir de la FORSU. T. 


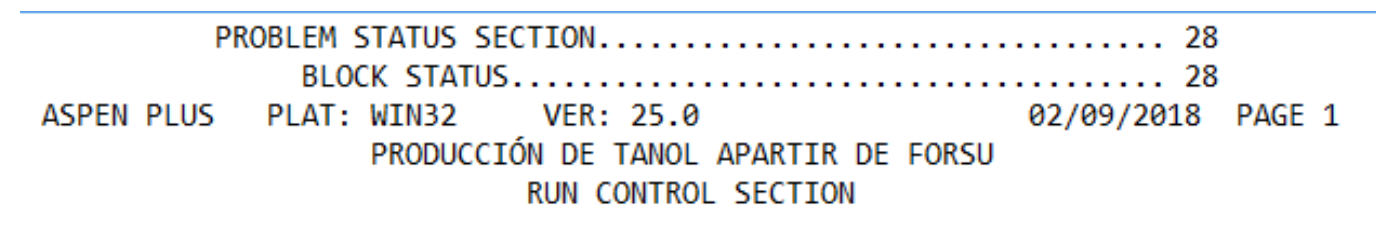

RUN CONTROL INFORMATION

THIS COPY OF ASPEN PLUS LICENSED TO LEGENDS

TYPE OF RUN: NEW

INPUT FILE NAME: _4837kfn.inm

OUTPUT PROBLEM DATA FILE NAME: _1420zbb

LOCATED IN:

PDF SIZE USED FOR INPUT TRANSLATION:

NUMBER OF FILE RECORDS (PSIZE) $=0$

NUMBER OF IN-CORE RECORDS $=256$

PSIZE NEEDED FOR SIMULATION = 1

CALLING PROGRAM NAME: apmain

LOCATED IN: $\quad$ C: $\backslash$ PROGRA 2\ASPENT 1 \ASPENP 2.3\Engine $\backslash x e q$

SIMULATION REQUESTED FOR ENTIRE FLOWSHEET

DESCRIPTION

-..........

Simulación de la producción de etanol aprovechando los carbohidratos pre sentes en la fracción orgánica de los residuos sólidos urbanos, a nivel laboratorio. Utilizando las etapas de disminución de partículas, explosi ón a vapor, fermentación y 
sólidos urbanos, a nivel laboratorio. Utilizando las etapas de disminución de partículas, explosi ón a vapor, fermentación y destilación.

+ ASPEN PLUS PLAT: WIN32 VER: 25.0 PRODUCCIÓN DE TANOL APARTIR DE FORSU

02/09/2018 PAGE 2 INPUT SECTION

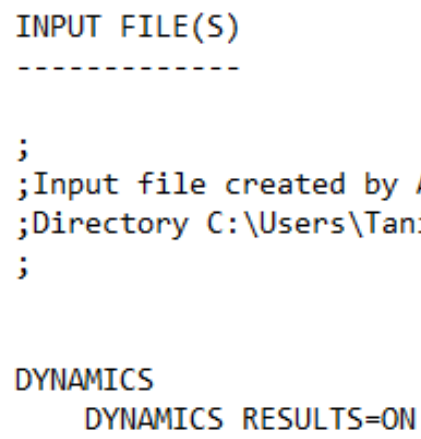

Anexos: Análisis energético y ambiental de la producción de bio-etanol a partir de la FORSU. T. 


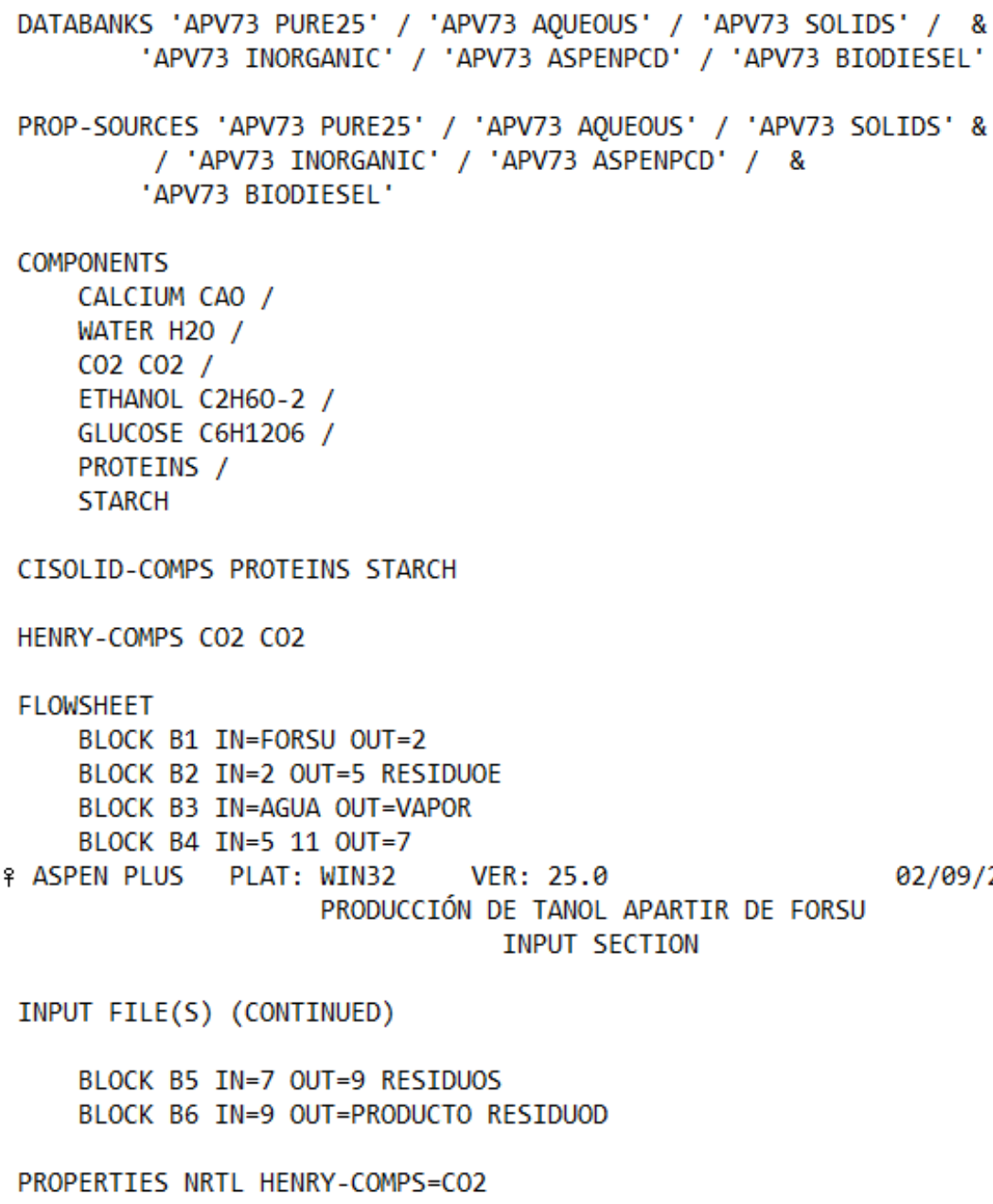

PROPERTIES NRTL HENRY - COMPS $=\mathrm{CO} 2$

Anexos: Análisis energético y ambiental de la producción de bio-etanol a partir de la FORSU. T. 


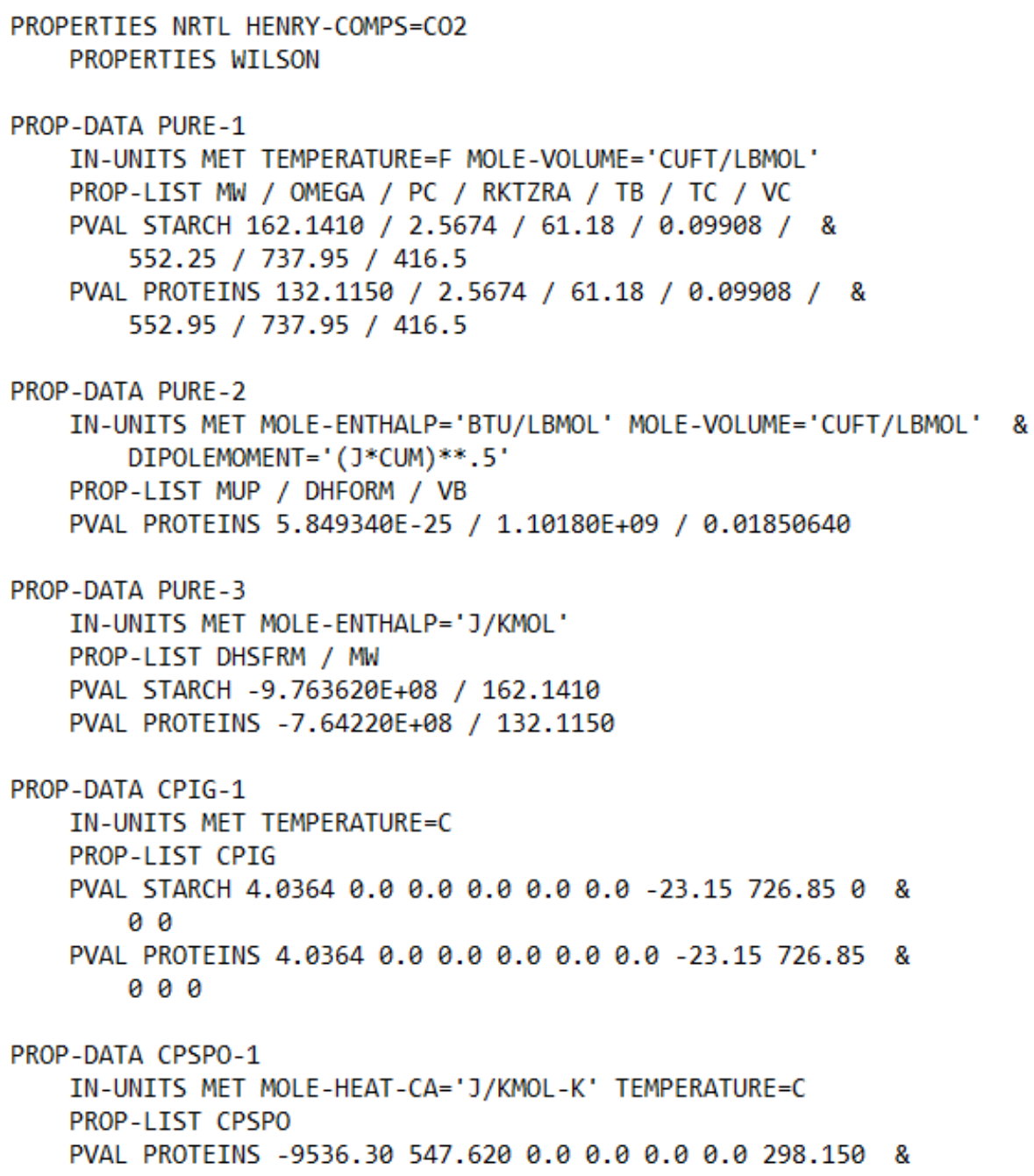

Anexos: Análisis energético y ambiental de la producción de bio-etanol a partir de la FORSU. T. 


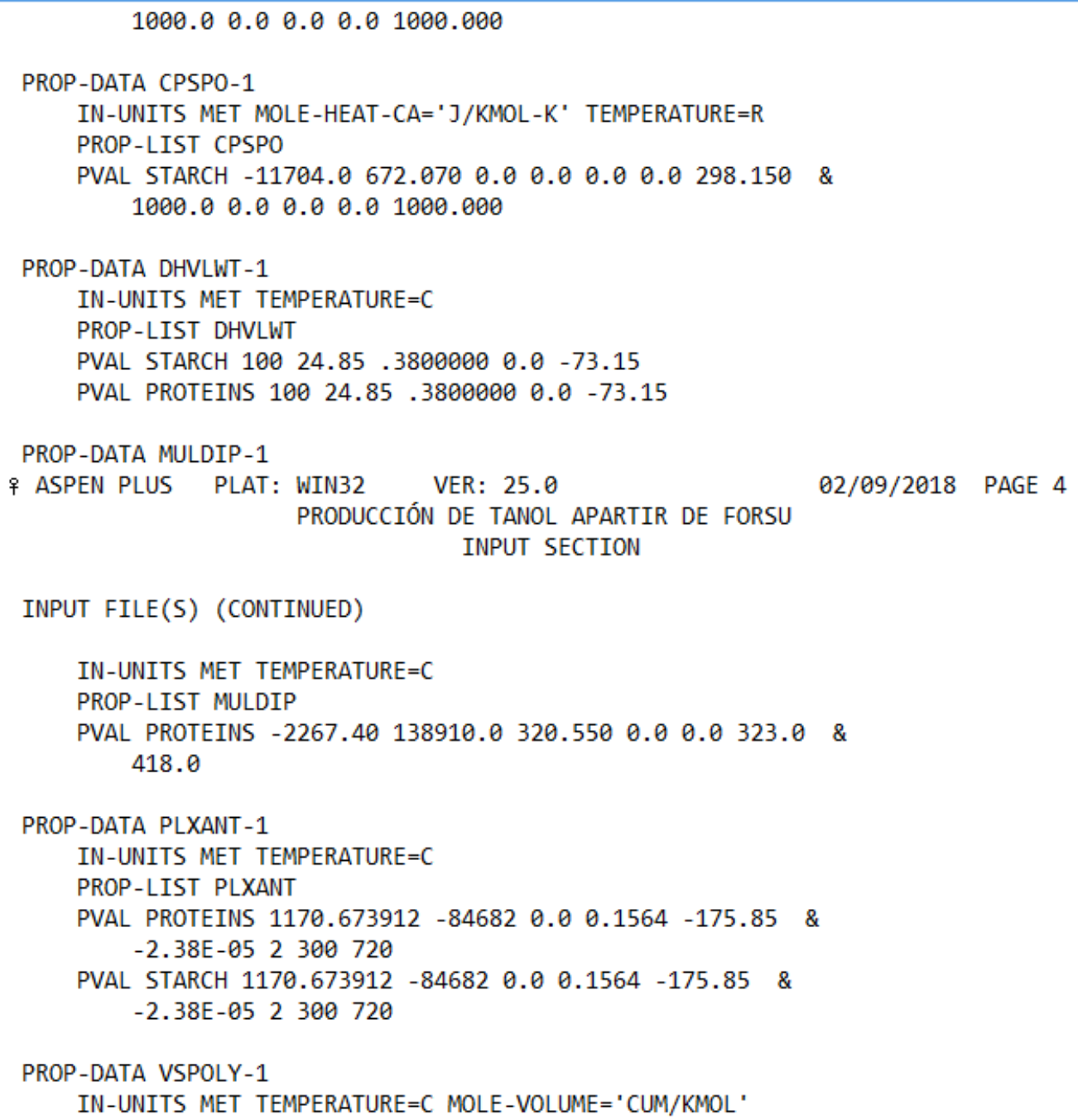




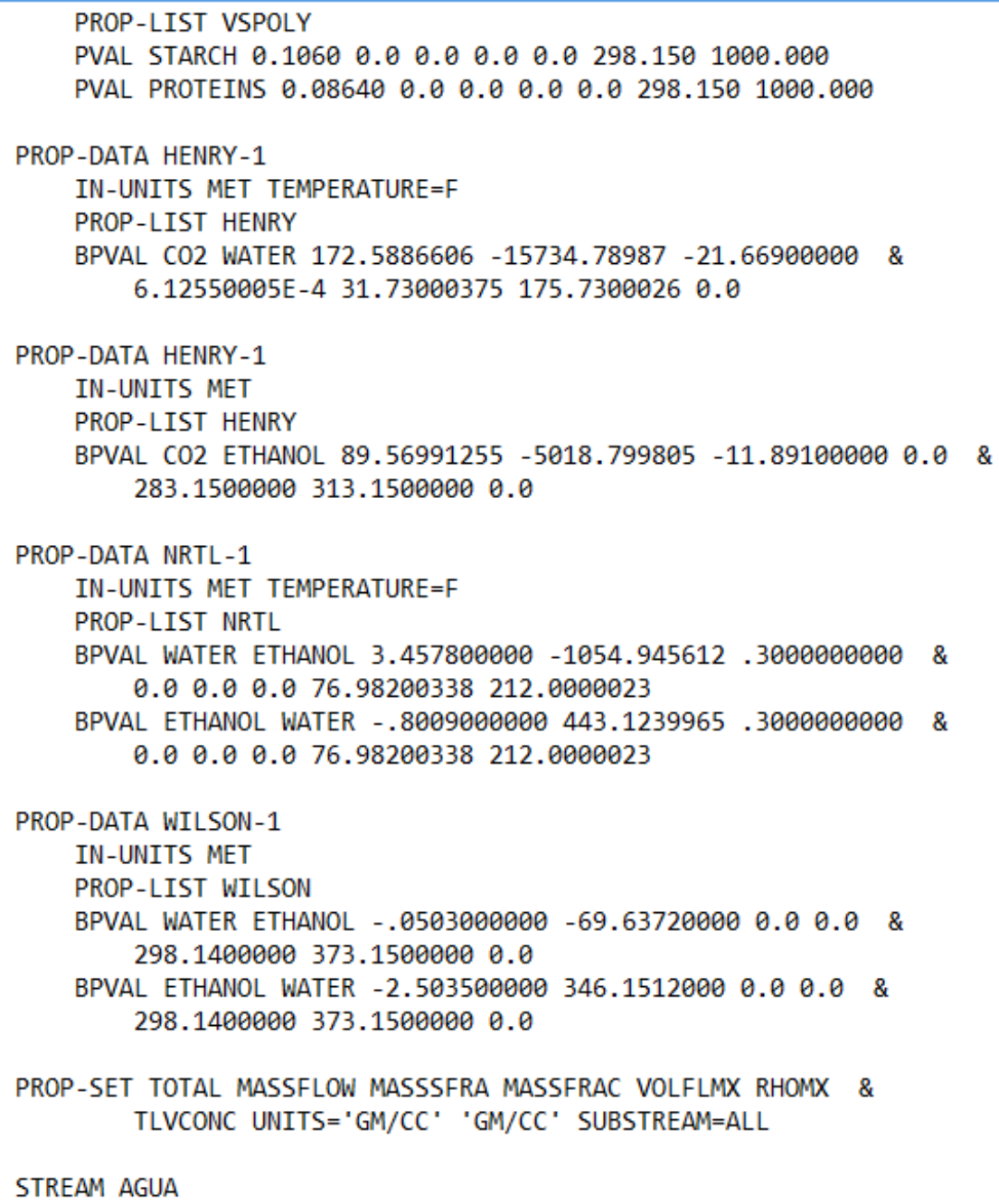




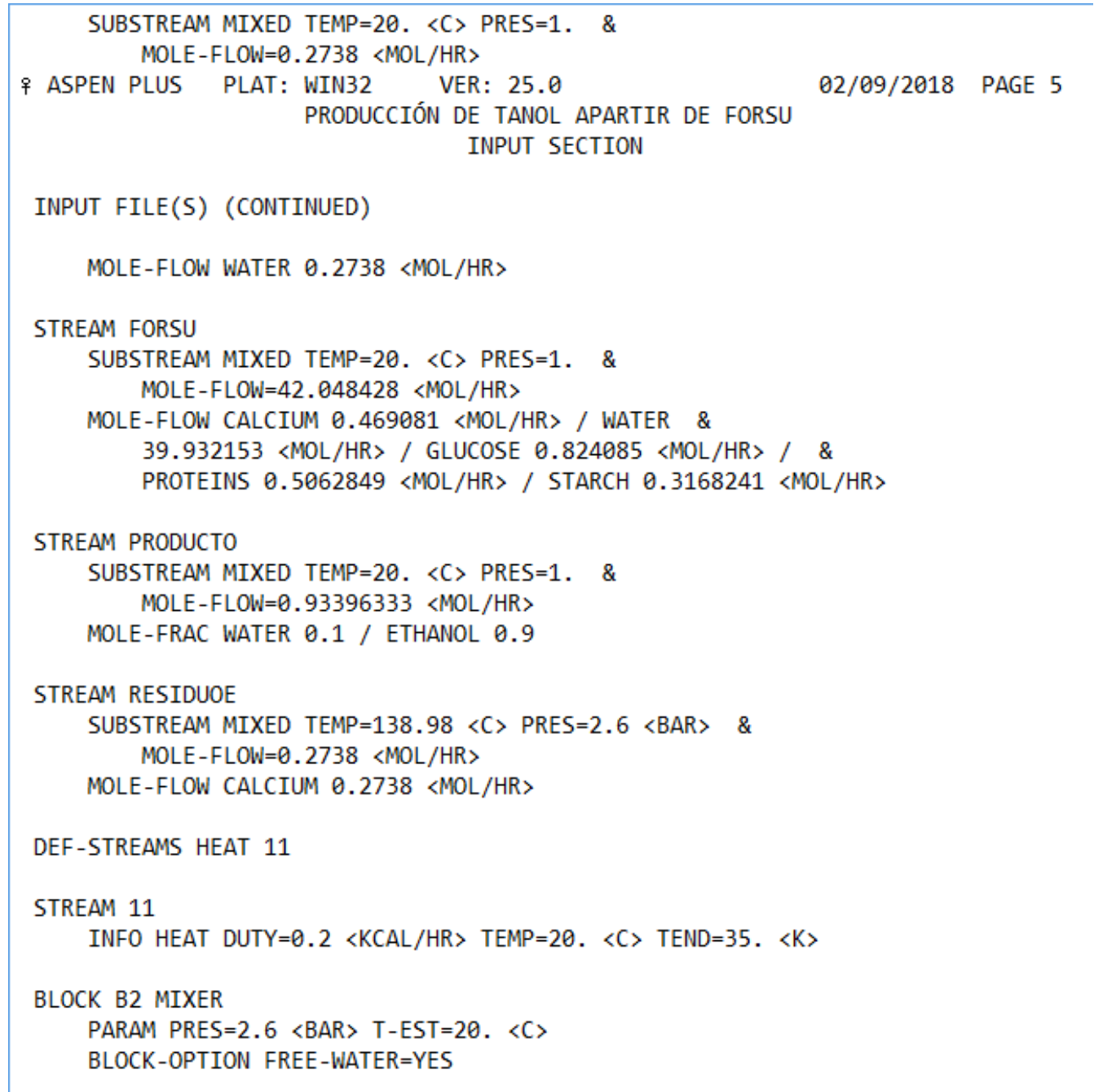

Anexos: Análisis energético y ambiental de la producción de bio-etanol a partir de la FORSU. T. P. Mendoza Tinoco 


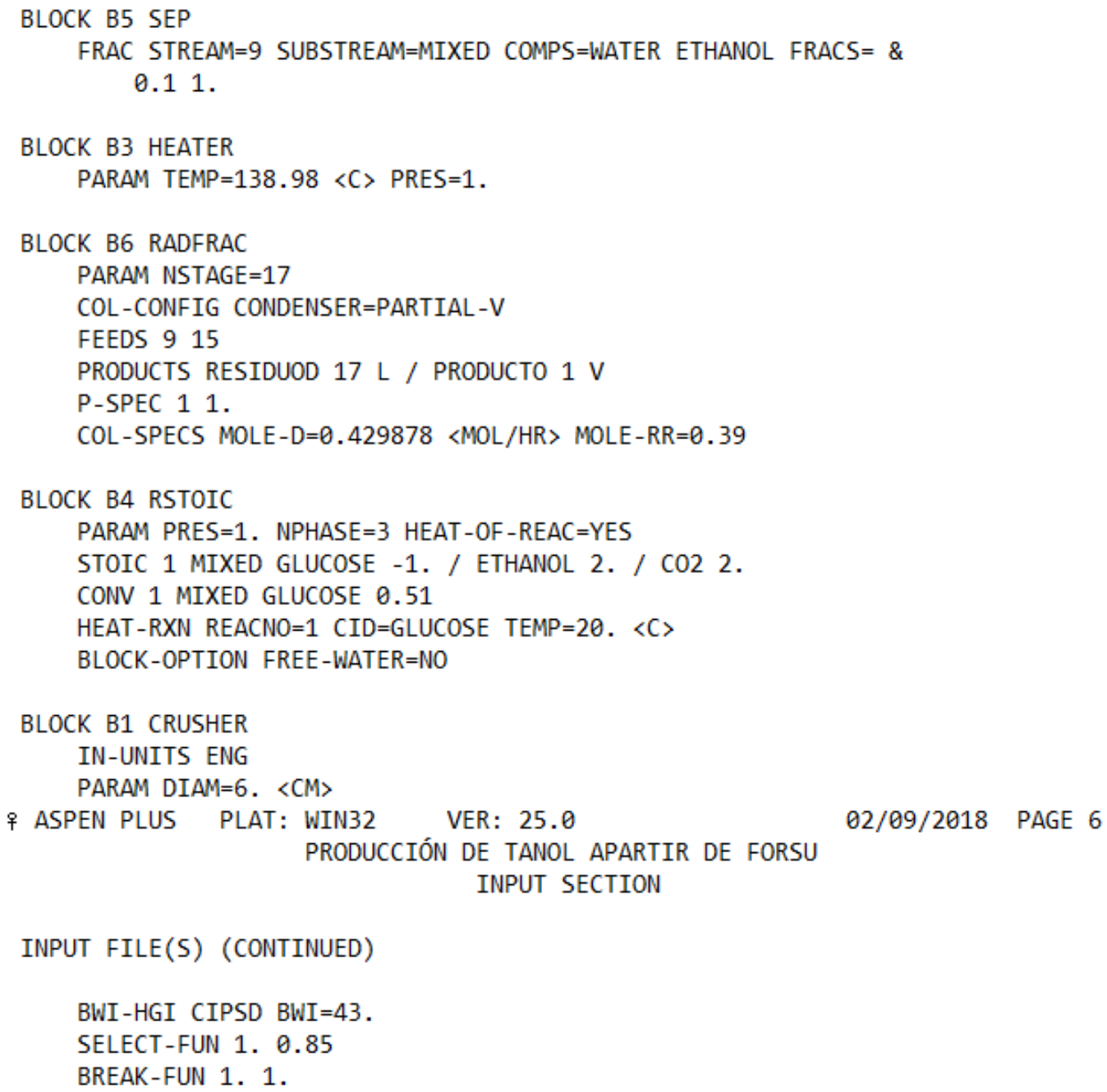




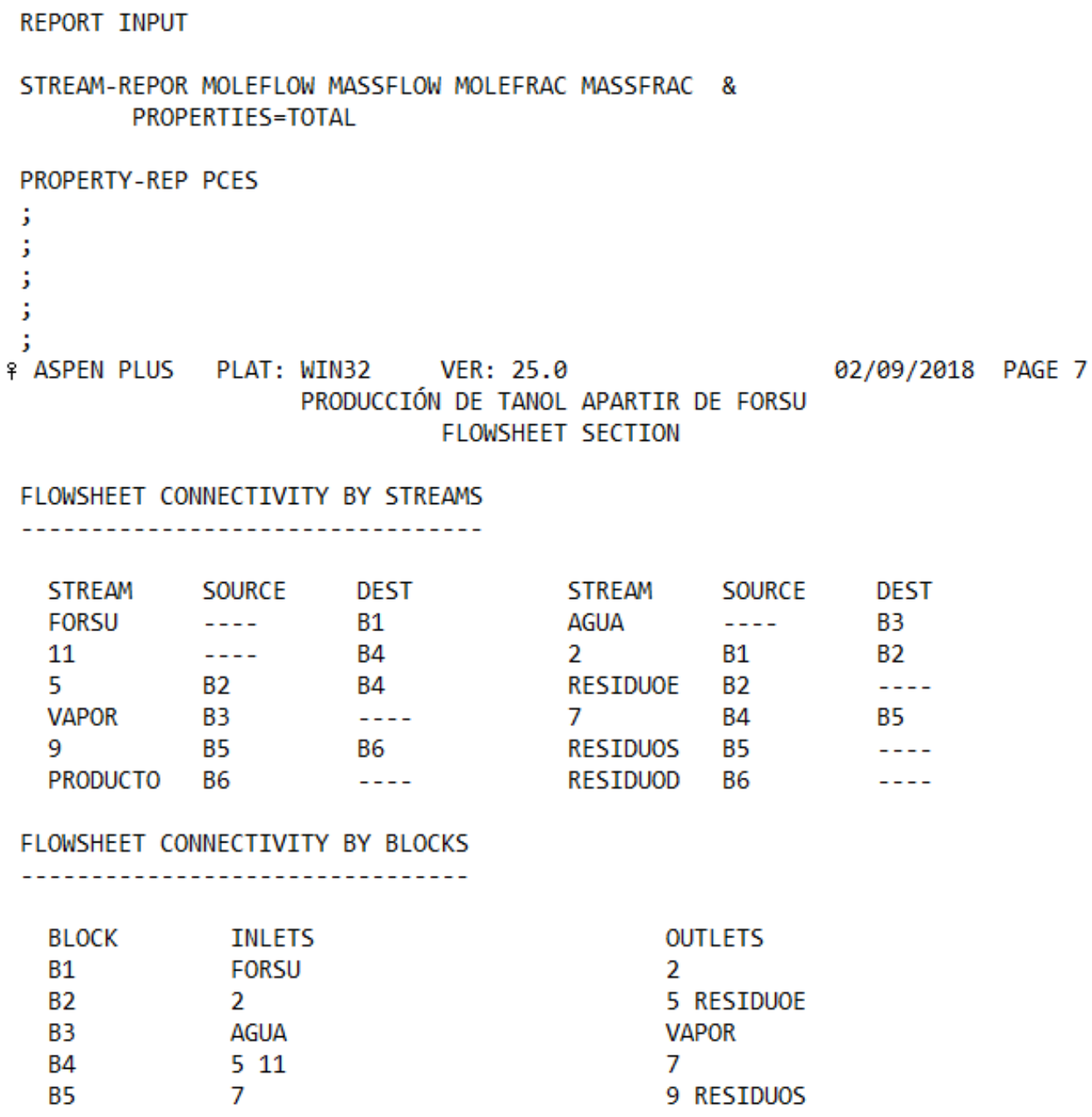

\begin{tabular}{|c|c|c|c|c|c|}
\hline STREAM & SOURCE & DEST & STREAM & SOURCE & DEST \\
\hline FORSU & $-\cdots$ & B1 & AGUA & -- & B3 \\
\hline 11 & $\ldots$ & B4 & 2 & B1 & B2 \\
\hline 5 & B2 & B4 & RESIDUOE & B2 & $\ldots$ \\
\hline VAPOR & B3 & $\ldots$ & 7 & B4 & B5 \\
\hline 9 & B5 & B6 & RESIDUOS & B5 & $\ldots$ \\
\hline PRODUCTO & B6 &.-- & RESIDUOD & B6 & $\ldots$ \\
\hline
\end{tabular}

FLOWSHEET CONNECTIVITY BY BLOCKS

-

$\begin{array}{lll}\text { BLOCK } & \text { INLETS } & \text { OUTLETS } \\ \text { B1 } & \text { FORSU } & 2 \\ \text { B2 } & 2 & 5 \text { RESIDUOE } \\ \text { B3 } & \text { AGUA } & \text { VAPOR } \\ \text { B4 } & 511 & 7 \\ \text { B5 } & 7 & 9 \text { RESIDUOS }\end{array}$

Anexos: Análisis energético y ambiental de la producción de bio-etanol a partir de la FORSU. T. 
B5

B6
7

9
9 RESIDUOS

PRODUCTO RESIDUOD

COMPUTATIONAL SEQUENCE

SEQUENCE USED WAS:

B3 B1 B2 B4 B5 B6

OVERALL FLOWSHEET BALANCE

OVERALL FLOUSHET BALAICE

*** MASS AND ENERGY BALANCE ***

IN OUT

CONVENTIONAL COMPONENTS (KMOL/HR )

\begin{tabular}{|c|c|c|}
\hline CALCIUM & $0.469081 \mathrm{E}-03$ & 0.46 \\
\hline WATER & $0.402060 \mathrm{E}-01$ & 0.4 \\
\hline $\mathrm{CO} 2$ & 0.00000 & \\
\hline ETHANOL & 0.00000 & \\
\hline GLUCOSE & $0.824085 E-03$ & \\
\hline PROTEINS & $0.506285 E-03$ & \\
\hline STARCH & $0.316824 \mathrm{E}-03$ & \\
\hline \multicolumn{3}{|l|}{ TAL BALANCE } \\
\hline MOLE (KMOL/HR ) & $0.423222 E-01$ & \\
\hline $\operatorname{MASS}(K G / H R \quad)$ & 1.01735 & \\
\hline ENTHALPY(CAL/SEC ) & $-0.127179 \mathrm{E}+16$ & -0 . \\
\hline$* * * \quad \mathrm{CO} 2$ & EQUIVALENT SUMM & ARY \\
\hline STREAMS CO2E & 0.00000 & $\mathrm{KG} / \mathrm{HF}$ \\
\hline UCT STREAMS CO2E & $0.369929 E-01$ & $\mathrm{KG} / \mathrm{HF}$ \\
\hline STREAMS CO2E PRODUCTION & N $0.369929 E-01$ & $\mathrm{KG} / \mathrm{H}$ \\
\hline TIES CO2E PRODUCTION & 0.0 & KG/ \\
\hline CO2E PRODU & $29 E-01$ & $\mathrm{KG} / \mathrm{H}$ \\
\hline
\end{tabular}

TOTAL CO2E PRODUCTION $0.369929 \mathrm{E}-01 \mathrm{KG} / \mathrm{HR}$

+ ASPEN PLUS PLAT: WIN32 VER: $25.0 \quad 02 / 09 / 2018$ PAGE 8
RELATIVE DIFF.
0.00000
0.00000
$-1.00000$
$-1.00000$
0.510000
0.00000
0.00000
$-0.289298 \mathrm{E}-01$
$0.826232 E-07$
$-0.697929 \mathrm{E}-04$

PRODUCCIÓN DE TANOL APARTIR DE FORSU

PHYSICAL PROPERTIES SECTION

Anexos: Análisis energético y ambiental de la producción de bio-etanol a partir de la FORSU. T. 


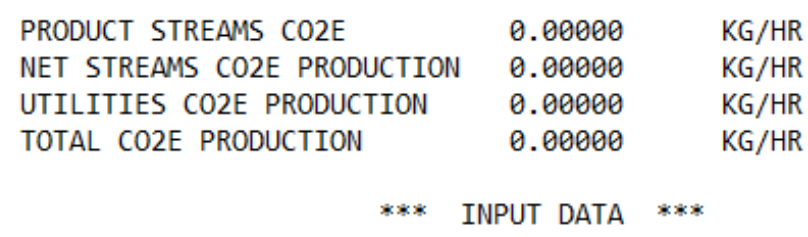

OPERATING MODE:

PRIMARY

CRUSHER TYPE:

DIAMETER OF SOLIDS OUTLET METER

BOND WORK INDEX FOR SUBSTREAM CIPSD, KWHR/TON

MAXIMUM NO. OF FLASH ITERATION

GYRATORY OR JAW

0.060000

FLASH TOLERANCE

43.0000

SEPARATION STRENGTH TABLE SUPPLIED BY USER:

0.000100000

SIZE RATIO

1.0000
SELECTION FUNCTION

0.85000

\section{*** RESULTS ***}

POWER REQUIREMENT KW

MISSING

PARTICLE DIAMETER WHICH IS

LARGER THAN $80 \%$ OF INLET MASS METER MISSING PARTICLE DIAMETER WHICH IS

LARGER THAN $80 \%$ OF OUTLET MASS METER MISSING

BLOCK: B2 MODEL: MIXER

$\begin{array}{llll}\text { INLET STREAM: } & 2 & \\ \text { OUTLET STREAM: } & 5 & \\ \text { OUTLET WATER STREAM: } & \text { RESIDUOE } & \\ \text { PROPERTY OPTION SET: } & \text { NRTL } & \text { RENON (NRTL) / IDEAL GAS } \\ \text { HENRY-COMPS ID: } & \text { CO2 } & \\ \text { FREE WATER OPTION SET: } & \text { SYSOP12 ASME STEAM TABLE } \\ \text { SOLUBLE WATER OPTION: } & \text { THE MAIN PROPERTY OPTION SET (NRTL ). }\end{array}$

Anexos: Análisis energético y ambiental de la producción de bio-etanol a partir de la FORSU. T. 


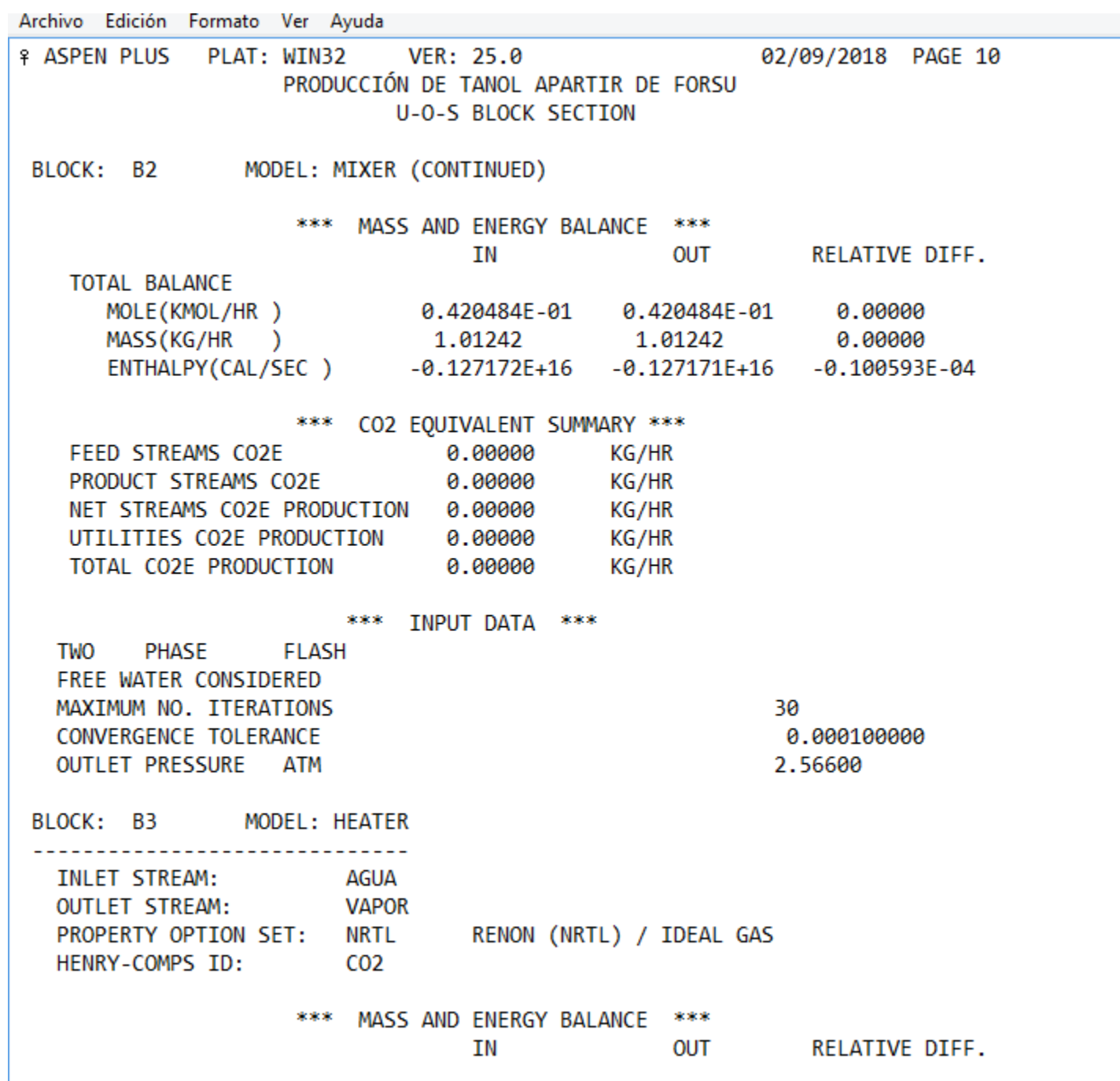

Anexos: Análisis energético y ambiental de la producción de bio-etanol a partir de la FORSU. T. 


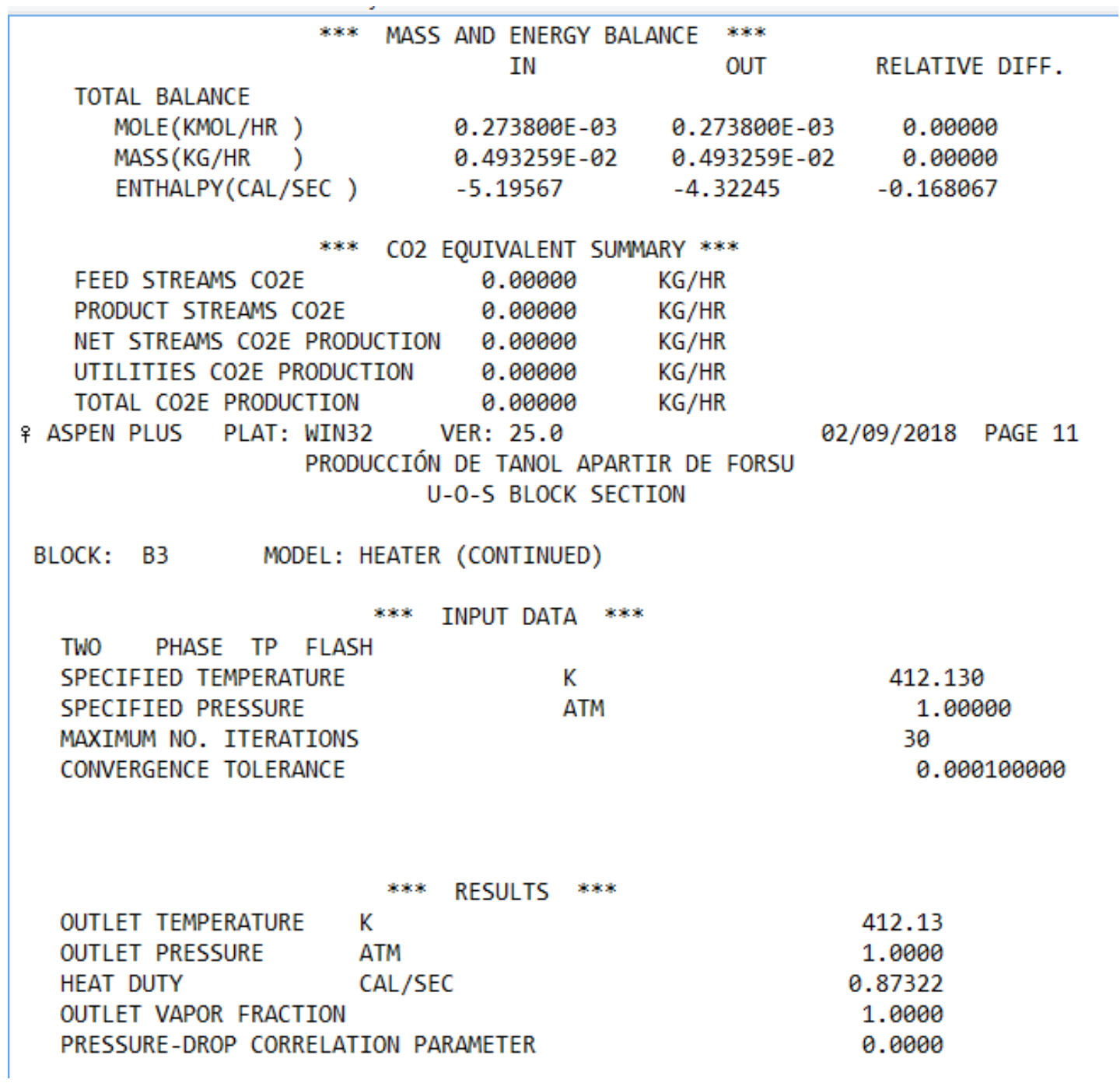

Anexos: Análisis energético y ambiental de la producción de bio-etanol a partir de la FORSU. T. P. Mendoza Tinoco 


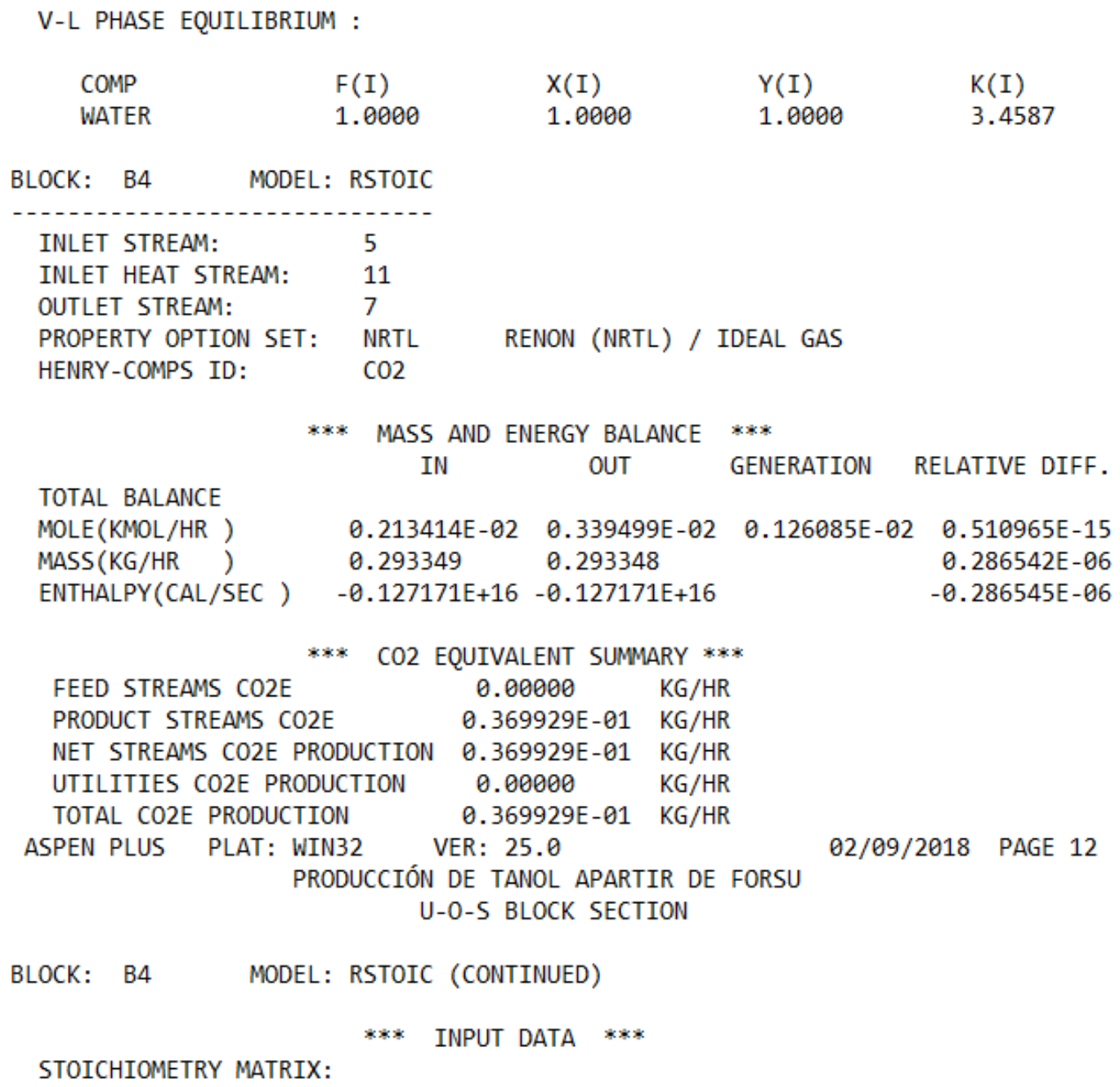




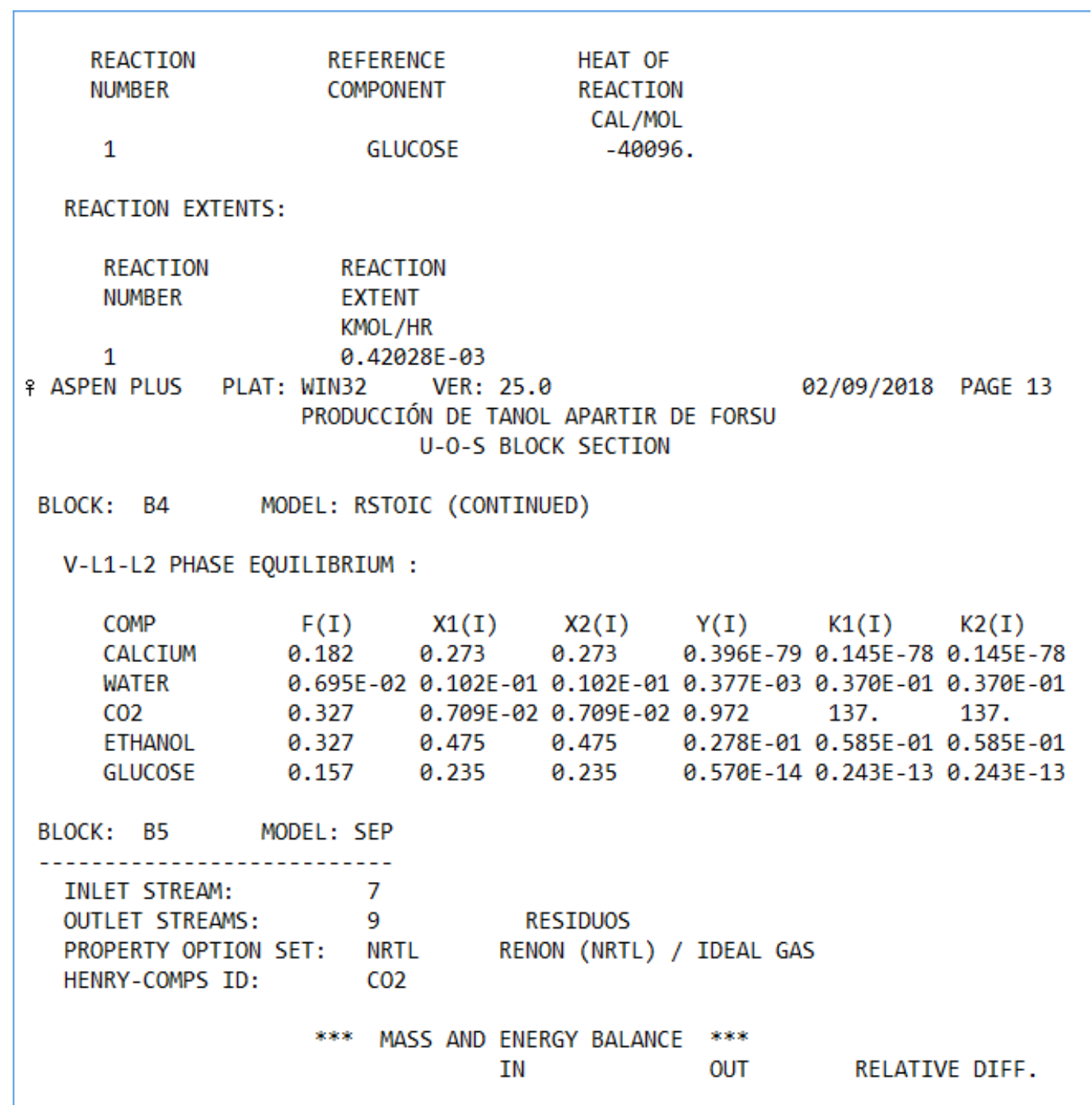

Anexos: Análisis energético y ambiental de la producción de bio-etanol a partir de la FORSU. T. P. Mendoza Tinoco 


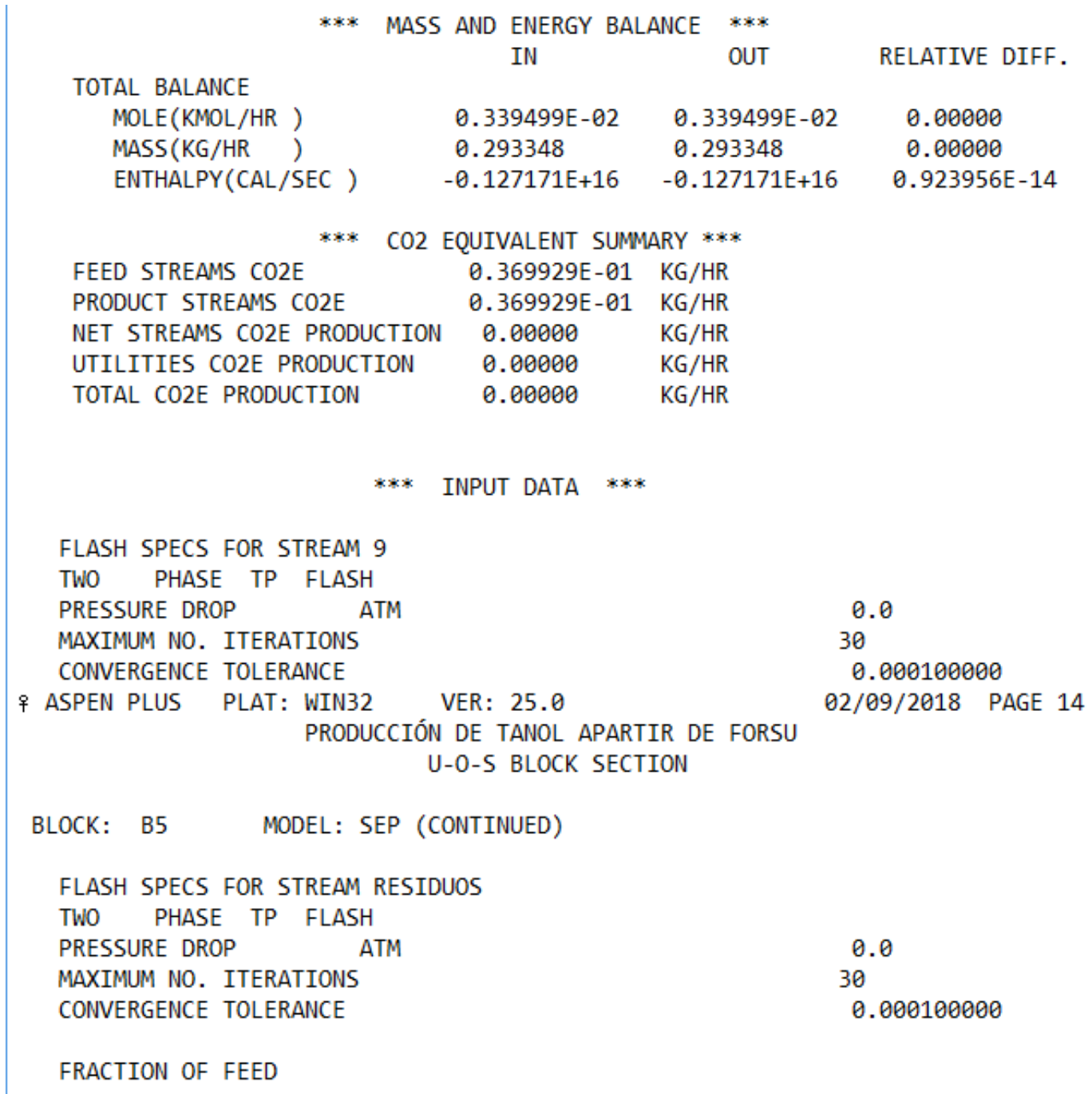

Anexos: Análisis energético y ambiental de la producción de bio-etanol a partir de la FORSU. T. 


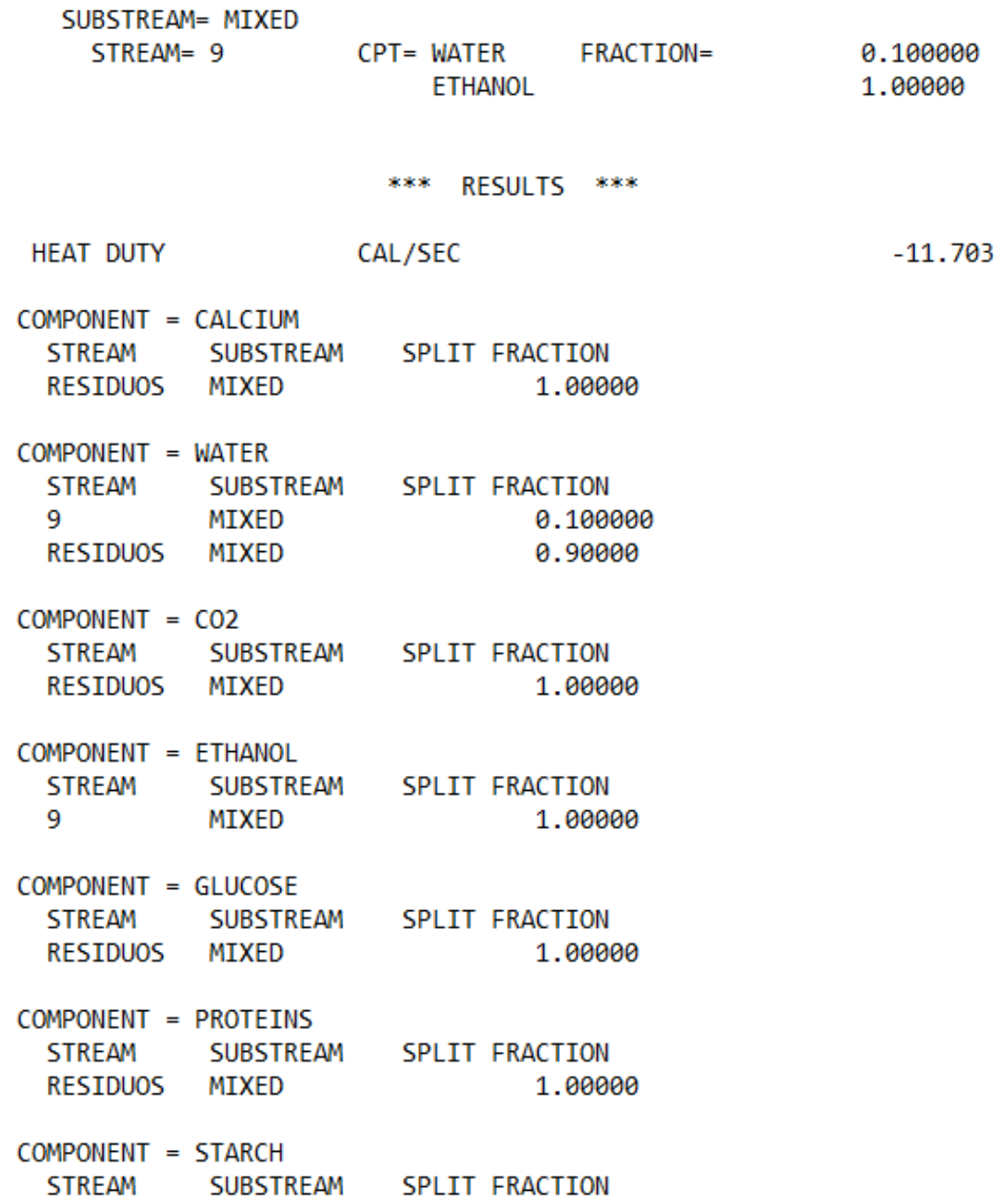

Anexos: Análisis energético y ambiental de la producción de bio-etanol a partir de la FORSU. T. 


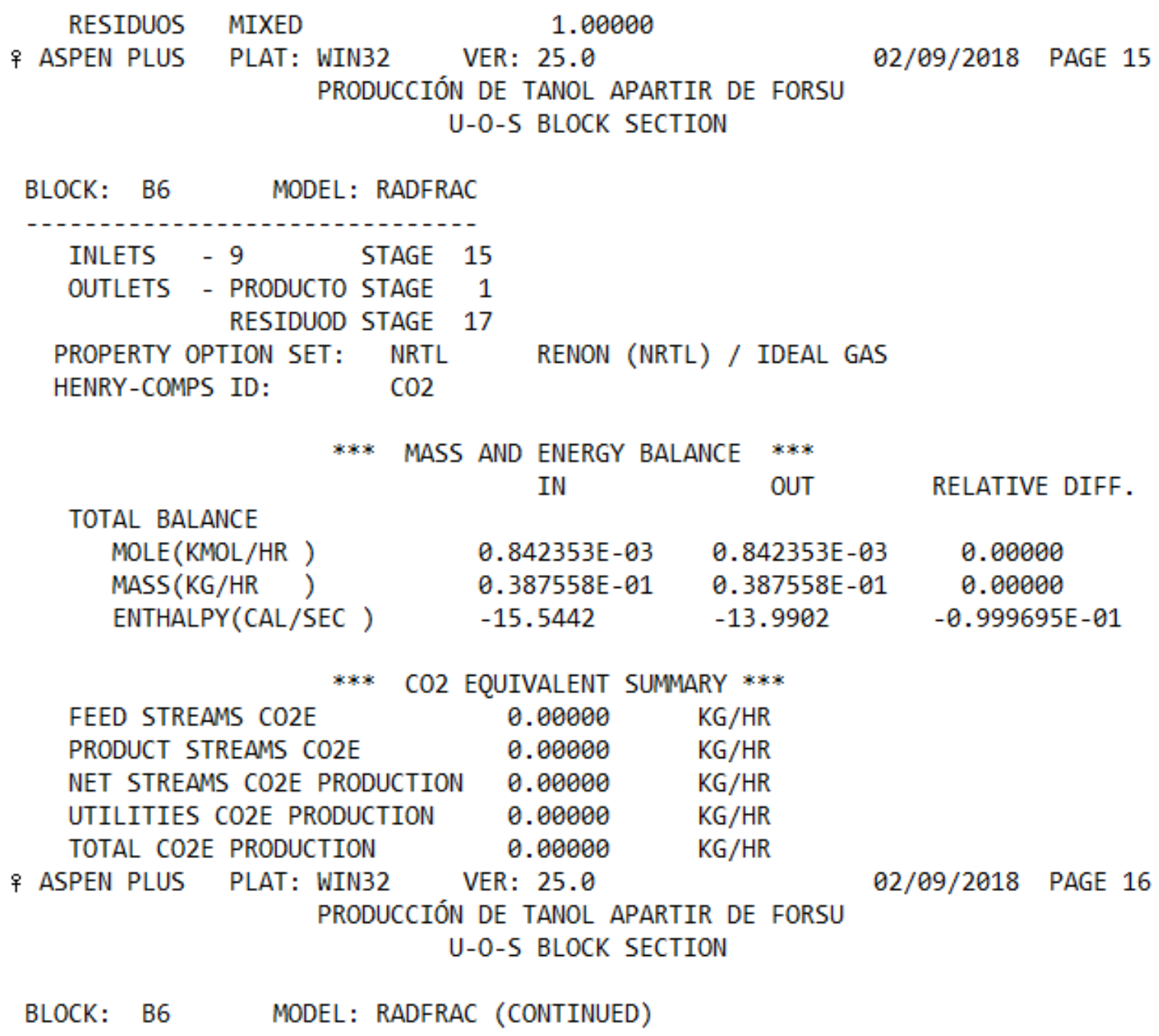




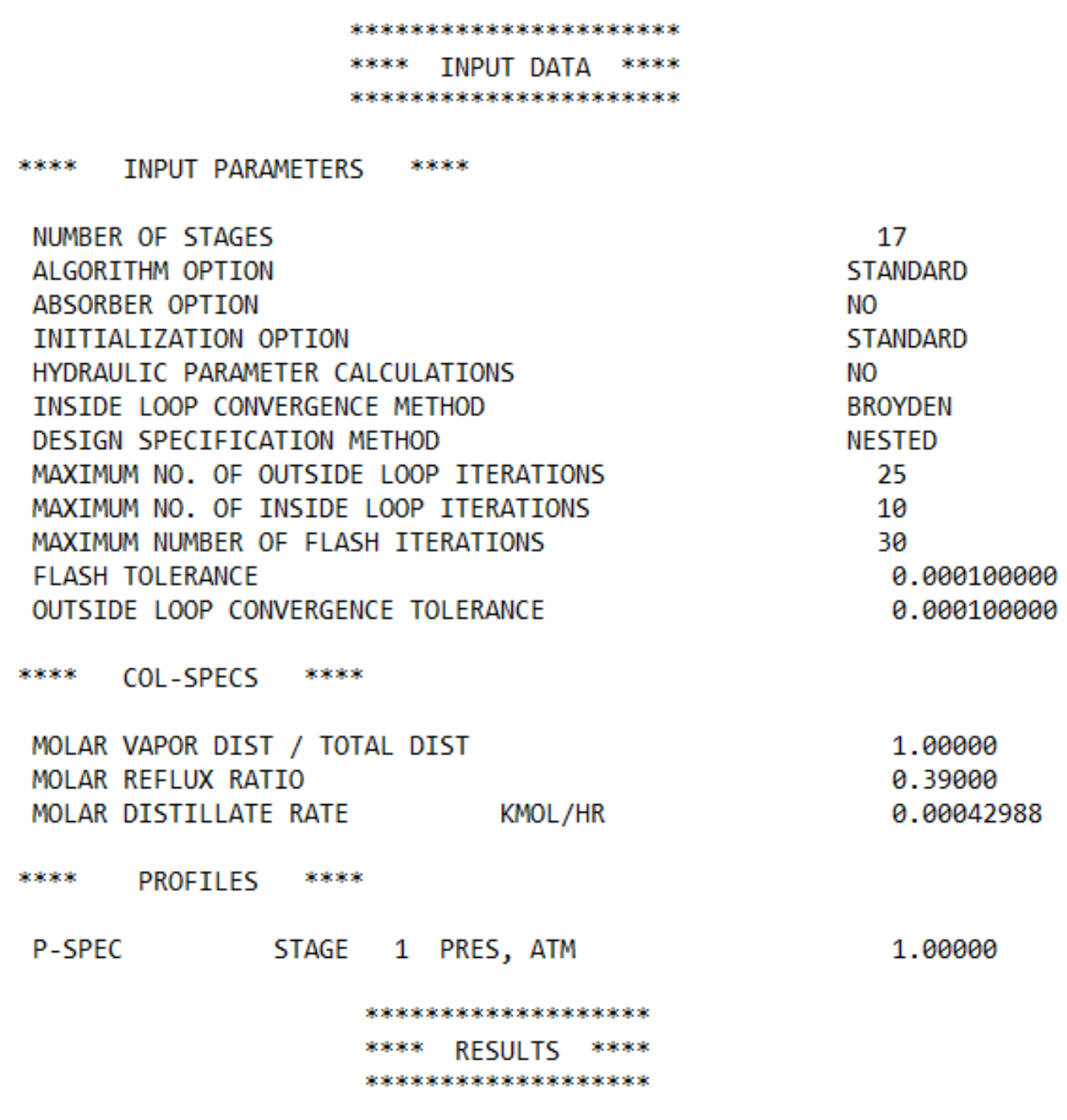

Anexos: Análisis energético y ambiental de la producción de bio-etanol a partir de la FORSU. T. P. Mendoza Tinoco 


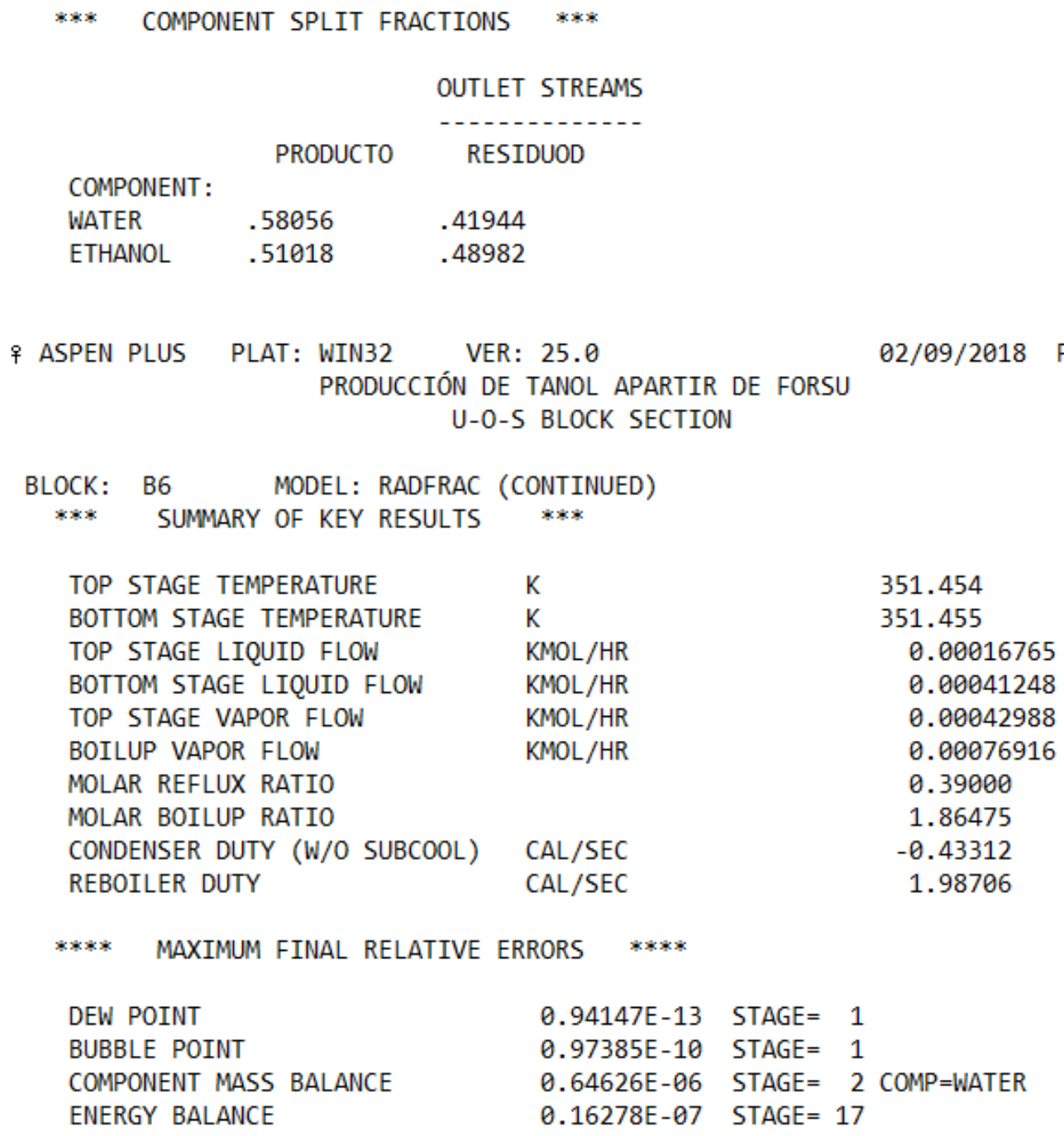

DEW POINT BUBBLE POINT COMPONENT MASS BALANCE ENERGY BALANCE
$0.94147 \mathrm{E}-13 \quad \mathrm{STAGE}=1$
$0.97385 \mathrm{E}-10 \quad \mathrm{STAGE}=1$
$0.64626 \mathrm{E}-06 \quad \mathrm{STAGE}=2 \mathrm{COMP}=$ WATER
$0.16278 \mathrm{E}-07 \quad \mathrm{STAGE}=17$ 


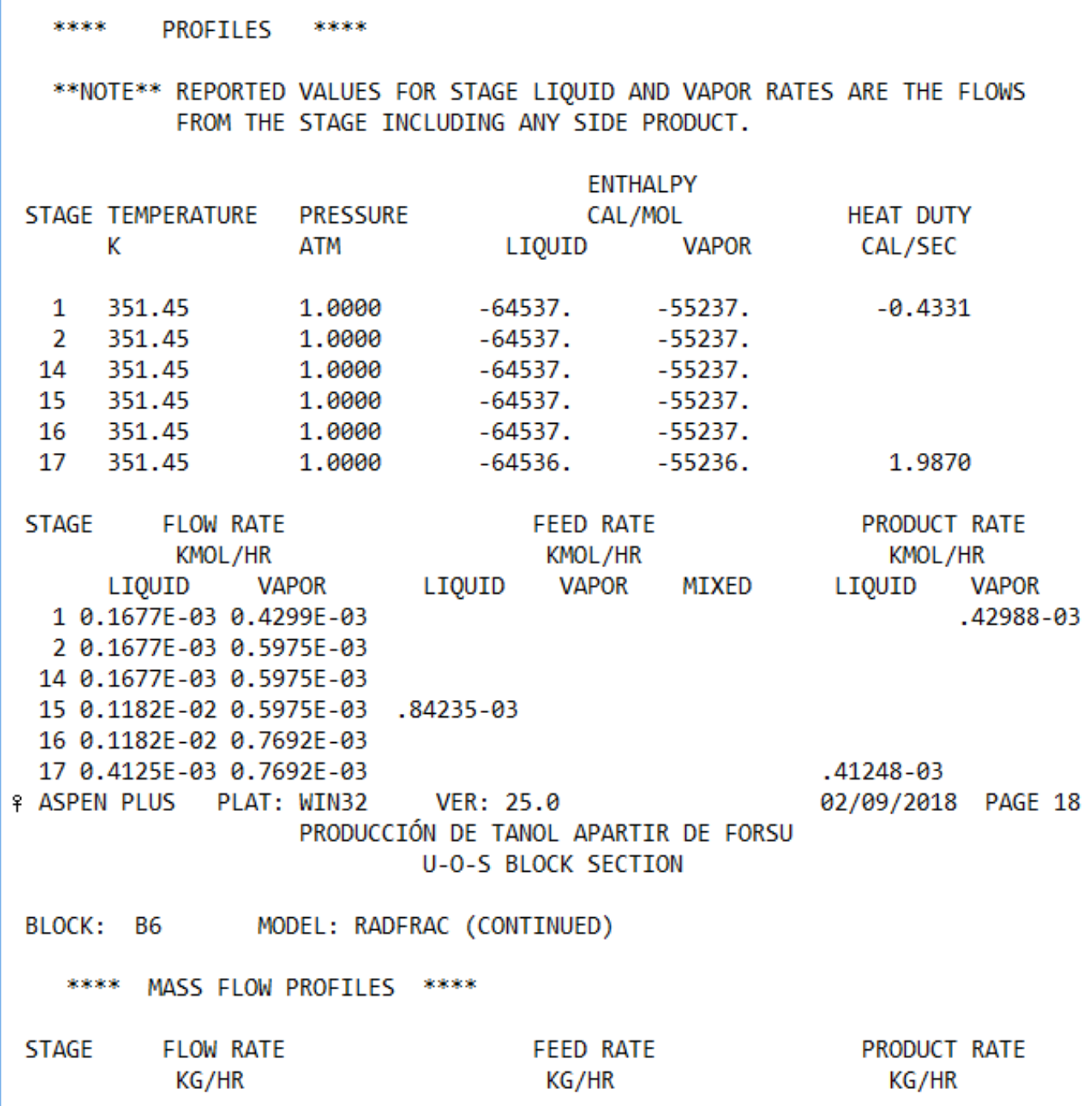

Anexos: Análisis energético y ambiental de la producción de bio-etanol a partir de la FORSU. T. 


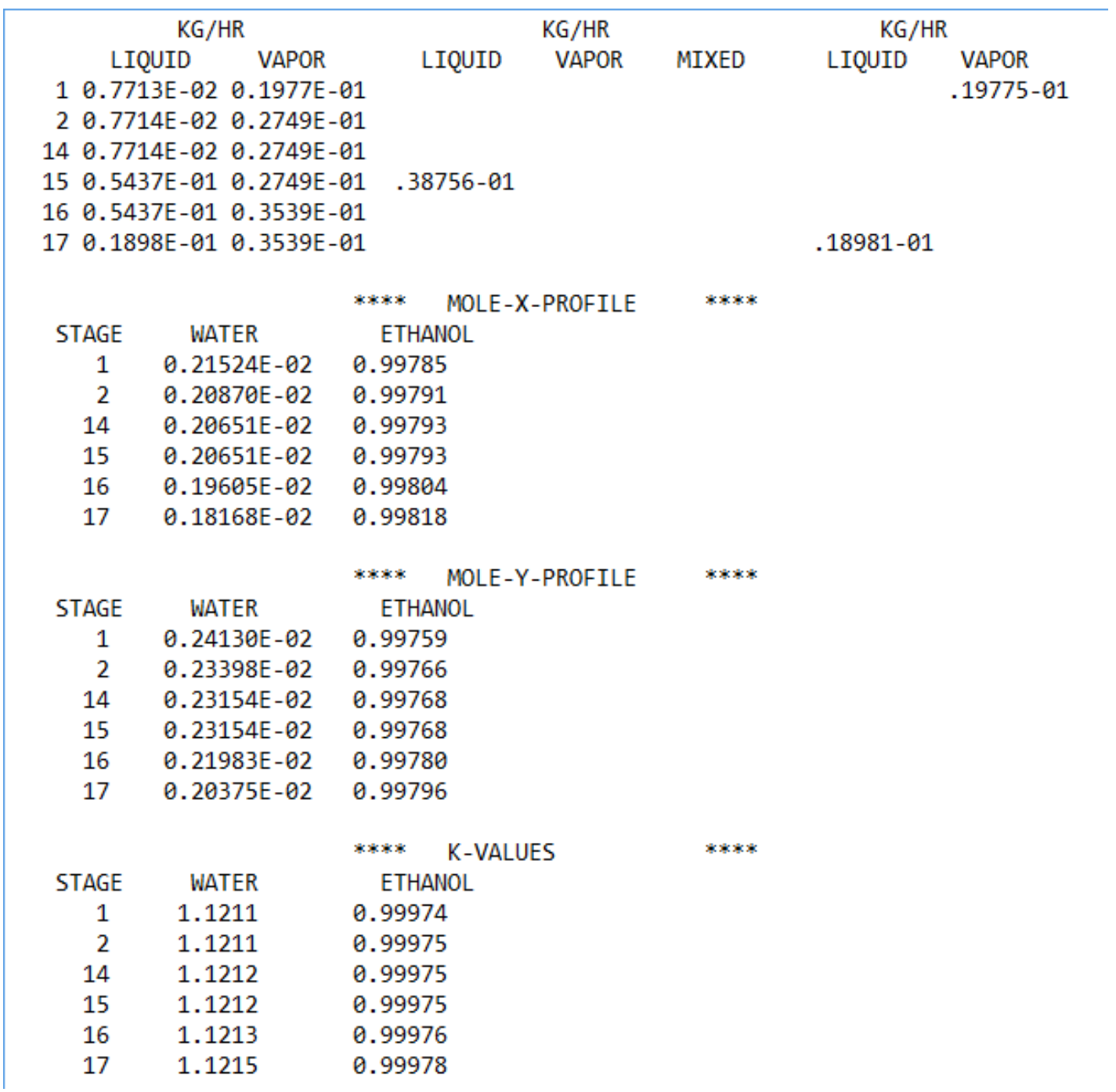

Anexos: Análisis energético y ambiental de la producción de bio-etanol a partir de la FORSU. T. 


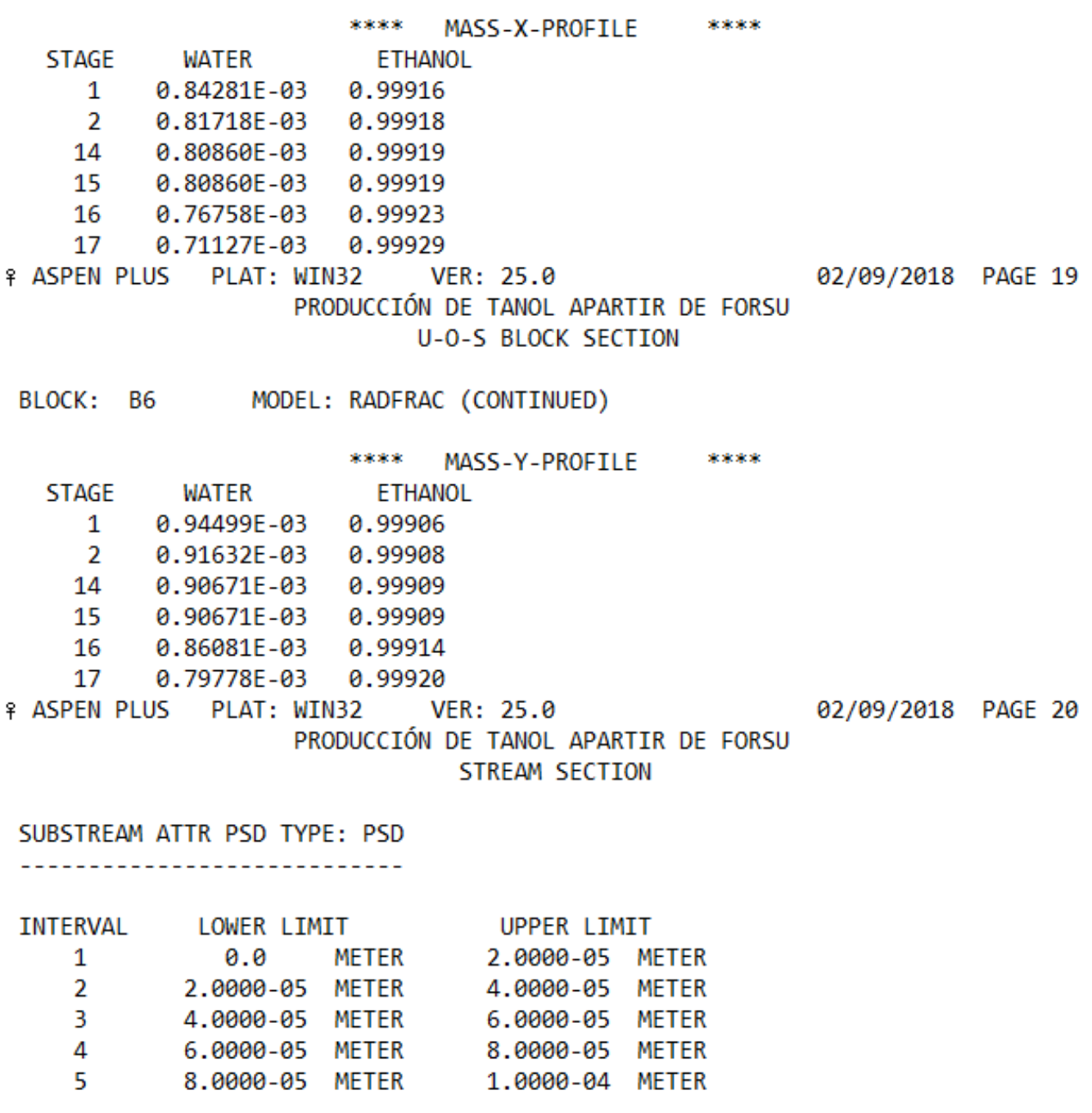




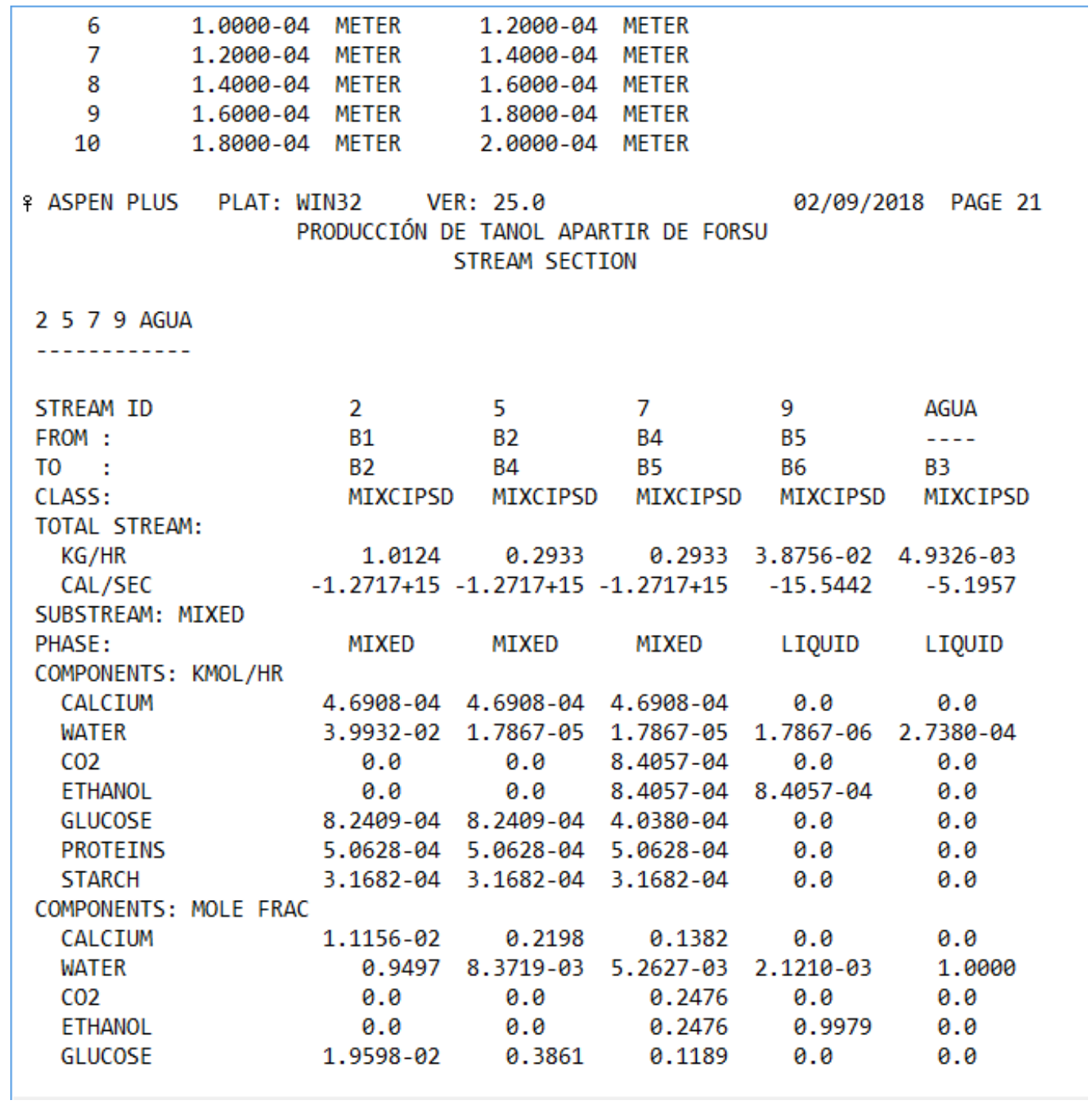

Anexos: Análisis energético y ambiental de la producción de bio-etanol a partir de la FORSU. T. 


\begin{tabular}{|lrrrrr} 
CAL/MOL & $-1.0888+17$ & $-2.1452+18$ & $-1.3485+18$ & $-6.6432+04$ & $-6.8314+04$ \\
CAL/GM & $-4.5220+15$ & $-1.5606+16$ & $-1.5606+16$ & -1443.8907 & -3792.0088 \\
CAL/SEC & $-1.2717+15$ & $-1.2717+15$ & $-1.2717+15$ & -15.5442 & -5.1957 \\
ENTROPY: & & & & & \\
CAL/MOL-K & $-3.6822+14$ & $-7.2548+15$ & $-4.5605+15$ & -83.1575 & -39.1242 \\
CAL/GM-K & $-1.5293+13$ & $-5.2779+13$ & $-5.2779+13$ & -1.8074 & -2.1717 \\
DENSITY: & & & & & \\
MOL/CC & $3.5505-02$ & $3.4687-03$ & $1.6149-04$ & $1.7483-02$ & $5.5440-02$ \\
GM/CC & 0.8549 & 0.4768 & $1.3954-02$ & 0.8044 & 0.9988 \\
AVG MW & 24.0774 & 137.4551 & 86.4062 & 46.0089 & 18.0153
\end{tabular}

TOTAL STREAM PROPERTIES:

\begin{tabular}{|c|c|c|c|c|c|}
\hline \multicolumn{6}{|l|}{$* * * \quad$ ALL P } \\
\hline \multicolumn{6}{|l|}{ MASSFLOW KG/HR } \\
\hline CALCIUM & $2.6305-02$ & $2.6305-02$ & $2.6305-02$ & 0.0 & 0.0 \\
\hline WATER & 0.7194 & $3.2187-04$ & $3.2187-04$ & $3.2187-05$ & $4.9326-03$ \\
\hline $\mathrm{CO} 2$ & 0.0 & 0.0 & $3.6993-02$ & 0.0 & 0.0 \\
\hline ETHANOL & 0.0 & 0.0 & $3.8724-02$ & $3.8724-02$ & 0.0 \\
\hline GLUCOSE & 0.1485 & 0.1485 & $7.2747-02$ & 0.0 & 0.0 \\
\hline PROTEINS & $6.6888-02$ & $6.6888-02$ & $6.6888-02$ & 0.0 & 0.0 \\
\hline STARCH & $5.1370-02$ & $5.1370-02$ & $5.1370-02$ & 0.0 & 0.0 \\
\hline \multicolumn{6}{|l|}{ MASSFRAC } \\
\hline CALCIUM & $2.5982-02$ & $8.9671-02$ & $8.9671-02$ & 0.0 & 0.0 \\
\hline WATER & 0.7106 & $1.0972-03$ & $1.0972-03$ & $8.3052-04$ & 1.0000 \\
\hline $\mathrm{CO} 2$ & 0.0 & 0.0 & 0.1261 & 0.0 & 0.0 \\
\hline ETHANOL & 0.0 & 0.0 & 0.1320 & 0.9992 & 0.0 \\
\hline GLUCOSE & 0.1466 & 0.5061 & 0.2480 & 0.0 & 0.0 \\
\hline PROTEINS & $6.6068-02$ & 0.2280 & 0.2280 & 0.0 & 0.0 \\
\hline STARCH & $5.0740-02$ & 0.1751 & 0.1751 & 0.0 & 0.0 \\
\hline \multicolumn{6}{|l|}{ TLVCONC $\quad \mathrm{GM} / \mathrm{CC}$} \\
\hline CALCIUM & $2.3763-02$ & $4.8900-02$ & MISSING & MISSING & MISSING \\
\hline WATER & 0.6499 & $5.9835-04$ & MISSING & $6.6806-04$ & 0.9988 \\
\hline $\mathrm{CO} 2$ & MISSING & MISSING & MISSING & MISSING & MISSING \\
\hline ETHANOL & MISSING & MISSING & MISSING & 0.8037 & MISSING \\
\hline GLUCOSE & 0.1341 & 0.2760 & MISSING & MISSING & MISSING \\
\hline
\end{tabular}




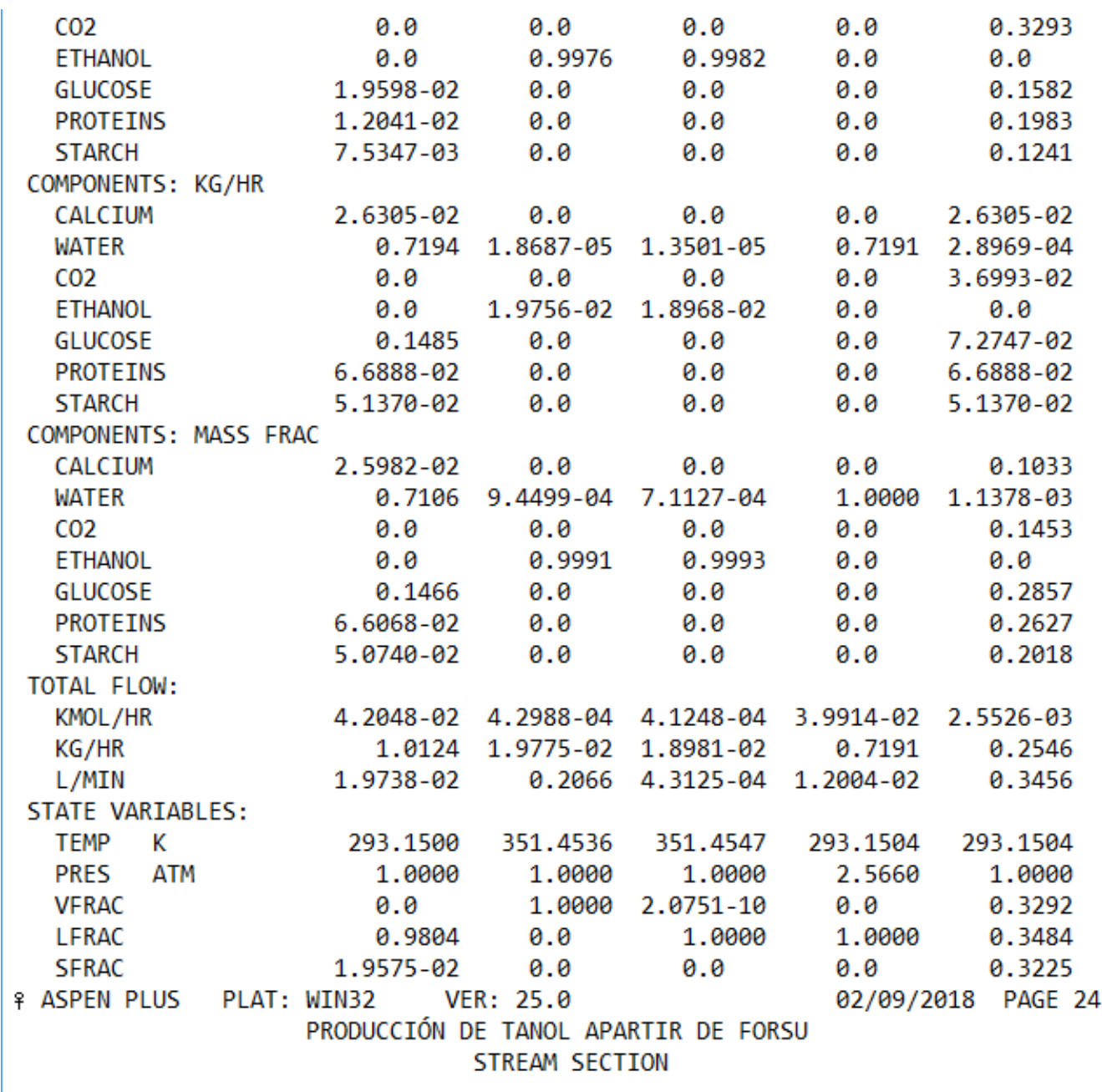

FORSU PRODUCTO RESIDUOD RESIDUOE RESIDUO (CONTINUED)

Anexos: Análisis energético y ambiental de la producción de bio-etanol a partir de la FORSU. T. 


\begin{tabular}{|c|c|c|c|c|c|}
\hline STREAM ID & FORSU & PRODUCTO & RESIDUOD & RESIDUOE & RESIDUOS \\
\hline \multicolumn{6}{|l|}{ ENTHALPY: } \\
\hline $\mathrm{CAL} / \mathrm{MOL}$ & $-1.0889+17$ & $-5.5237+04$ & $-6.4536+04$ & $-6.8357+04$ & $-1.7935+18$ \\
\hline $\mathrm{CAL} / \mathrm{GM}$ & $-4.5223+15$ & -1200.7923 & -1402.4281 & -3794.3729 & $-1.7982+16$ \\
\hline $\mathrm{CAL} / \mathrm{SEC}$ & $-1.2718+15$ & -6.5959 & -7.3943 & -757.8921 & $-1.2717+15$ \\
\hline \multicolumn{6}{|l|}{ ENTROPY: } \\
\hline $\mathrm{CAL} / \mathrm{MOL}-\mathrm{K}$ & $-3.6824+14$ & -50.8940 & -77.3879 & -39.2701 & $-6.0654+15$ \\
\hline $\mathrm{CAL} / \mathrm{GM}-\mathrm{K}$ & $-1.5294+13$ & -1.1064 & -1.6817 & -2.1798 & $-6.0814+13$ \\
\hline \multicolumn{6}{|l|}{ DENSITY: } \\
\hline $\mathrm{MOL} / \mathrm{CC}$ & $3.5505-02$ & $3.4675-05$ & $1.5941-02$ & $5.5420-02$ & $1.2309-04$ \\
\hline $\mathrm{GM} / \mathrm{CC}$ & 0.8549 & $1.5951-03$ & 0.7336 & 0.9984 & $1.2276-02$ \\
\hline AVG MW & 24.0774 & 46.0007 & 46.0174 & 18.0153 & 99.7371 \\
\hline \multicolumn{6}{|c|}{ TOTAL STREAM PROPERTIES: } \\
\hline *** ALL PHASES & & & & & \\
\hline \multicolumn{6}{|l|}{ MASSFLOW KG/HR } \\
\hline CALCIUM & $2.6305-02$ & 0.0 & 0.0 & 0.0 & $2.6305-02$ \\
\hline WATER & 0.7194 & $1.8687-05$ & $1.3501-05$ & 0.7191 & $2.8969-04$ \\
\hline $\mathrm{CO} 2$ & 0.0 & 0.0 & 0.0 & 0.0 & $3.6993-02$ \\
\hline ETHANOL & 0.0 & $1.9756-02$ & $1.8968-02$ & 0.0 & 0.0 \\
\hline GLUCOSE & 0.1485 & 0.0 & 0.0 & 0.0 & $7.2747-02$ \\
\hline PROTEINS & $6.6888-02$ & 0.0 & 0.0 & 0.0 & $6.6888-02$ \\
\hline STARCH & $5.1370-02$ & 0.0 & 0.0 & 0.0 & $5.1370-02$ \\
\hline \multicolumn{6}{|l|}{ MASSFRAC } \\
\hline CALCIUM & $2.5982-02$ & 0.0 & 0.0 & 0.0 & 0.1033 \\
\hline WATER & 0.7106 & $9.4499-04$ & $7.1127-04$ & 1.0000 & $1.1378-03$ \\
\hline $\mathrm{CO} 2$ & 0.0 & 0.0 & 0.0 & 0.0 & 0.1453 \\
\hline ETHANOL & 0.0 & 0.9991 & 0.9993 & 0.0 & 0.0 \\
\hline GLUCOSE & 0.1466 & 0.0 & 0.0 & 0.0 & 0.2857 \\
\hline PROTEINS & $6.6068-02$ & 0.0 & 0.0 & 0.0 & 0.2627 \\
\hline STARCH & $5.0740-02$ & 0.0 & 0.0 & 0.0 & 0.2018 \\
\hline \multicolumn{6}{|l|}{ TLVCONC GM/CC } \\
\hline CALCIUM & $2.3763-02$ & MISSING & MISSING & MISSING & MISSING \\
\hline
\end{tabular}

Anexos: Análisis energético y ambiental de la producción de bio-etanol a partir de la FORSU. T. 


\begin{tabular}{|c|c|c|c|c|c|c|}
\hline & WATER & 0.6499 & MISSING & MISSING & 0.9984 & MISSING \\
\hline & $\mathrm{CO} 2$ & MISSING & MISSING & MISSING & MISSING & MISSING \\
\hline & ETHANOL & MISSING & MISSING & MISSING & MISSING & MISSING \\
\hline & GLUCOSE & 0.1341 & MISSING & MISSING & MISSING & MISSING \\
\hline & PROTEINS & $6.0424-02$ & MISSING & MISSING & MISSING & MISSING \\
\hline & STARCH & $4.6406-02$ & MISSING & MISSING & MISSING & MISSING \\
\hline & CALCIUM & $2.3763-02$ & MISSING & MISSING & MISSING & MISSING \\
\hline & WATER & 0.6499 & MISSING & MISSING & 0.9984 & MISSING \\
\hline & $\mathrm{CO} 2$ & MISSING & MISSING & MISSING & MISSING & MISSING \\
\hline & ETHANOL & MISSING & MISSING & MISSING & MISSING & MISSING \\
\hline & GLUCOSE & 0.1341 & MISSING & MISSING & MISSING & MISSING \\
\hline & PROTEINS & $6.0424-02$ & MISSING & MISSING & MISSING & MISSING \\
\hline & STARCH & $4.6406-02$ & MISSING & MISSING & MISSING & MISSING \\
\hline & MASSSFRA & 0.1168 & 0.0 & 0.0 & 0.0 & 0.4645 \\
\hline & VOLFLMX L/MIN & $1.9738-02$ & 0.2066 & $4.3601-04$ & $1.2004-02$ & 0.3456 \\
\hline & RHOMX GM/CC & 0.8549 & $1.5951-03$ & 0.7256 & $0.9984 \quad 1$ & $1.2276-02$ \\
\hline & $\mathrm{GM} / \mathrm{CC}$ & 0.8549 & $1.5951-03$ & 0.7256 & $0.9984 \quad 1$ & $1.2276-02$ \\
\hline & ASPEN PLUS PLAT: & $\begin{array}{l}\text { WIN32 VE } \\
\text { PRODUCCIÓN D }\end{array}$ & $\begin{array}{l}\text { R: } 25.0 \\
\text { E TANOL APA } \\
\text { STREAM SECT }\end{array}$ & $\begin{array}{l}\text { RTIR DE FORSL } \\
\text { ION }\end{array}$ & SU & 18 PAGE 25 \\
\hline \multicolumn{7}{|c|}{ VAPOR } \\
\hline \multicolumn{7}{|c|}{$-\ldots$} \\
\hline & STREAM ID & VAPOR & & & & \\
\hline & FROM : & B3 & & & & \\
\hline & TO : &.-- & & & & \\
\hline & CLASS: & MIXCIPSD & & & & \\
\hline \multicolumn{7}{|c|}{ TOTAL STREAM: } \\
\hline & $\mathrm{KG} / \mathrm{HR}$ & $4.9326-03$ & & & & \\
\hline & $\mathrm{CAL} / \mathrm{SEC}$ & -4.3225 & & & & \\
\hline \multicolumn{7}{|c|}{ SUBSTREAM: MIXED } \\
\hline & PHASE : & VAPOR & & & & \\
\hline \multicolumn{7}{|c|}{ COMPONENTS: KMOL/HR } \\
\hline & CALCIUM & 0.0 & & & & \\
\hline & WATER & $2.7380-04$ & & & & \\
\hline
\end{tabular}

Anexos: Análisis energético y ambiental de la producción de bio-etanol a partir de la FORSU. T. P. Mendoza Tinoco 


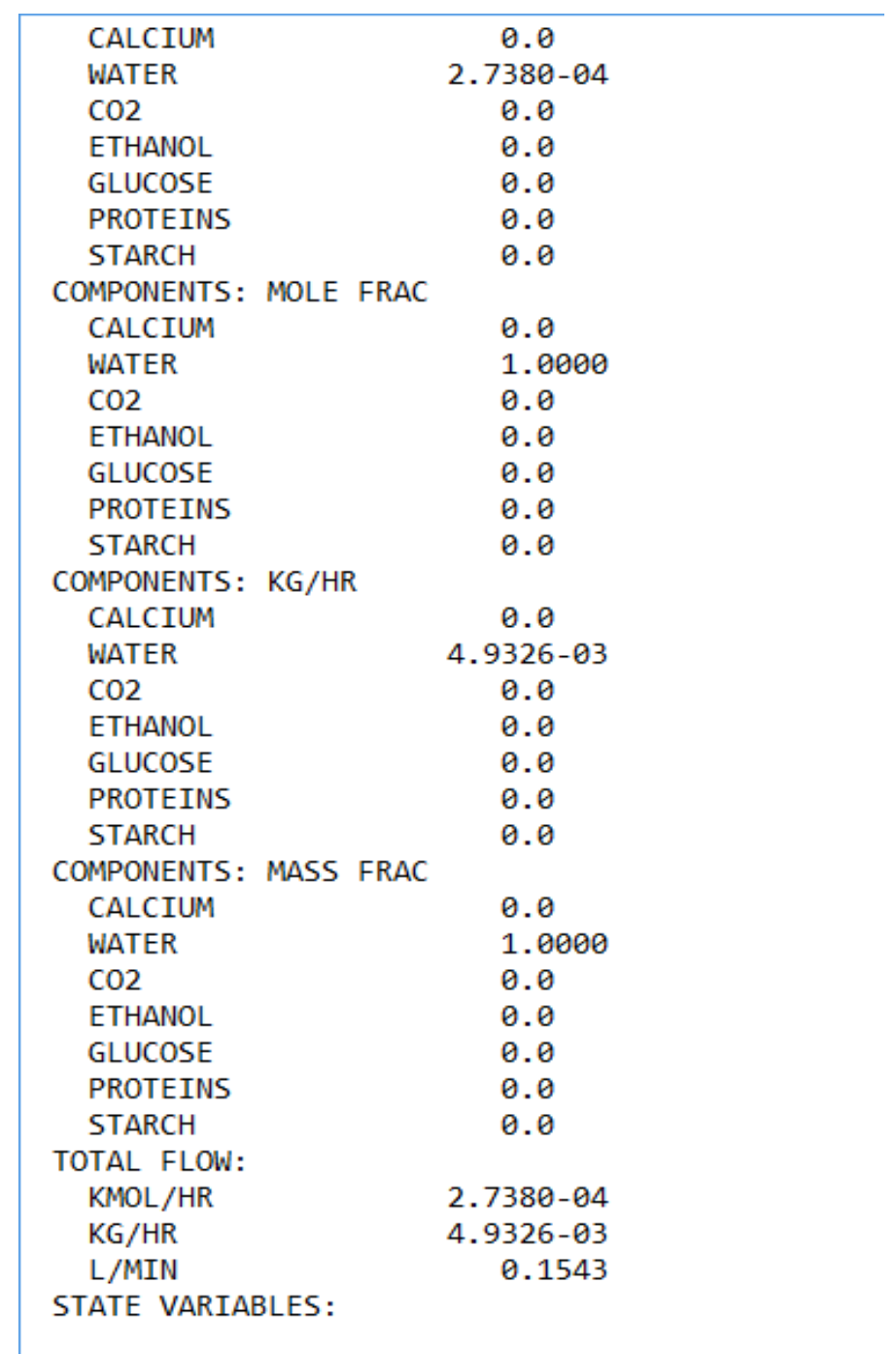

Anexos: Análisis energético y ambiental de la producción de bio-etanol a partir de la FORSU. T. P. Mendoza Tinoco 


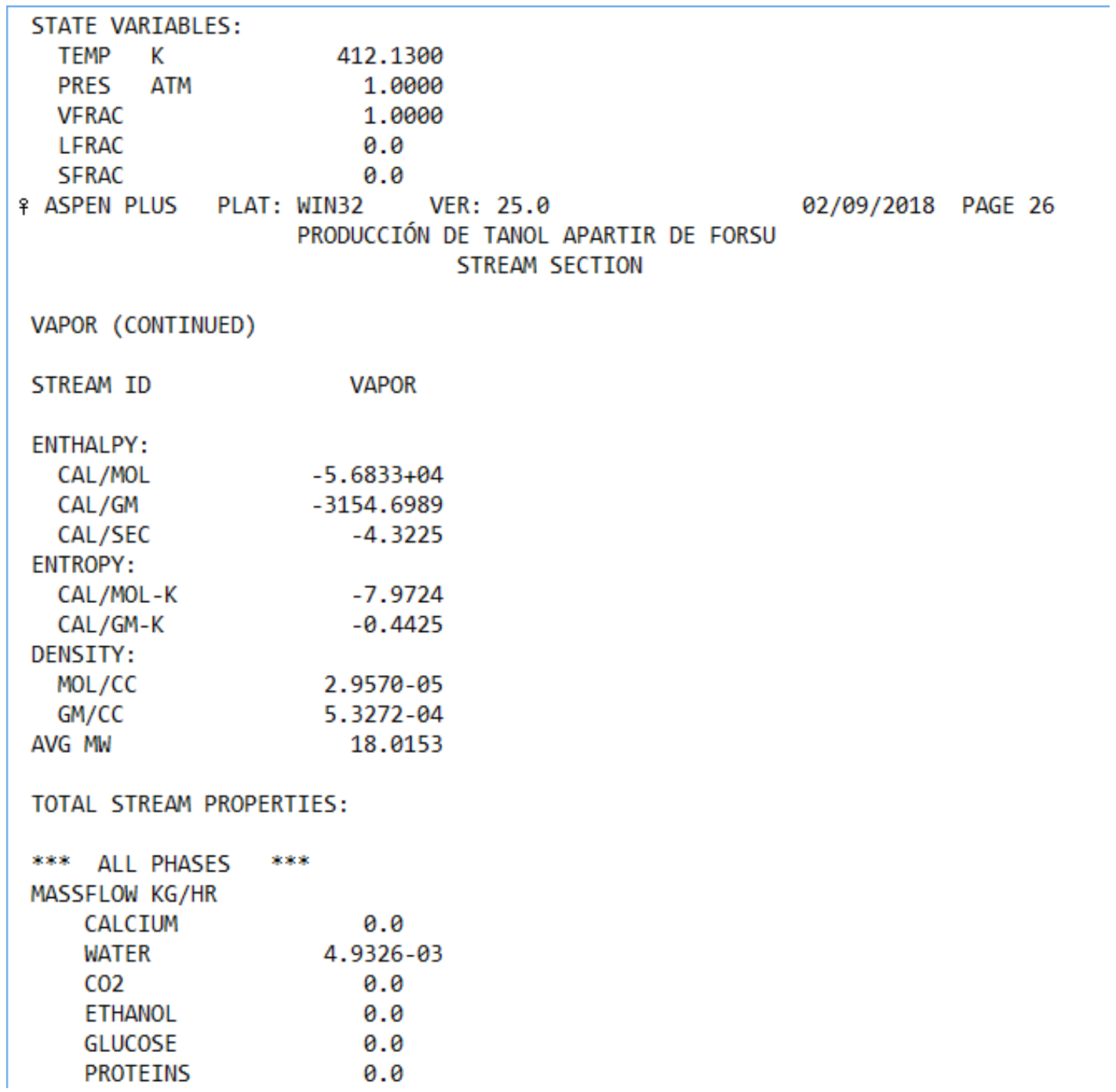

Anexos: Análisis energético y ambiental de la producción de bio-etanol a partir de la FORSU. T. P. Mendoza Tinoco 


\begin{tabular}{|ll}
\hline PROTEINS & 0.0 \\
STARCH & 0.0 \\
MASSFRAC & \\
CALCIUM & 0.0 \\
WATER & 1.0000 \\
CO2 & 0.0 \\
ETHANOL & 0.0 \\
GLUCOSE & 0.0 \\
PROTEINS & 0.0 \\
STARCH & 0.0 \\
TLVCONC GM/CC & MISSING \\
CALCIUM & MISSING \\
WATER & MISSING \\
CO2 & MISSING \\
ETHANOL & MISSING \\
GLUCOSE & MISSING \\
PROTEINS & MISSING \\
STARCH & MISSING \\
CALCIUM & MISSING \\
WATER & MISSING \\
CO2 & MISSING \\
ETHANOL & MISSING \\
GLUCOSE & MISSING \\
PROTEINS & MISSING \\
STARCH & 0.0 \\
MASSSFRA & 0.1543 \\
VOLFLMX L/MIN & $5.3272-04$ \\
RHOMX GM/CC & $5.3272-04$ \\
GM/CC & PRODUCCIÓN DE TANOL APARTIR DE FORSU \\
O PSPEN PLUS PLAT: & WIN32 STREAM SECTION \\
&
\end{tabular}

Anexos: Análisis energético y ambiental de la producción de bio-etanol a partir de la FORSU. T. P. Mendoza Tinoco 
STREAM ID

FROM :

TO :

CLASS:
11

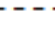

B4

HEAT

STREAM ATTRIBUTES:

HEAT

Q CAL/SEC $\quad 5.5556-02$

$\begin{array}{lll}\text { TBEG } & \mathrm{K} & 293.1500\end{array}$

TEND K 35.0000

+ ASPEN PLUS PLAT: WIN32 VER: $25.0 \quad 02 / 09 / 2018$ PAGE 28

PRODUCCIÓN DE TANOL APARTIR DE FORSU

PROBLEM STATUS SECTION

\section{BLOCK STATUS}

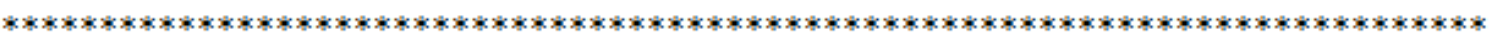

*

* Calculations were completed normally

* All Unit Operation blocks were completed normally

* All streams were flashed normally

*

Anexos: Análisis energético y ambiental de la producción de bio-etanol a partir de la FORSU. T. P. Mendoza Tinoco 


\section{C Anexo C. Resumen de resultados de impactos ambientales de la planta piloto (WAR GUI).}

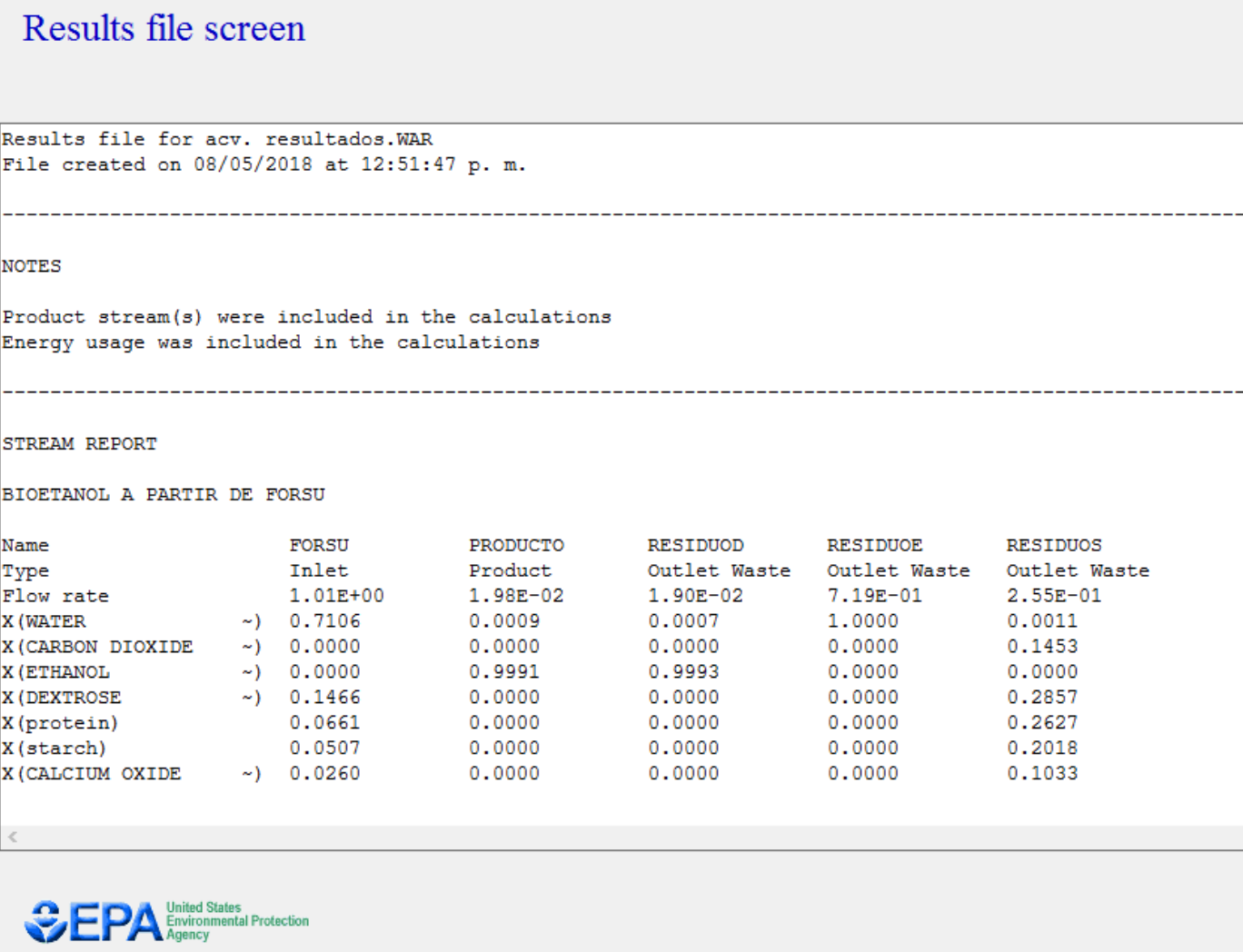

Results file screen

\begin{tabular}{|c|c|c|c|c|}
\hline \multicolumn{3}{|l|}{ Name } & \multicolumn{2}{|l|}{ VAPOR } \\
\hline \multicolumn{3}{|l|}{ Type } & \multicolumn{2}{|l|}{ Inlet } \\
\hline \multicolumn{3}{|l|}{ Flow rate } & \multicolumn{2}{|l|}{$4.93 \mathrm{E}-03$} \\
\hline \multicolumn{3}{|l|}{$\mathrm{x}$ (WATER } & \multicolumn{2}{|l|}{1.0000} \\
\hline \multicolumn{2}{|c|}{$X$ (CARBON DIOXIDE } & $\sim)$ & \multicolumn{2}{|l|}{0.0000} \\
\hline \multicolumn{2}{|l|}{$\mathrm{X}$ (ETHANOL } & $\sim)$ & \\
\hline \multicolumn{2}{|l|}{ X (DEXTROSE } & $\sim)$ & \multirow{2}{*}{\multicolumn{2}{|c|}{$\begin{array}{l}0.0000 \\
0.0000\end{array}$}} \\
\hline \multicolumn{2}{|l|}{$x$ (protein) } & & & \multirow{2}{*}{$\begin{array}{l}0.0000 \\
0.0000\end{array}$} \\
\hline \multicolumn{2}{|l|}{ X (starch) } & & 0.0000 & \\
\hline \multicolumn{2}{|c|}{$\mathrm{X}$ (CALCIUM OXIDE } & $\sim)$ & \multicolumn{2}{|l|}{0.0000} \\
\hline \multicolumn{5}{|c|}{ ENERGY USAGE REPORT } \\
\hline \multirow{2}{*}{$\begin{array}{l}\text { Case } \\
\text { BIOETANOL }\end{array}$} & \multirow{2}{*}{\multicolumn{3}{|c|}{ Energy Usage $(\mathrm{MJ} / \mathrm{hr})$}} & Fuel Type \\
\hline & & & & Oil \\
\hline
\end{tabular}

\section{BEPA}

Anexos: Análisis energético y ambiental de la producción de bio-etanol a partir de la FORSU. T. 
Results file screen

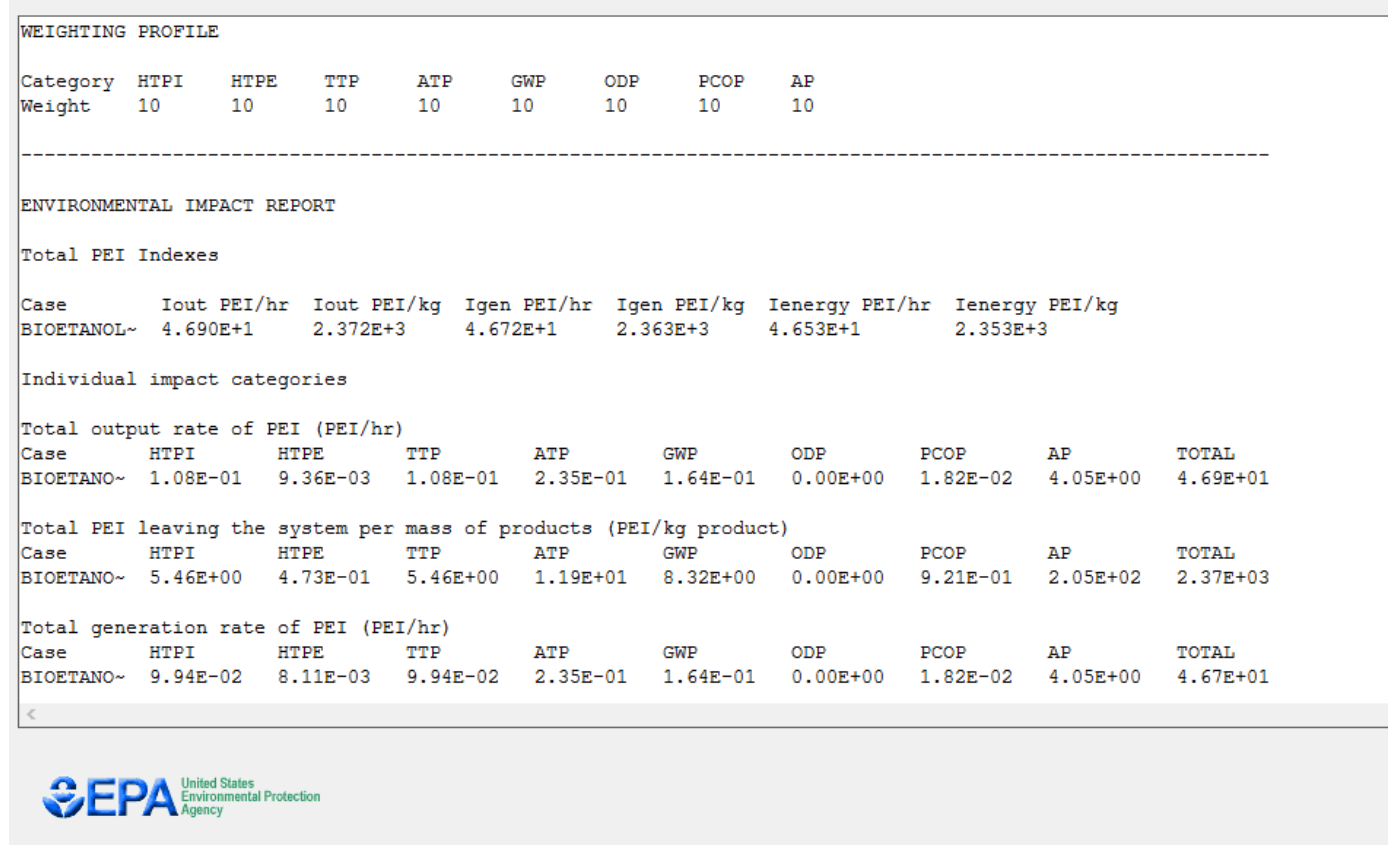

\section{Results file screen}

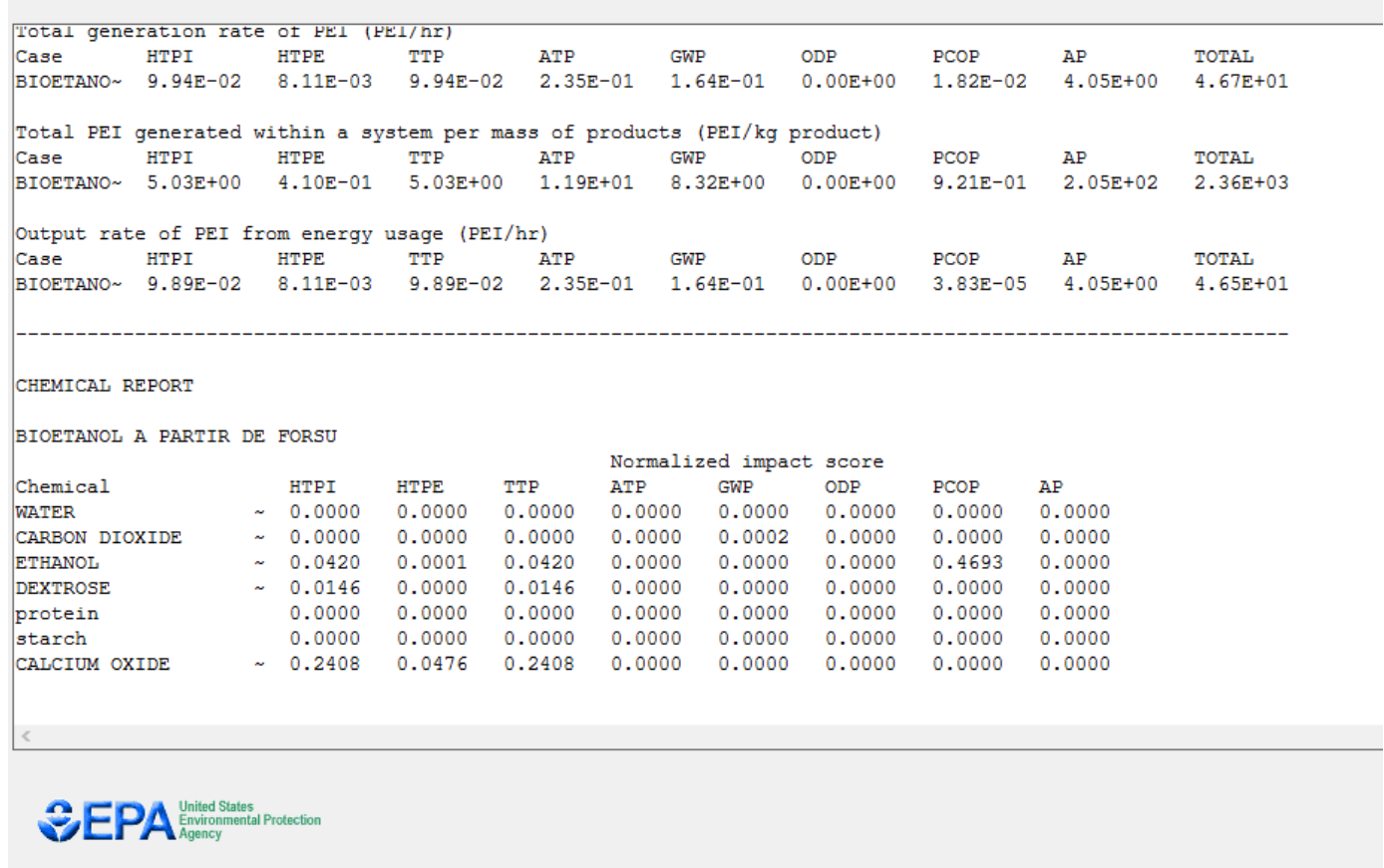


9. D Anexo D. Resumen de resultados de impactos ambientales de la planta de compostaje de Bordo Poniente (WAR GUI)

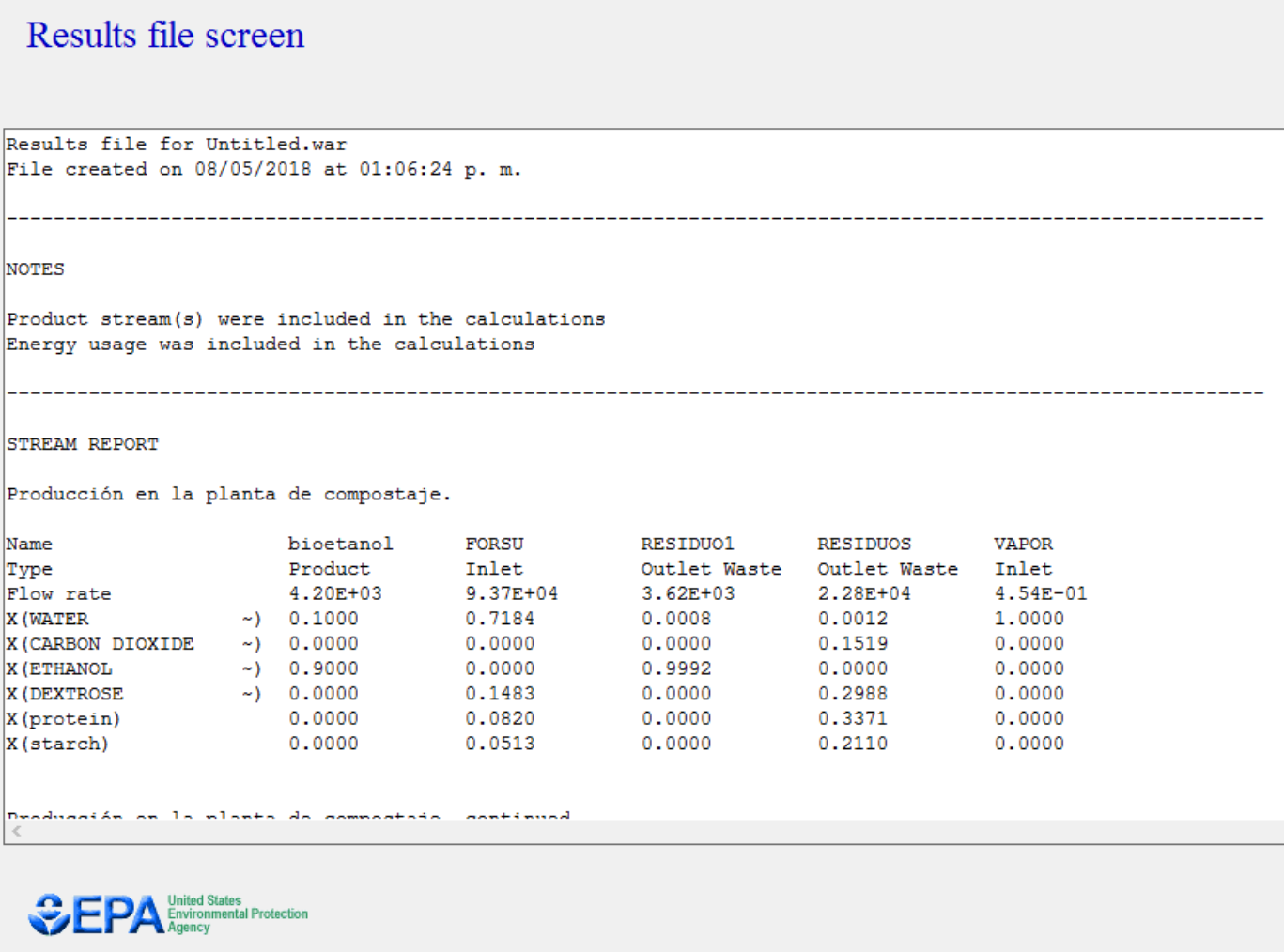

Anexos: Análisis energético y ambiental de la producción de bio-etanol a partir de la FORSU. T. 
Results file screen

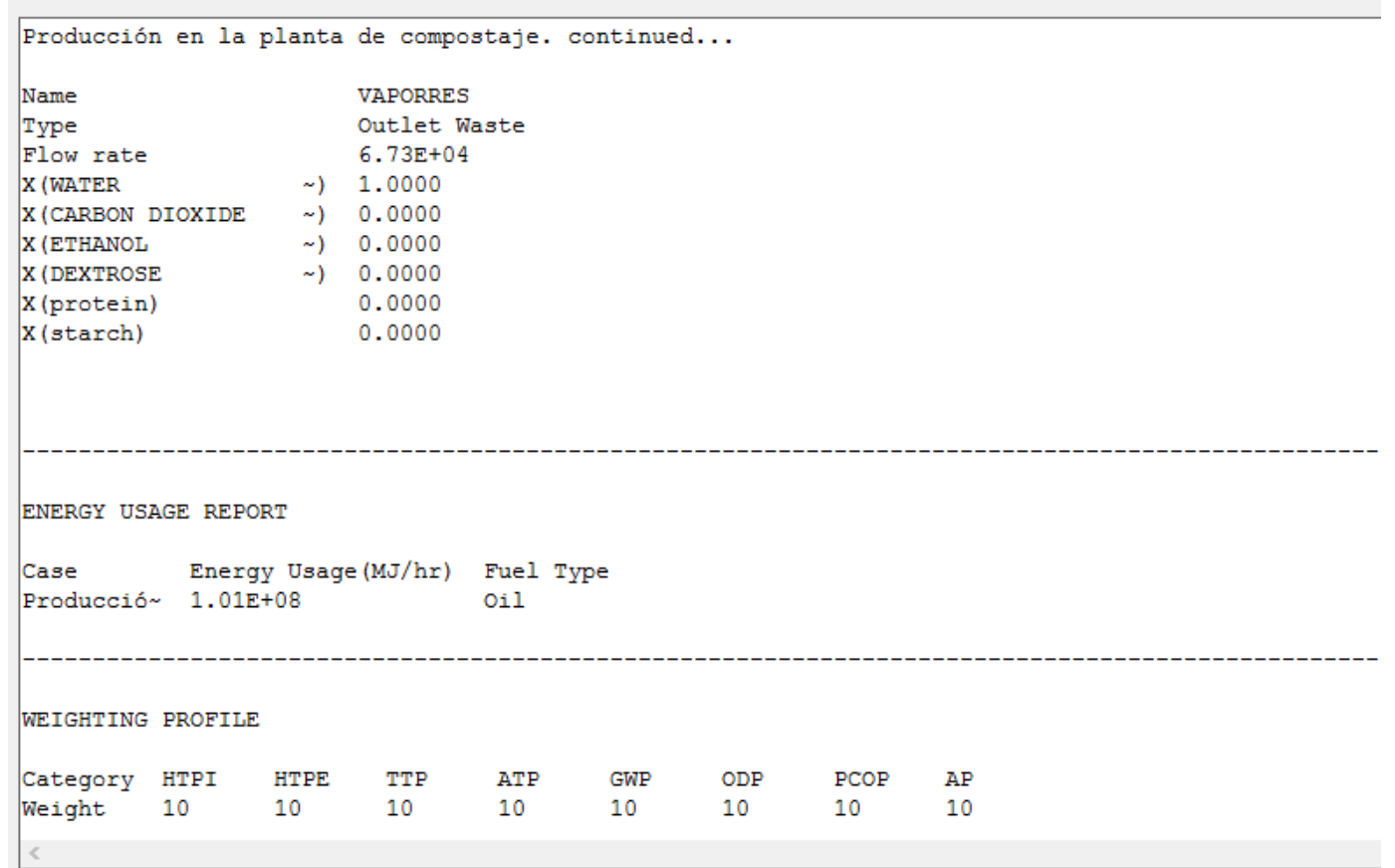

\section{BEPA}

Anexos: Análisis energético y ambiental de la producción de bio-etanol a partir de la FORSU. T. 
Results file screen

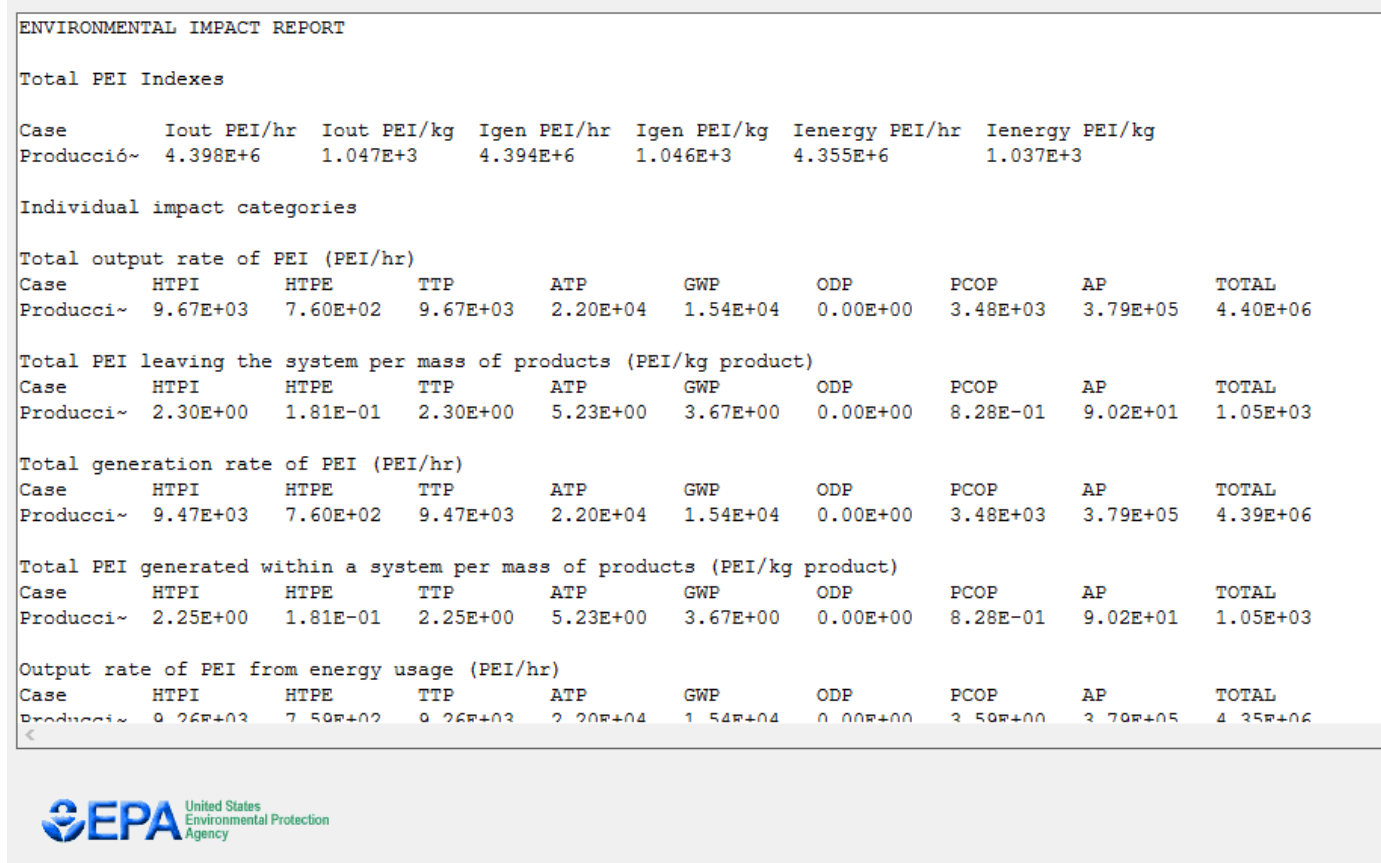

Results file screen

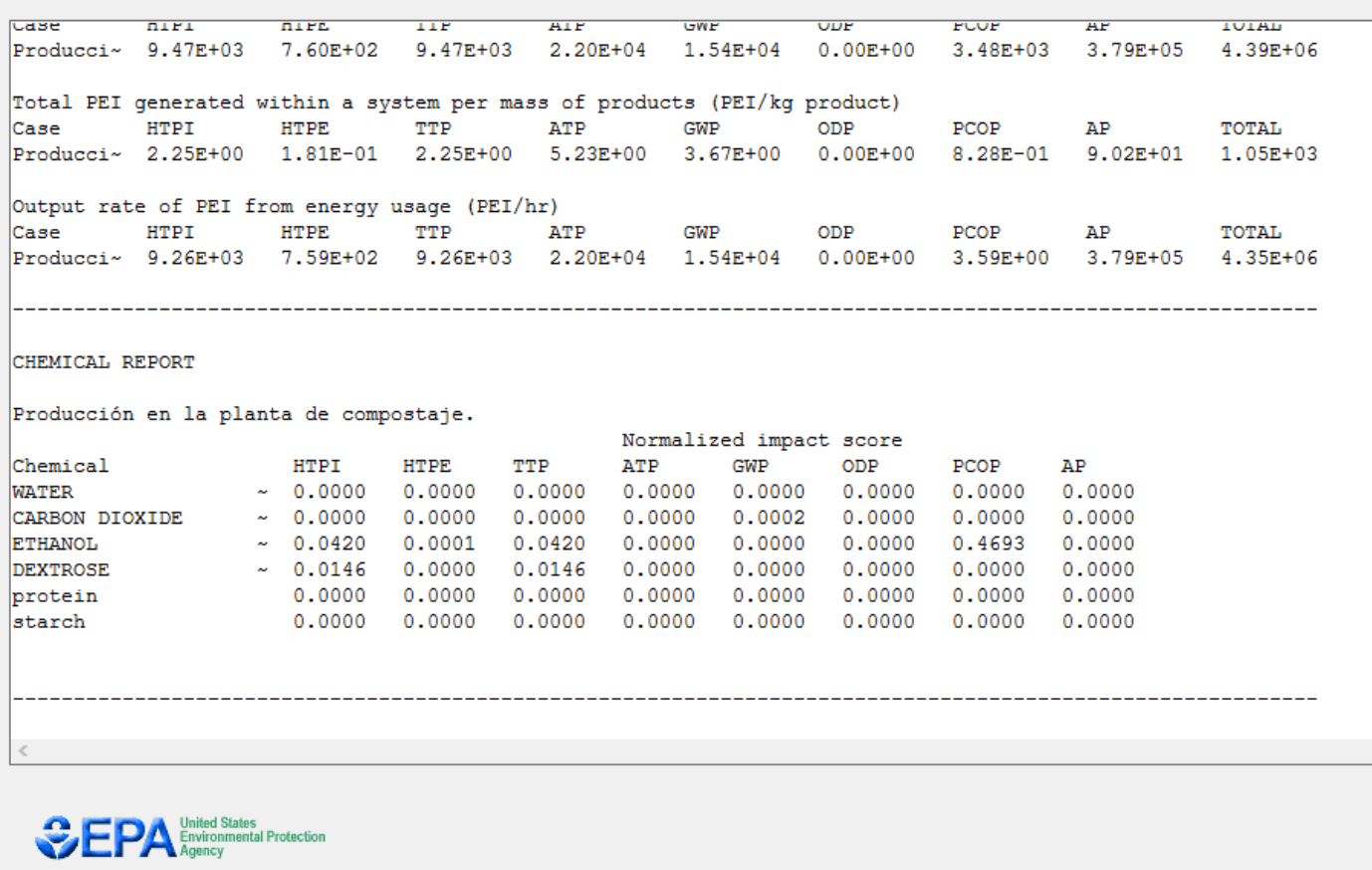

Anexos: Análisis energético y ambiental de la producción de bio-etanol a partir de la FORSU. T. 


\title{
9. E Anexo E. Tasa de retorno energético de la producción de bio-etanol a partir de la fracción orgánica de los residuos sólidos urbanos.
}

\section{TASA DE RETORNO ENERGÉTICO DE LA PRODUCCIÓN DE BIO-ETANOL A PARTIR DE LA FRACCIÓN ORGÁNICA DE LOS RESIDUOS SÓLIDOS URBANOS}

\author{
Mendoza-Tinoco, T. P., Estrada-Martínez, R., Hernandez-Gamez, L. y Saucedo-Castañeda, G. \\ Universidad Autónoma Metropolitana, Unidad Iztapalapa, Ciudad de México, México. CP 09340 \\ Departamento de Ciencias Básicas e Ingeniería y Ciencias Biológicas y de la Salud \\ taniamt91@outlook.com; saucedo@xanum.uam.mx
}

Palabras clave: Análisis energético, Bio-etanol, FORSU.

\section{Introducción}

Actualmente, la producción de bio-etanol no es considerada viable energéticamente debido a que no se cuenta con un proceso industrial de bajo requerimiento energético. El uso de maíz y caña de azúcar como materia prima lleva consigo un gasto energético alto comparado con la energía que se puede obtener de ella, ya que su uso implica un proceso agrícola adicional. Una de las alternativas planteadas es el uso de biomasa lignocelulósica, considerada como materia prima de segunda generación, donde se aprovechan los carbohidratos presentes por un proceso de fermentación con levaduras (1). La fracción orgánica de los residuos sólidos urbanos (FORSU) se estudia como una alternativa para la obtención de bio-etanol debido a que son residuos de fácil acceso, abundante, de bajo costo y no implica una etapa agrícola. Por lo que el objetivo planteado fue determinar la relación de la energía invertida en el proceso de producción de bio-etanol a partir de la FORSU y la energía útil generada por el mismo para determinar la tasa de retorno energético (TRE), con el fin de conocer si su uso es energéticamente viable.

\section{Materiales y métodos}

Se determinó el consumo de energía en la producción de bio-etanol a partir de FORSU a nivel piloto por medio de una simulación, con la ayuda del programa Aspen plus 7.3 (Cardona, Sánchez, Montoya, y Quintero, 2005a). Con los datos experimentales obtenidos en la producción de bio-etanol, se consideraron la composición de la materia prima y las condiciones de operación de cada equipo. La composición utilizada en la simulación fue (\%): agua, 70; carbohidratos, 14.45; cenizas, 2.56; almidón, 5 y proteínas, 7.99. Las etapas que se consideraron en el proceso de producción de bio-etanol son: disminución de partícula, explosión a vapor, fermentación y destilación. Se simuló una planta con una capacidad de aprovechar hasta 9 Ton al año de FORSU, con una producción de 430 L de bio-etanol al 90\%. Con los resultados obtenidos de requerimientos energéticos se llevó a cabo el cálculo de la TRE.

\section{Resultados}

En la Tabla 1, se observan los requerimientos energéticos de cada etapa considerada. Se obtuvo un consumo energético total de $0.20 \mathrm{MJ} / \mathrm{h}$. Considerando el poder calorífico del bio-etanol (23. $6 \mathrm{MJ})$, se

Anexos: Análisis energético y ambiental de la producción de bio-etanol a partir de la FORSU. T. P. Mendoza Tinoco 
calculó una energía útil de 10,148 MJ/año (Hammerschlag, 2006b). Al realizar la relación de la energía útil y la energía invertida como se muestra en la ecuación 1, se obtiene una tasa de retorno energético de 1:5, es decir, por cada unidad de energía invertida se obtienen 5 de energía útil, este valor es mayor al reportado para los combustibles líquidos.

Tabla 1. Requerimientos energéticos de la producción de bio-etanol.

\begin{tabular}{cc}
\hline Etapa & $\begin{array}{c}\text { Requerimiento } \\
\text { energético }(\mathrm{MJ} / \mathrm{h})\end{array}$ \\
\hline Disminución de partícula & 0.159041096 \\
Fermentación & 0.01316157 \\
Destilación & 0.01308375 \\
Total & 0.02235554 \\
Requerimiento & 1818.94 \\
energético anual & \\
\hline TRE $=\frac{10,148 \mathrm{MJ}}{1,818.94 \mathrm{MJ}}=$ & $5.57(1)$
\end{tabular}

\section{Conclusiones}

El uso del programa Aspen plus para determinar la tasa de retorno energético solo es aplicable cuando los límites del sistema están ubicados al inicio y final de proceso de producción, es decir, sin considerar la obtención de la materia prima, distribución y uso, como es el caso de este estudio. Con el uso de la FORSU como materia prima se disminuye la energía invertida para la obtención de bio-etanol. Con una TRE de 5.57, se indica que es energéticamente viable el proceso planteado de producción de bio-etanol.

\section{Agradecimientos}

Al Consejo Nacional de Ciencia y Tecnología (CONACyT) por la beca de maestría otorgada a Tania MendozaTinoco, a Raziel Estrada-Martínez por brindar la información experimental necesaria para llevar a cabo esta simulación y al Dr. Eduardo Cisneros por otorgar el programa utilizado.

Anexos: Análisis energético y ambiental de la producción de bio-etanol a partir de la FORSU. T. 


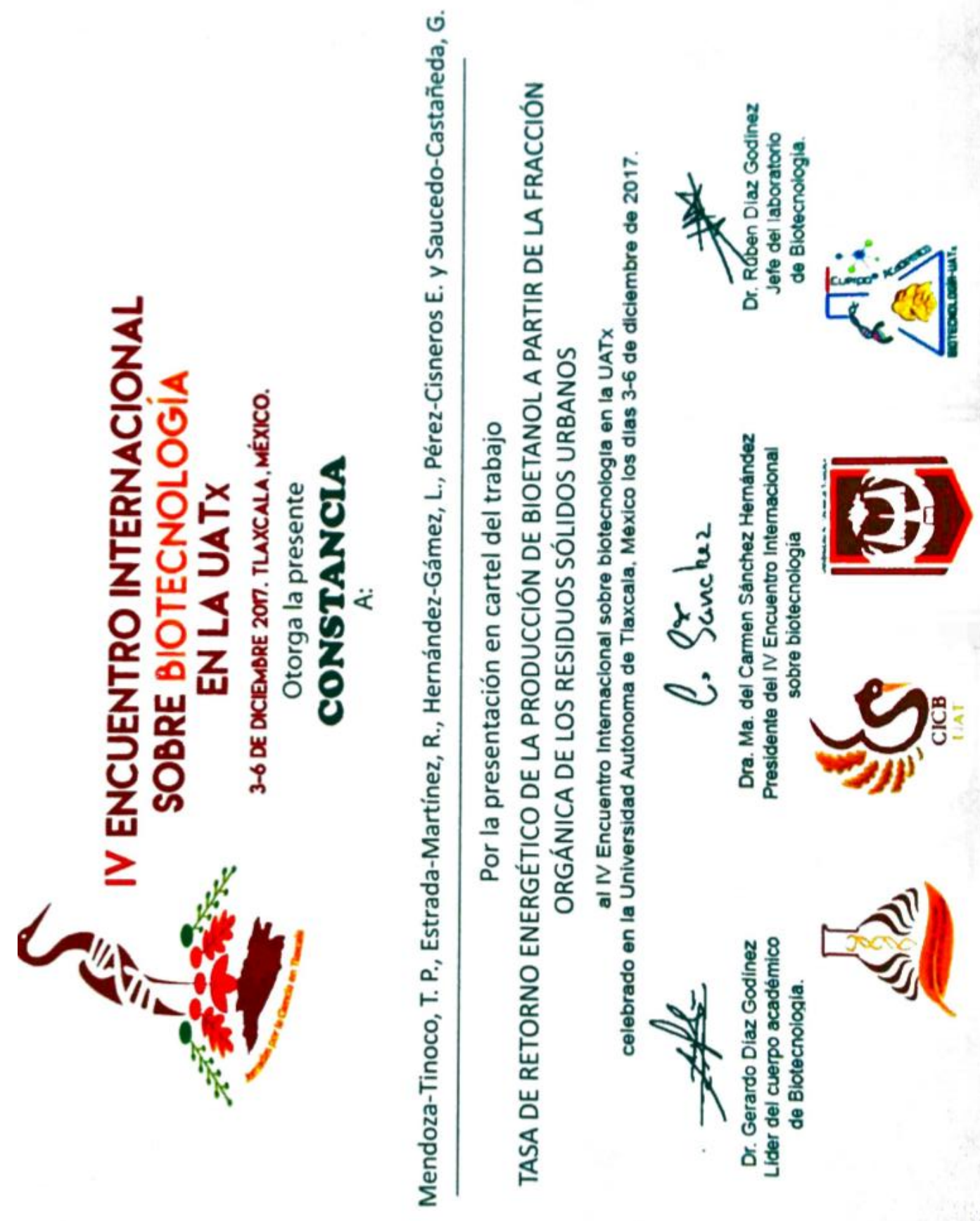

Anexos: Análisis energético y ambiental de la producción de bio-etanol a partir de la FORSU. T. 
MNTITSS ENERGETICO Y

AKBIENTAL DE LA PRODUCCION

DE BIO-ETANOI EN MÉXICO A

PARTIR DB LA FRACCION

ORGEAICA DE LOS RESIDDOS

SOLIDOS URBAMOS
En la ciudad de Mexico, se presentaron a las 15:00 horas del ds 19 del es de novicmbre del año 201 a en la unidad Iztapalapa de la Univeraidad Autonoma Metropolitana, las suscritos miembros del jurado:

DR. RICARDO BERISTAIN CARDOSO DRA. FABIOLA SAGRARIO SOSA RODAYCOEZ MTRO RAZIBL JESUS ESTRADA MARTINEZ DRA - LYSETE SANDEA HRBNANDEZ GANE?

Bafo la Presidencia del primero y con carácter de Secretarla la última, se reunieron para proceder al Examen de Grado cuya denominación aparece al margen, para la obtención del grado de:

MAESTRA EN CIENCIAS (ENERGIA $Y$ MEDIO AHEIENTE)

DE: TANIA PAOLA MENDO2A TINOCO

ach articulo 7 fracción III del Reglamento de Estudios superiores de la Universidad Autonoma Metropolitana; los miembros del jurado resolvieron:

\section{APROBAR}

Acto continuo, el presidente del jurado comunicb a 1 interesada el resultado de $l a$ evaluactón $y$, en caso aprobatorio, le fue tomada la protests.

\section{UC JUUO CESA OE LARO ISASSI} DIRECTOR DE SIST

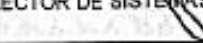

OIRECTOR DE LADIVISIÓN DE CSI

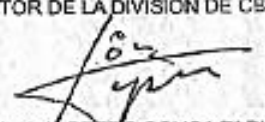

DR. JESUS ALBEPTO OCHOA TAPIA

PRESIDENTE

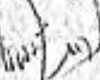

DR. RICARDO BERISTAIN CARDOSO
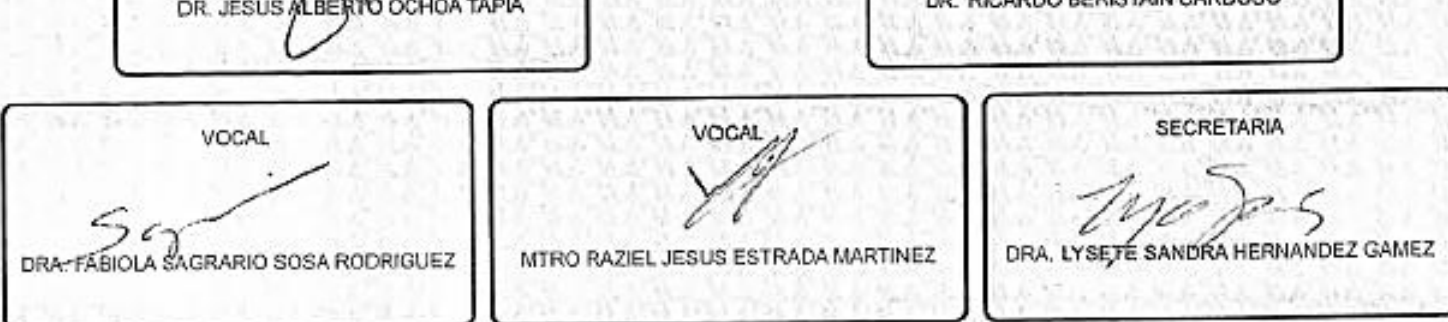

MTTRO RAZIEL JESUS ESTRADA MARTINEZ

Anexos: Análisis energético y ambiental de la producción de bio-etanol a partir de la FORSU. T. 